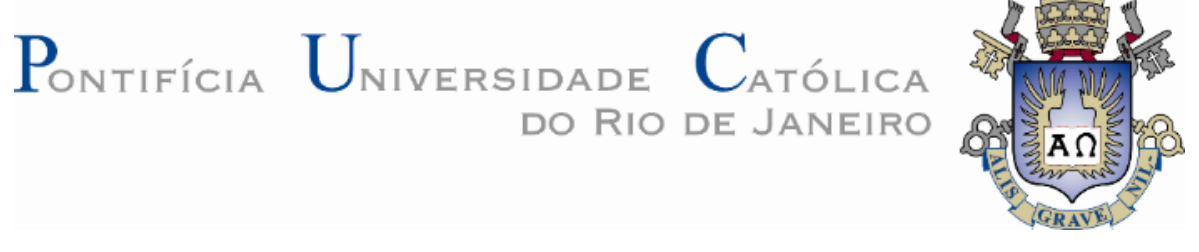

Thiago Almeida Cunha

Characterization of The Mechanical Behavior Under Multiaxial Low Cycle Fatigue of SAE 1020 Steel and 6351-T6 Aluminum Alloys

Dissertação de Mestrado

Dissertation presented to the Programa de Pós-graduação em Engenharia Mecânica of PUC-Rio in partial fulfillment of the requirements for the degree of Mestre em Engenharia Mecânica.

Advisor: Prof. Jaime Tupiassú Pinho de Castro Co-Advisor: Prof. Marco Antonio Meggiolaro 


\section{Characterization of The Mechanical Behavior Under Multiaxial Low Cycle Fatigue of SAE 1020 Steel and 6351-T6 Aluminum Alloys}

Dissertation presented to the Programa de Pós-graduação em Engenharia Mecânica of PUC-Rio in partial fulfillment of the requirements for the degree of Mestre em Engenharia Mecânica. Approved by the Examination Committee.

Prof. Jaime Tupiassú Pinho de Castro

Advisor Departamento de Engenharia Mecânica - PUC-Rio

Prof. Marco Antonio Meggiolaro Co-Advisor Departamento de Engenharia Mecânica - PUC-Rio

Prof. Paulo Pedro Kenedi Departamento de Engenharia Mecânica - Cefet/RJ

Prof. Marcos Venicius Soares Pereira Departamento de Engenharia Química e de Materiais - PUC-Rio

Prof. Ivan Fabio Mota de Menezes Pontifícia Universidade Católica do Rio de Janeiro - PUC-Rio 
All rights reserved

Thiago Almeida Cunha

Graduated in Mechanical Engineering at Pontifícia Universidade Católica do Rio de Janeiro in 2015

Bibliographic data

Cunha, Thiago Almeida

Characterization of The Mechanical Behavior Under Multiaxial Low Cycle Fatigue of SAE 1020 Steel and 6351-T6 Aluminum Alloys / Thiago Almeida Cunha ; advisor: Jaime Tupiassú Pinho de Castro. ; coadvisor: Marco Antonio Meggiolaro. - 2019.

84 f. : il. color. ; $30 \mathrm{~cm}$

Dissertação (mestrado)-Pontifícia Universidade Católica do Rio de Janeiro, Departamento de Engenharia Mecânica, 2019.

Inclui bibliografia

1. Engenharia Mecânica - Teses. 2. Theoretical Background. 3. Components Design and Machine Adaptations. 4. Experimental Methodology. 5. Results and Discussion. Castro, Jaime. Meggiolaro, Marco II. Pontifícia Universidade Católica do Rio de Janeiro. Departamento de Engenharia Mecânica. III. Título. 
In memory of my grandma, Eneida Santos da Cunha 


\section{Acknowledgments}

This study was financed in part by the Coordenação de Aperfeiçoamento de Pessoal de Nível Superior - Brasil (CAPES) - Código de Financiamento 001.

To my advisor, Professor Jaime Tupiassú Pinho de Castro, for the orientation.

To my co-advisor, Professor Marco Antonio Meggiolaro, for the advices and patience on the explanations about multiaxial fatigue.

To IME and ITUC, for allowing me to use their laboratories during my research.

To Simone and all the staff of the Department of Mechanical Engineering (DEM) for the support.

To Julian Gonzalez, Adrian Giassone, Gabriela Paiva and all members of ITUC's Mechanical Testing Laboratory for helping me during the experiments.

To my friends João Virgolino, Rodrigo Bianchi, André Leitão, Eduardo Cota, Edson Sabino and Jefferson Rios for all the support during my studies at PUCRio. And also for the coffee-breaks! I am very grateful for our friendship.

To my long-time friends Bernardo Cid, Jose Hugo Elsas, Julio Ho, Felipe Diniz and Helder Filho for all the advices and support in my times of need. I would never accomplish it without you guys.

To my mother, Enizia de Almeida, for all the affection and love.

To my father, João Luiz Cunha for always caring about me and my studies.

To my grandma, Eneida Cunha, for always being a light spot even on the darkest days. 


\section{Abstract}

Cunha, Thiago Almeida; Castro, Jaime Tupiassú Pinho de (advisor); Meggiolaro, Marco Antônio (co-advisor). Characterization of The Mechanical Behavior Under Multiaxial Low Cycle Fatigue of SAE 1020 Steel and 6351-T6 Aluminum Alloys. Rio de Janeiro, 2019. 84p. Dissertação de Mestrado - Departamento de Engenharia Mecânica, Pontifícia Universidade Católica do Rio de Janeiro.

The mechanical failure known as fatigue is characterized by the formation and/or propagation of cracks caused by variable forces. Its traditional methodologies normally calculate an equivalent uniaxial tensile stress acting on the component, in order to compare it with the known experimental mechanical behavior data of the component's material measured under uniaxial loads. This assumption can lead to non-conservative results because it considers the material to be equally sensitive to shear and tensile stresses, which is not true in a wide range of practical applications. Therefore, torsional and multiaxial experimental data is necessary to better predict the fatigue life of components. To execute those experiments, the present work proposes a variety of component designs and assembly methodologies to use on an Instron 8874 axial-torsional testing machine a hydraulic grip originally designed for an Instron 8501 uniaxial testing machine. Furthermore, a simplified method to estimate shear $(\gamma \mathrm{N})$ low-cycle fatigue properties via displacement-controlled experiments is proposed to avoid the need of using expensive equipment and different specimen designs, and used for characterization of SAE 1020 Steel and 6351-T6 Aluminum alloys. This data is compared with the measured tensile $(\varepsilon N)$ low-cycle fatigue properties to identify if these materials are tensile or shear sensitive under multiaxial loading conditions. A numerical computing code is used to fit $\varepsilon \mathrm{N}$ and $\gamma \mathrm{N}$ curves to the experimental data, and its implementation procedures are discussed. Finally, the most suitable criticalplane multiaxial fatigue models are proposed and calibrated for each material tested, based on the measured data.

\section{Keywords}

Low-cycle fatigue; multiaxial fatigue; shear-tensile sensibility; critical plane damage model; alignment accuracy; mechanical design; mechanical testing 


\section{Resumo}

Cunha, Thiago; Castro, Jaime Tupiassú Pinho de (orientador); Meggiolaro, Marco Antônio (co-orientador). Caracterização do Comportamento Mecânico Sob Fadiga Multiaxial de Baixo Ciclo das Ligas de Aço SAE 1020 e Alumínio 6351-T6. Rio de Janeiro, 2019. 84p. Dissertação de Mestrado - Departamento de Engenharia Mecânica, Pontifícia Universidade Católica do Rio de Janeiro.

A falha mecânica conhecida como fadiga é caracterizada pela iniciação e/ou propagação de trincas, causada por forças variáveis. Suas metodologias tradicionais calculam uma tensão elástica uniaxial equivalente que atua no componente, a fim de compará-la com os dados experimentais de comportamento mecânico do material do componente sob cargas uniaxiais. Esta hipótese pode levar a resultados não conservativos, por considerar que o material é igualmente sensível a tensões normais e cisalhantes, o que é falso em várias aplicações práticas. Portanto, dados torcionais e multiaxiais são necessários para melhor prever a vida em fadiga dos componentes. Para executar estes experimentos, o presente trabalho propõe uma variedade de projetos de componentes e metodologias de montagem para que se possa usar em uma máquina de tração-torção Instron 8874 uma garra hidráulica originalmente projetada para uma máquina tração pura Instron 8501. É proposto um método simplificado para estimar, por controle de deslocamento, as propriedades de fadiga de baixo ciclo em cisalhamento $(\gamma \mathrm{N})$, evitando assim a necessidade de usar equipamentos caros e diferentes tipos de corpos de prova. Este método é usado para caracterização das ligas Aço SAE 1020 e Alumínio 6351-T6 e os dados levantados são comparados com as propriedades medidas de fadiga de baixo ciclo em tração $(\varepsilon N)$, identificando assim se o material é mais sensível a tensões normais ou cisalhantes. Um programa numérico é usado para ajustar as curvas $\varepsilon \mathrm{N}$ e $\gamma \mathrm{N}$ nos dados experimentais, e seus procedimentos de implementação são discutidos. Por fim, são propostos e calibrados modelos de fadiga multiaxial de plano crítico mais adequados para cada material testado, com base nos dados medidos.

\section{Palavras-chave}

Fadiga de baixo ciclo; fadiga multiaxial; sensibilidade a tipos de tensões; modelos de dano por plano crítico; alinhamento; design mecânico; ensaio mecânico 


\section{Table of Contents}

1 Introduction 18

$\begin{array}{lll}1.1 & \text { Motivation } & 18\end{array}$

1.2 Multiaxial Fatigue 19

1.3 Machine Design for Fatigue Testing 20

1.4 Dissertation Outline 21

2 Theoretical Background 23

2.1 High-cycle Fatigue 23

2.2 Low-cycle Fatigue $\quad 24$

2.2.1 Ramberg-Osgood 24

2.2.2 Coffin-Manson 26

2.3 Multiaxial Fatigue Analysis 27

$\begin{array}{ll}\text { 2.3.1 Definitions } & 27\end{array}$

2.3.2 Shear-Tensile sensitivity 28

$\begin{array}{lr}\text { 2.3.3 Failure Criteria } & 29\end{array}$

2.3.3.1 Maximum Distortional Energy Criterion 29

2.3.3.2 Maximum Shear-Stress Criterion 30

2.3.4 Critical Plane Approach 32

2.3.5 Critical Plane Multiaxial Fatigue Damage Models 34

3 Components Design and Machine Adaptations 36

3.1 Components Design and Manufacturing 36

3.1.1 Pair of adapters 36

3.1.2 Double-screwed thread 38

3.2 Assembly Protocol 39

3.3 Alignment 41

3.3.1 Misalignment Consequences $\quad 42$

3.3.2 Alignment Methodology 43

3.3.2.1 Visual Identification of Misalignment 43 
3.3.2.2 Dial Indicator Method 45

3.3.2.3 Strain Reading Method 46

3.3.2.4 External Alignment Fixture Method 47

4 Experimental Methodology 51

4.1 Specimen Design 51

4.2 Mechanical Properties 52

4.3 Measuring $\varepsilon \mathrm{N}$ Properties 53

4.4 Elastoplastic Behavior $\quad 54$

4.5 Measuring $\gamma \mathrm{N}$ Properties $\quad 55$

4.6 Curve Fitting 57

$\begin{array}{lll}4.7 & \text { Comparison Procedures } & 58\end{array}$

4.8 Fatemi-Socie Damage Model Calibration 59

5 Results and Discussion $\quad 61$

$\begin{array}{lll}5.1 \text { Components Performance } & 61\end{array}$

5.2 Experimental Results $\quad 61$

$\begin{array}{lll}5.3 & \text { Discussion } & 66\end{array}$

6 Conclusion $\quad 69$

$\begin{array}{lll}6.1 & \text { Future Works } & 70\end{array}$

$\begin{array}{lll}7 & \text { Bibliography } & 71\end{array}$

Appendix A Programming Codes using MATLAB 73 


\section{List of Figures}

Figure 1.1: a) The donated fuselage submerged into water [4]. b) Picture of a window corner of the fuselage after 6042 cycles. Note the crack starting at the countersunk rivet hole [3].

Figure 1.2: Pipeline configuration.

Figure 1.3: INSTRON 8874 Biaxial servohydraulic Fatigue Testing System (photo and schematic [7]).

Figure 2.1: Example of cyclic hardening and softening in pure $\mathrm{Cu}$ with two different initial states. (modified from [1]).

Figure 2.2: Schematic of cyclic softening (a) and cyclic hardening (b) behaviors observed on the stress-time graphic of strain-controlled experiments (modified from [1]).

Figure 2.3: Schematic of the cyclic stress-strain curve obtained by joining the tips of various concentric hysteresis concentric loops [1]. 26 Figure 2.4: Plane-stress proportional and non-proportional examples [1].

Figure 2.5: Strain waveforms examples [5].

Figure 2.6: Mohr Circle of a tridimensional stress configuration.

Figure 2.7: Coordinate transformations, where $z$ is defined perpendicular to the free surface [1].

Figure 2.8: Stress states for the initiation of A90 and B45 cracks (modified from [1]).

Figure 3.1: INSTRON 25kN/100Nm axial/torsional hydraulic grip.

Figure 3.2: a) The assembly used. b) individual pieces used. c) schematics of the lower adapter.

Figure 3.3: Picture of the left-over threaded rod together with the old threaded screw. Schematic of the new threaded screw.

Figure 3.4: Schematics of the experimental set-up used (modified from [15]).

Figure 3.5: Two examples of pre-load washers. Helical on the left, inclined on the right.

Figure 3.6: Schematics of the problem. 
Figure 3.7: Bending of the backstop plates and shearing of the screws, caused by usage of a misaligned system.

Figure 3.8: Misalignment caused be a bent hydraulic piston column. The specimen should be pointing towards the center of the undercut 43 circle.

Figure 3.9: Example of a considerably misaligned assembly. The specimen should be within the same distance from each jaw face

Figure 3.10: Example of an assembly for the Dial Indicator

Method.

Figure 3.11: Specimen instrumentation.

Figure 3.12: Experimental setup, as well as the Daq reading on the computer screen.

Figure 3.13: Instron Alignment Fixture Model 8000-073 (photo and schematic [15]).

Figure 3.14: Types of strain displacement on the specimen [15].

Figure 3.15: Schematic of the strain gauge configuration for this reading [15].

Figure 4.1: Schematic of the specimen.

Figure 4.2: Stress-strain diagram with the lines needed for the determining SY via Offset Method (Modified from [17]).

Figure 4.3: a) Instron 8501 Servo Hydraulic Fatigue Testing System;

b) Instron 2630-100 Series Clip-on Extensometer; c) Instron 8874 Biaxial Servo Hydraulic Fatigue Testing System.

Figure 4.4: Stress-sample graphic with the first 130,000 data acquired from two strain controlled cyclic tensile-compression tests. Note that the stress amplitude necessary to maintain the strain amplitude constant decreases on steel, while on aluminum it increases.

Figure 4.5: Elastoplastic shear stress and strain profiles on a specimen's cross-section area under pure torsion.

Figure 4.6: Stress and strain Mohr circles for pure torsion.

Figure 4.7: Stress and strain Mohr Circles for a pure axial tension stress state.

Figure 5.1: SAE 1020 cyclic Ramberg-Osgood curve. 
Figure 5.2: 6351-T6 Al cyclic Ramberg-Osgood curve. 63

Figure 5.3: SAE 1020 and 6351-T6 Al $\varepsilon N$ curves. 64

Figure 5.4: SAE 1020 and 6351-T6 Al YN curves. 64

Figure 5.5: Comparison between $\varepsilon N$ curves with $(\varepsilon N)_{\text {Mises }}$ and $(\varepsilon N)_{\text {Tresca }}$ equivalent curves for 6351-T6 Aluminum.

Figure 5.6: Comparison between $\varepsilon N$ curves with $(\varepsilon N)_{\text {Mises }}$ and $(\varepsilon N)_{\text {Tresca equivalent curves for SAE } 1020 \text { Steel. }} 65$

Figure 5.7: Damage Map for 1045 Steel [13]. 67

Figure 5.8: عN Comparison graphic of SAE 1045. 


\section{List of Tables}

Table 4.1: Specimen measurements (in $\mathrm{mm}$ )

Table 5.1: Mechanical properties for SAE 1020 and 6351-T6 AI

62

Table 5.2: Angular displacements and their corresponding number

of cycles up to failure for SAE 1020 and 6351-T6 Al

62 


\section{List of Symbols and Abbreviations}

$A_{0} \quad$ - Initial cross-sectional area of the specimen $\left[\mathrm{mm}^{2}\right]$

A90(S) - Case A shear microcrack, perpendicular to the free surface $\left(\varphi=90^{\circ}\right)$

A90(T) - Case A shear tensile, perpendicular to the free surface $\left(\varphi=90^{\circ}\right)$

$A R \quad$ - Area reduction of the specimen

ASTM American Society for Testing and Materials

$b$

- Elastic exponent of the $\varepsilon \mathrm{N}$ equation

$b_{\gamma} \quad-\quad$ Elastic exponent of the $\gamma \mathrm{N}$ equation

$B$

Wöhler's exponent for high-cycle fatigue life

predictions

B45(S) - Case B shear microcrack, making $\varphi=45^{\circ}$ with the free surface

BOAC - British Overseas Airways Corporation

$c$

- Plastic exponent of the $\varepsilon \mathrm{N}$ equation

$c_{\gamma}$

- Plastic exponent of the $\gamma \mathrm{N}$ equation

C Wöhler's coefficient for high-cycle fatigue life predictions

$\mathrm{ccw}$

- Counter-clockwise orientation of rotation

$\mathrm{cW}$

- Clockwise orientation of rotation

d Smaller diameter of the specimen [mm]

$\mathrm{D}$

- Bigger diameter of the specimen [mm]

Daq

- Data acquisition system

$\mathrm{E}$

- Elasticity (or Young's) modulus in tension [GPa]

F force carried by the specimen during the rupture $[\mathrm{N}]$

$F_{N P}$

- Non-proportionality factor for multiaxial history

$G$

- Shear elasticity modulus [GPa]

$h$ Monotonic strain-hardening exponent of RambergOsgood equation 


\begin{tabular}{|c|c|c|}
\hline$H$ & - & $\begin{array}{l}\text { Monotonic strain-hardening coefficient of Ramberg- } \\
\text { Osgood equation [MPa] }\end{array}$ \\
\hline$h_{c}$ & - & $\begin{array}{l}\text { Cyclic strain-hardening exponent of Ramberg-Osgood } \\
\text { equation }\end{array}$ \\
\hline$H_{c}$ & - & $\begin{array}{l}\text { Cyclic strain-hardening coefficient of Ramberg- } \\
\text { Osgood equation }[\mathrm{MPa}]\end{array}$ \\
\hline IME & - & Military Institute of Engineering, Rio de Janeiro, RJ \\
\hline $\mathrm{L}$ & & Length of the specimen $[\mathrm{mm}]$ \\
\hline lsqnonlin() & - & nonlinear least-squares solver (MATLAB function) \\
\hline LVDT & - & Linear Variable Differential Transformer \\
\hline$N$ & - & Number of cycles up to failure by fatigue \\
\hline SAE & - & Society of Automotive Engineers \\
\hline$S_{F}(N)$ & & Fatigue Strength for a given number of cycles $[\mathrm{MPa}]$ \\
\hline$S_{U}$ & - & Ultimate Strength [MPa] \\
\hline$S_{Y c}$ & - & Cyclic Yield Strength [MPa] \\
\hline$S_{Y}$ & - & Yield Strength [MPa] \\
\hline SWT & - & Smith-Watson-Topper's strain-life model \\
\hline$U_{\text {distortion }}$ & - & shear distortion elastic energy of a material $[\mathrm{J}]$ \\
\hline$U_{\text {tension }}$ & - & simple tension elastic energy of a material $[\mathrm{J}]$ \\
\hline$\alpha, \beta$ & - & Constants of the critical plane models \\
\hline$\gamma_{a}$ & - & shear strain amplitude \\
\hline$\gamma_{A}$ & - & in-plane shear strain \\
\hline$\gamma_{B}$ & - & out-of-plane shear strain \\
\hline$\gamma_{c}$ & - & Plastic coefficient of the $\gamma \mathrm{N}$ equation \\
\hline$\gamma_{x y}, \gamma_{x z}, \gamma_{y z}$ & - & Tri-axial shear strains \\
\hline$\Delta \gamma(\theta, \varphi)$ & - & Shear strain amplitude on a candidate plane \\
\hline$\Delta \varepsilon_{\perp}(\theta, \varphi)$ & - & $\begin{array}{l}\text { normal strain amplitude perpendicular to a candidate } \\
\text { plane }\end{array}$ \\
\hline$\Delta \sigma_{\perp}(\theta, \varphi)$ & - & $\begin{array}{l}\text { normal stress amplitude perpendicular to a candidate } \\
\qquad \text { plane }[\mathrm{MPa}]\end{array}$ \\
\hline$\Delta \tau(\theta, \varphi)$ & - & Shear stress amplitude on a candidate plane $[\mathrm{MPa}]$ \\
\hline$\varepsilon$ & - & tensile strain \\
\hline$\varepsilon_{1}, \varepsilon_{2}, \varepsilon_{3}$ & - & principal strains \\
\hline
\end{tabular}




\begin{tabular}{|c|c|c|}
\hline$\varepsilon_{a}$ & - & tensile strain amplitude \\
\hline$\varepsilon_{c}$ & - & Plastic coefficient of the $\varepsilon N$ equation \\
\hline$\varepsilon_{e l}$ & - & Elastic component of the mechanical strain \\
\hline$\varepsilon_{\text {MISES }}$ & - & von Mises critical strain \\
\hline$\varepsilon_{\text {Tresca }}$ & - & Tresca critical strain \\
\hline$\varepsilon_{U}$ & - & Ultimate strain \\
\hline$\varepsilon_{x}, \varepsilon_{y}, \varepsilon_{z}$ & - & Tri-axial normal strains \\
\hline$\varepsilon_{Y}$ & - & Yield strain \\
\hline$\varepsilon_{\perp}$ & - & tensile strain perpendicular to the plane \\
\hline$\theta$ & - & $\begin{array}{l}\text { Critical plane's latitudinal angle from the surface } \\
\qquad[\mathrm{rad}]\end{array}$ \\
\hline$v$ & - & Poisson ratio \\
\hline $\bar{v}$ & - & Effective Poisson ratio \\
\hline$\sigma$ & - & tensile stress $[\mathrm{MPa}]$ \\
\hline$\sigma_{1}, \sigma_{2}, \sigma_{3}$ & - & principal stresses $[\mathrm{MPa}]$ \\
\hline$\sigma_{c}$ & - & Elastic coefficient of the $\varepsilon \mathrm{N}$ equation $[\mathrm{MPa}]$ \\
\hline$\sigma_{\text {Mises }}$ & - & von Mises critical stress $[\mathrm{MPa}]$ \\
\hline$\sigma_{\text {Tresca }}$ & - & Tresca critical stress $[\mathrm{MPa}]$ \\
\hline$\sigma_{x}, \sigma_{y}, \sigma_{z}$ & - & Tri-axial normal stresses $[\mathrm{MPa}]$ \\
\hline$\sigma_{Y c}$ & - & yield critical stress $[\mathrm{MPa}]$ \\
\hline$\sigma_{\perp}$ & - & tensile stress perpendicular to the plane [MPa] \\
\hline$\sigma_{\perp \max }(\theta, \varphi)$ & - & $\begin{array}{l}\text { peak normal stress perpendicular to a candidate plane } \\
\qquad[\mathrm{MPa}]\end{array}$ \\
\hline$\tau_{A}$ & - & in-plane shear stress [MPa] \\
\hline$\tau_{B}$ & - & out-of-plane shear stress [MPa] \\
\hline$\tau_{c}$ & - & Elastic coefficient of the $\gamma \mathrm{N}$ equation [MPa] \\
\hline$\tau_{x y}, \tau_{x z}, \tau_{y z}$ & - & Tri-axial shear stresses [MPa] \\
\hline$\varphi$ & - & $\begin{array}{l}\text { critical plane's longitudinal angle from the surface } \\
\qquad[\mathrm{rad}]\end{array}$ \\
\hline$\varphi_{a}$ & - & $\begin{array}{c}\text { Amplitude of the angle controlled by the torsional } \\
\text { testing machine [degrees] }\end{array}$ \\
\hline
\end{tabular}


Empty your mind. Be formless, shapeless, like water. Now you pour water in a cup, it becomes the cup. You pour water in a bottle, it becomes the bottle. You pour water in a teapot, it becomes the teapot. Water can flow or it can crash. Be water my friend.

Bruce Lee 


\section{Introduction}

\section{1 Motivation}

Most practical problems in structural engineering are due to a mechanical failure mechanism known as fatigue, which is primarily caused by cyclic loads that originates and propagates cracks [1]. Many advances in mechanical design were motivated by the constant onset of fatigue problem, and at a high cost.

Take for example the famous British Overseas Airways Corporation (BOAC) Flight 781 accident. It was a de Havilland Comet passenger jet that crashed on 10 January 1954 after suffering an explosive decompression at altitude, causing the death of all 35 passengers [2].

To contribute for the investigations of this unexpected decompression, an entire Comet I G-ALYR was grounded by BOAC and donated for mechanical testing. For one of the experiments, an airplane size reservoir was built to fill with and submerge all the fuselage in water (Fig. 1.1a), with all the internal pressurize cycles being applied by pumping in and out more water, emulating in that way the air compression-decompression cycles during flight [3]. Inspections revealed that all fatigue cracks appeared at the countersunk rivet holes closer to the window and escape hatches corners (Fig. 1.1b). The stated cause of the accident was failure by fatigue caused by the pressurization cycles on the aircraft cabin during flight.

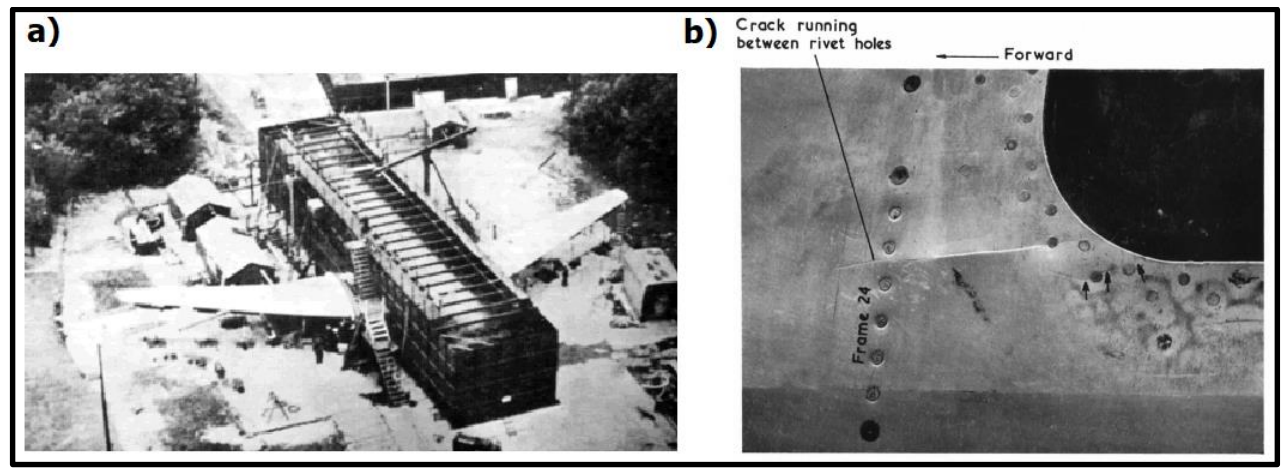

Figure 1.1: a) The tested fuselage submerged into water [4]. b) Picture of a window corner of the fuselage after 6042 cycles. Note the crack starting at the countersunk rivet hole [3]. 
This example highlights the importance of a proper fatigue analysis, showing that consequences might lead to very high financial losses and even loss of human lives in the vicinity of accidents.

\section{2 \\ Multiaxial Fatigue}

Most engineering components are subjected to multiaxial forces. For example, Fig. 1.2 illustrates a pipeline configuration used to drain water from a hole and transport it horizontally. Some turbulence on the pumping system is causing two transverse constraints on the lower end of the pipeline, one parallel and other perpendicular to the upper pipe. This force configuration would subject the connector present on the upper pipe to tension, bending and torsion, causing both normal and shear stresses at the same time. Given those forces a cyclic pattern, we have multiaxial fatigue.

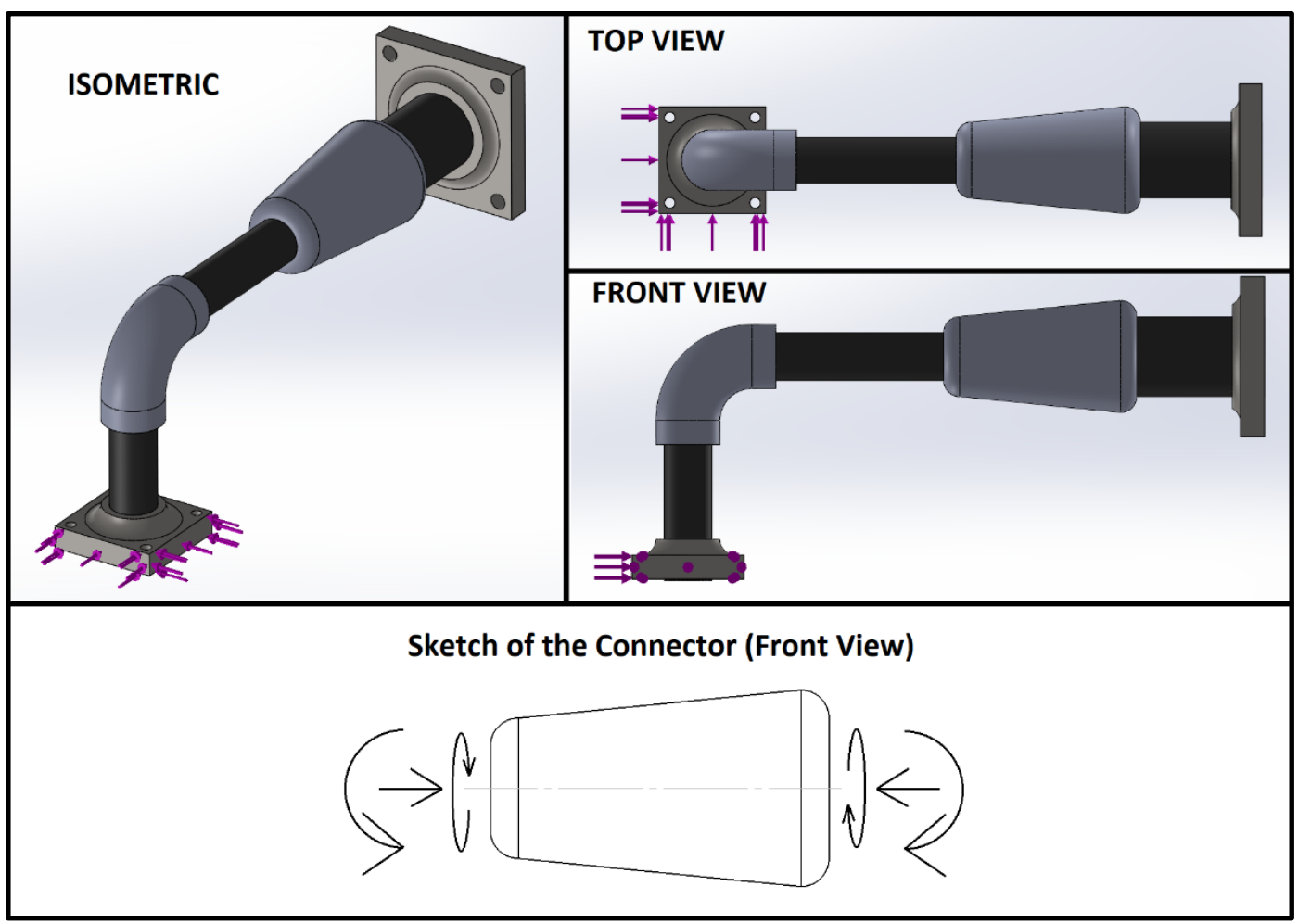

Figure 1.2: Pipeline configuration.

The mechanical behavior of components subjected to multiaxial forces often tends to be unique and quite different from those under a simple uniaxial loading condition [5]. The traditional fatigue modelling methodologies are designed to predict the damage accumulation assuming only a uniaxial stress, and 
tridimensional stress configurations are normally dealt by previously calculating its equivalent uniaxial stress assuming some failure criteria. This technique is proven to be non-conservative when the constraints follow distinct frequency patterns. Since most engineering components are subjected to multiaxial constraints, a better methodology to predict fatigue life under such circumstances is necessary.

This present work performs the fatigue characterization of two metals, the SAE 1020 Steel and 6351-T6 Aluminum alloys, along with the correlation between their tensile and shear fatigue properties and the identification of their appropriate multiaxial fatigue damage model. Each material chosen for the tests has several applications in various engineering designs. As stated on the ASM Metals Handbook [6], 6xxx series aluminum alloys are commonly used in bicycle frames, transportation equipment, as well as architectural applications because of its good formability, machinability and corrosion resistance. Plain low carbon steels in the 10xx group are used in a variety of applications, because of their relatively inexpensive manufacturing process.

\section{3 \\ Machine Design for Fatigue Testing}

For a better understanding of the mechanical behavior of materials, distinct experimental methodologies were developed and many companies design and manufacture a variety of machinery to execute then. For example, the Instron 8874 Biaxial Servohydraulic Fatigue Testing System (Fig. 1.3) is commonly used in medical prosthetics design and research due to its range of compatibility, allowing a variety of grip designs and flexible testing protocols [7].

Although normally used on medical devices and prosthetics testing, its assembly flexibility allows the Instron 8874 biaxial testing machine for a variety of other applications, one of those being the fatigue testing on structural materials.

This work describes the design and implementation of an adapter designed to allow on the biaxial system the mounting of a pair of hydraulic grips originally designed for an Instron 8501 uniaxial servohydraulic testing machine and, therefore, enabling the proper torsional experiments for the chosen materials to be tested. 


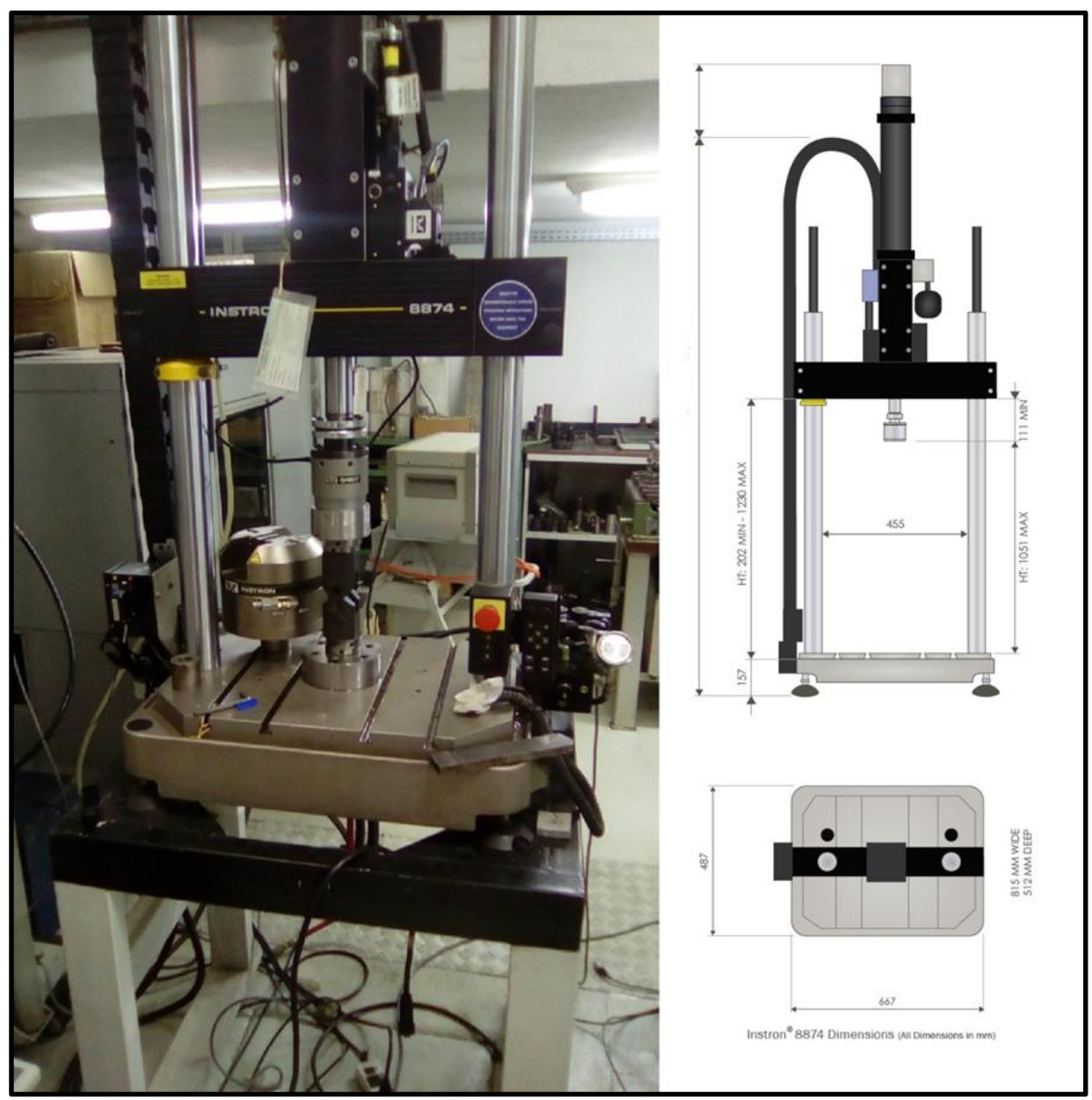

Figure 1.3: INSTRON 8874 Biaxial servohydraulic Fatigue Testing System (photo and schematic [7]).

\section{4}

\section{Dissertation Outline}

This thesis is divided into 6 chapters that are structured as follows:

Chapter 2 presents the fundamental concepts and theoretical background used in the stress/strain analysis and fatigue life predictions, including basic high-cycle and low-cycle fatigue methodologies, multiaxial fatigue concepts, multiaxial fatigue damage models and the mathematics used on the adaptation of two stress failure criteria into strain versions.

Chapter 3 presents all designed components used on the adaptation of the Instron 8874 system, as well as its manufacturing processes, assembly protocol and tips for a proper alignment of a mechanical testing.

Chapter 4 details the followed experimental protocol. Also, a new methodology for low-cycle pure torsion fatigue experiments is proposed. 
Chapter 5 shows the tensile-test mechanical properties of both materials as well as results obtained from the low-cycle pure tension and pure torsion fatigue experiments. A shear-tensile correlation model is used to characterize each material. This model is compared with the analysis made using damage maps.

Chapter 6 presents the conclusions and suggestions for future works.

Finally, Appendix A shows Matlab codes used in the data analyses in this thesis. 


\section{2 \\ Theoretical Background}

The mechanical failure mechanism known as fatigue is primarily caused by variable loads, which induces cyclic movements of dislocations in the microstructure of the component. In the macroscopic scope, the accumulation of these dislocations initiates and/or propagates a crack [1]. To model this phenomenon and predict the number of cycles necessary for a component to fail, a variety of distinct methodologies are available.

\section{1 \\ High-cycle Fatigue}

Fatigue failure predictions were first developed by Wöhler in his pioneer work in the mid-nineteenth century [8]. In his SN Method, the ranges and maximum values of cyclic stresses are correlated with the number of cycles necessary to initiate a crack, as seen in Eq. (2-1). This methodology is recommended for highcycle fatigue cases, when strains generated by the component constraints are elastic.

$$
N S_{F}^{B}=C
$$

where $\mathrm{B}$ and $\mathrm{C}$ are constants of each material (also known as Wöhler exponent and coefficient, respectively) and $\mathrm{S}_{\mathrm{F}}$ is the fatigue strength of the material corresponding to the given number of cycles $\mathrm{N}$ [1].

However, in low-cycle fatigue problems, where plastic deformations are dominant, this method tends to be non-conservative and should not be used. Instead, a correlation between the range and maximum cyclic deformations imposed on the component are better correlated with its life prediction [1]. Therefore, stress-strain correlations are useful for low-cycle fatigue problems. 


\section{2 \\ Low-cycle Fatigue}

\subsection{1 Ramberg-Osgood}

The Ramberg-Osgood equation is one reasonable option to associate the stress and strain on the plastic regime of many structural alloys [1]. It models the uniaxial strain-hardening behavior by assuming that any given strain $\varepsilon$ can be decomposed into an elastic $\left(\varepsilon_{\mathrm{el}}\right)$ and plastic $\left(\varepsilon_{\mathrm{pl}}\right)$ parts. $\varepsilon_{\mathrm{el}}$ grows linearly with the stress, while $\varepsilon_{\mathrm{pl}}$ grows following a power function with respect to the imposed stress, as seen in Eq. (2-2).

$$
\varepsilon=\varepsilon_{e l}+\varepsilon_{p l}=\left(\frac{\sigma}{E}\right)+\left(\frac{\sigma}{H}\right)^{\frac{1}{h}}
$$

where $\mathrm{H}$ is the hardening coefficient and $\mathrm{h}$ is the hardening exponent. Note that this equation models monotonic curves and an adapted version is necessary for problems involving cyclic plastic deformations, using the cyclic coefficients $\mathrm{H}_{\mathrm{c}}$ and $\mathrm{h}_{\mathrm{c}}$ instead. This is due to the fact that metallic alloys can soften, harden, or event have a mixed elastoplastic behavior.

During the strain-controlled experiments for the $\varepsilon \mathrm{N}$ curve one can record the stress and strain data to plot hysteresis loops for each one of the strain amplitudes tested. If the material cyclic softens, a contraction of the hysteresis loops will be noticed, due to the fact that for each cycle the same strain amplitude requires a lower stress value. On the other hand, cyclic hardening cases show a stretch of its hysteresis loops in the stress-axis direction because, after each cycle, a bigger stress value is necessary to maintain the same strain amplitude (Fig. 2.1).

This behavior can also be observed on the stress-time curve, in which the amplitude of the stress increases or decreases, depending on the material's elastoplastic behavior (Fig. 2.2). Note that normally materials tend to stabilize after a few cycles.

To plot the cyclic Ramberg-Osgood curve, the largest stress value (after stabilization of the curve) of each strain amplitude tested is collected, and the $h_{c}$ and $\mathrm{H}_{\mathrm{c}}$ values are calculated in order to fit the Ramberg-Osgood equation onto those stress-strain points (Fig. 2.3). 


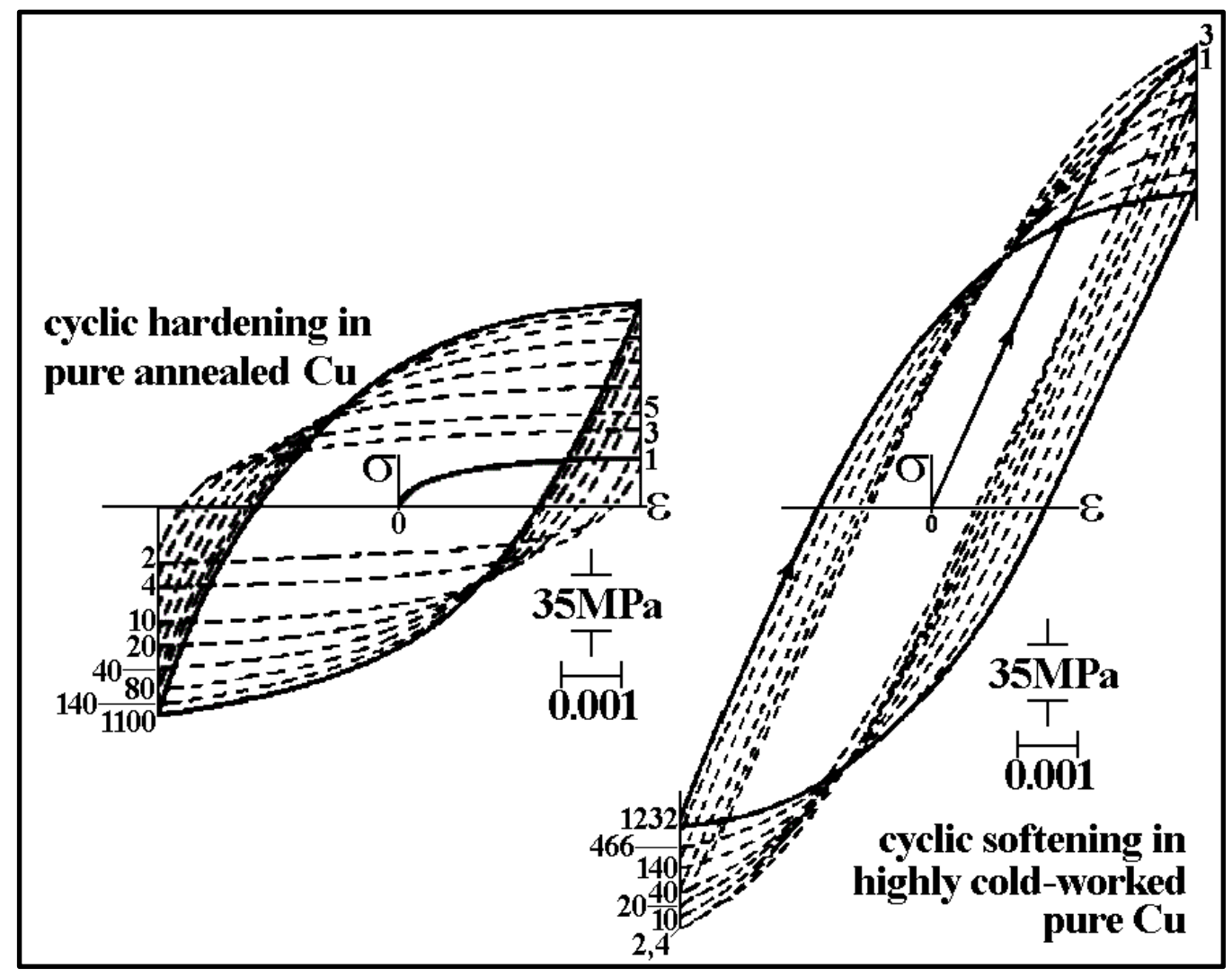

Figure 2.1: Example of cyclic hardening and softening in pure $\mathrm{Cu}$ with two different initial states. (modified from [1]).

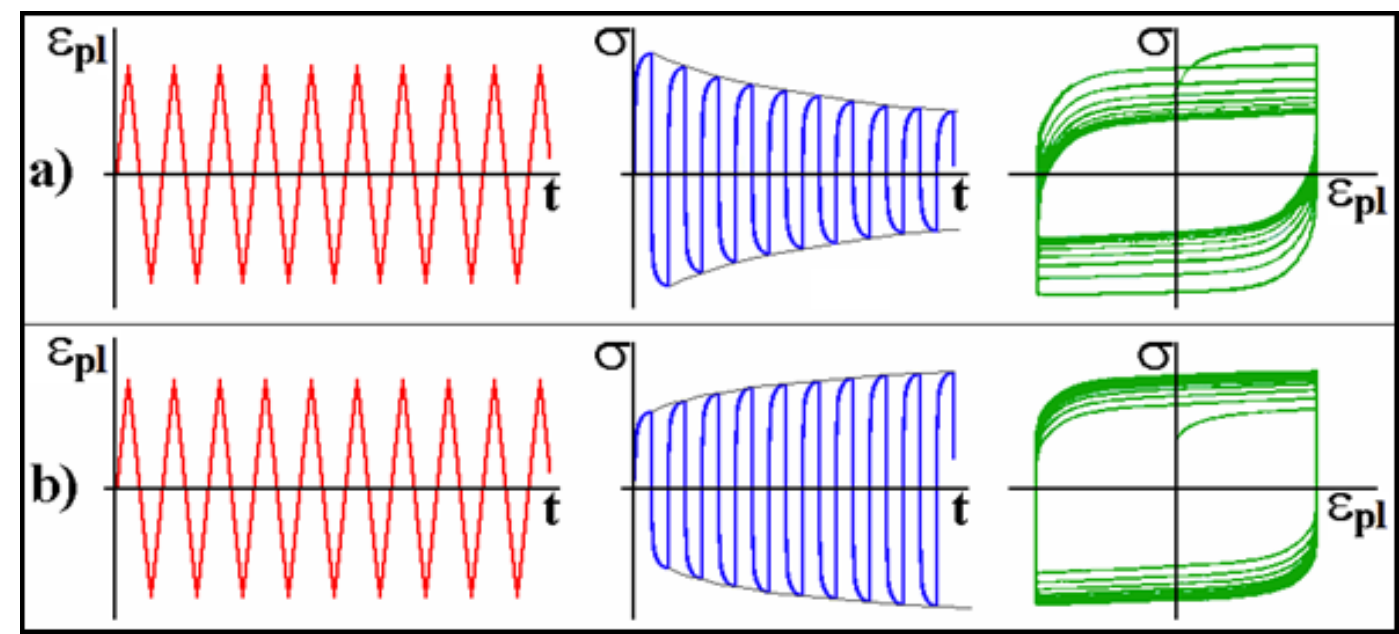

Figure 2.2: Schematic of cyclic softening (a) and cyclic hardening (b) behaviors observed on the stress-time graphic of strain-controlled experiments (modified from [1]). 


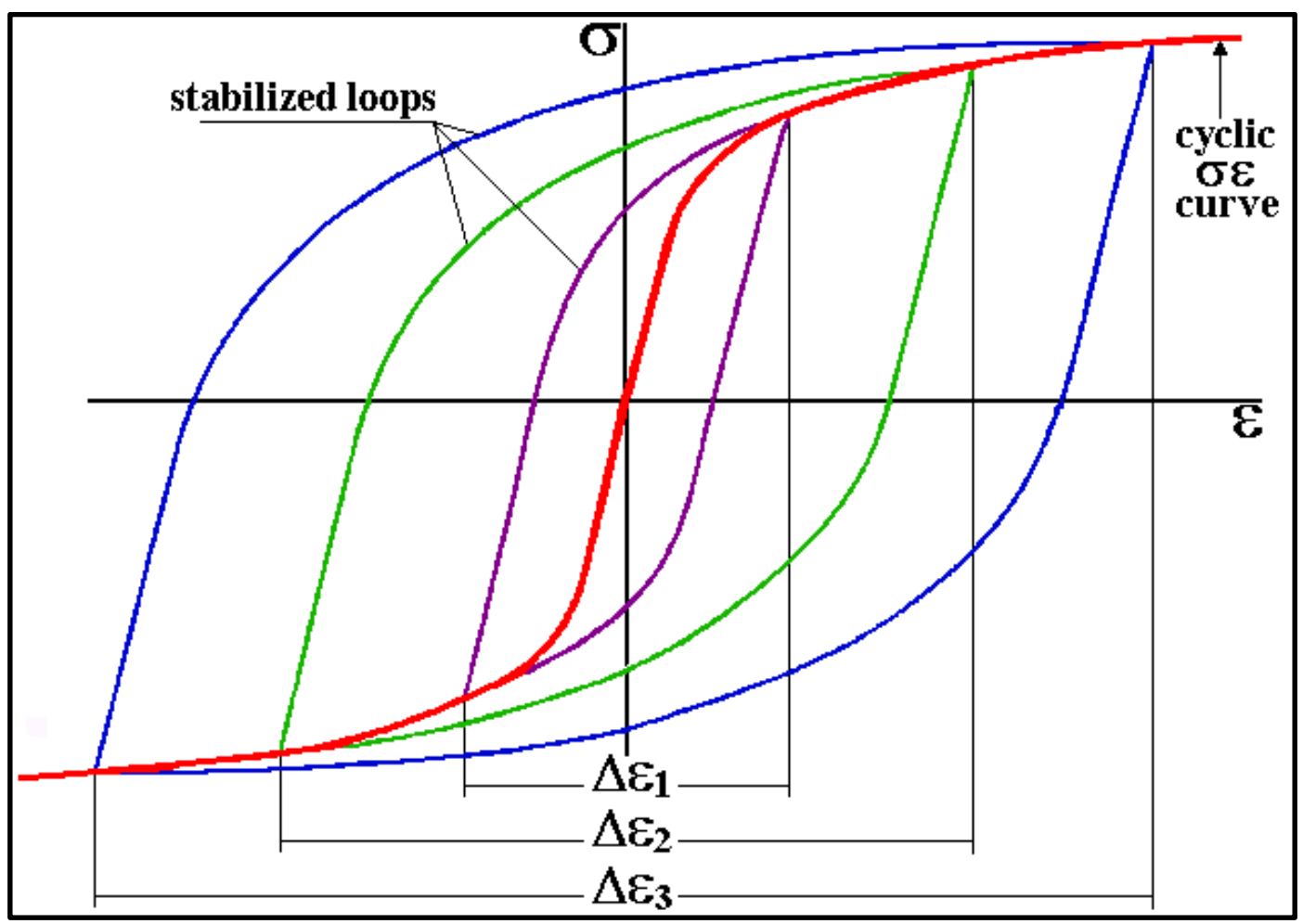

Figure 2.3: Schematic of the cyclic stress-strain curve obtained by joining the tips of various concentric hysteresis concentric loops [1].

\subsection{2}

\section{Coffin-Manson}

The standard methodology for modeling low-cycle fatigue cases is the $\varepsilon \mathrm{N}$ method, which correlates the strain amplitude $\varepsilon_{\mathrm{a}}$ and the number of cycles $\mathrm{N}$ using the Coffin-Manson rule [1], as seen in Eq. (2-3).

$$
\varepsilon_{a}=\left(\frac{\sigma_{c}}{E}\right)(2 N)^{b}+\varepsilon_{c}(2 N)^{c}
$$

where $\mathrm{E}$ is Young's modulus, $\sigma_{\mathrm{c}}$ and $\varepsilon_{\mathrm{c}}$ are the elastic and plastic coefficients (also known as fatigue strength and fatigue ductility coefficients) and b and c are their respective exponents. Those constants are calculated based on experimental data, which are commonly obtained following the procedures recommended in the ASTM E606 Standard Test Method for Strain-Controlled Fatigue Testing [9]. Fitting the experimental data generates the $\varepsilon \mathrm{N}$ curve, which assists on the fatigue life prediction of different materials under distinct plastic strain amplitudes. 


\section{3 \\ Multiaxial Fatigue Analysis}

The methodologies discussed above assume that failure under cyclic loadings can be predicted by calculating an equivalent uniaxial stress from all the tridimensional stress configuration. This is reasonable when the tensile and shear stresses are in-phase and proportional, but when one or both of the cited requirements are not met, this assumption turns to be non-conservative [1,5]. Since most engineering components are subjected to multiaxial constraints, a more detailed study on multiaxial fatigue is necessary.

\subsection{1 \\ Definitions}

Multiaxial fatigue stress/strain histories are proportional when their principal axes, and consequently their maximum-shear planes, are fixed during their entire duration. This can be concluded by observing if the ratio between tensile and shear stresses remains constant. On the other hand, a non-proportional stress/strain history induces principal directions which change in time. The non-proportionality can be quantified by a factor $\mathrm{F}_{\mathrm{NP}}$ which is the ratio between both diameters of an ellipse involving all the constraints history [1]. Fig. 2.4 shows three plane-stress examples to illustrate the proportional and non-proportional cases.

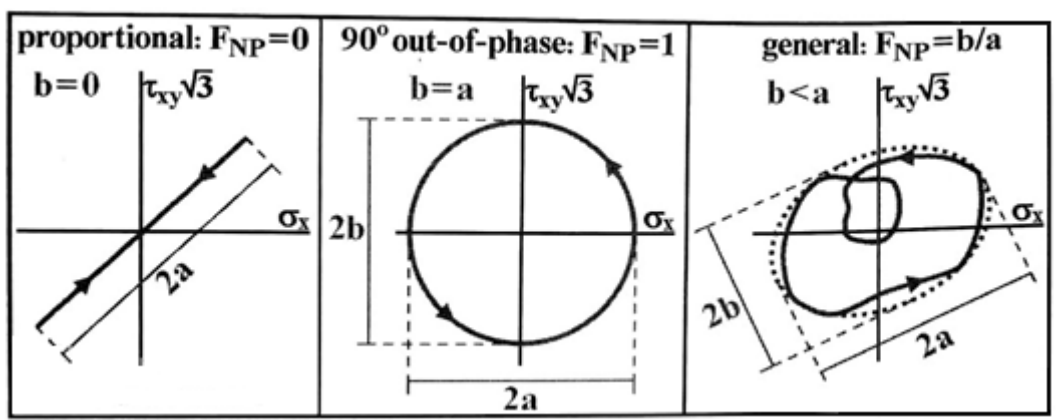

Figure 2.4: Plane-stress proportional and non-proportional examples [1].

Stress and strain can also be classified as in-phase when they have the same periodic waveform and frequency. Otherwise, they are classified as out-of-phase. Fig. 2.5 shows two examples of strain waveforms. On the left, the shear and tensile waveforms follow the same sine waveform and have the same frequencies, which 
configures an in-phase multiaxial state. On the right, the axial strain is $75^{\circ}$ out-ofphase with respect to the shear strain.

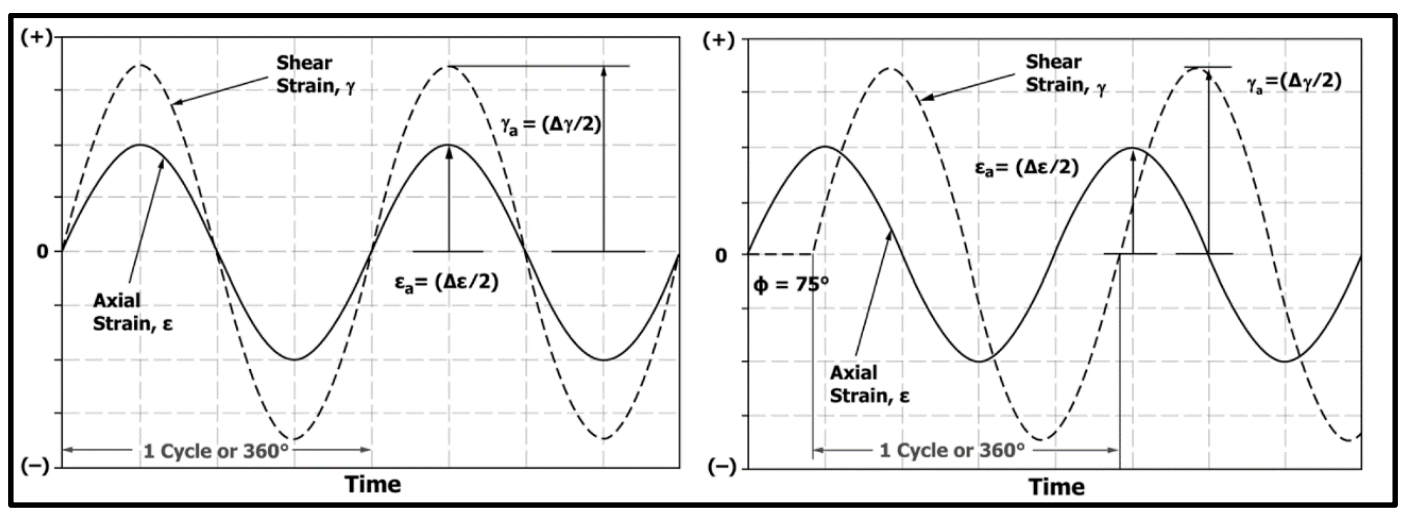

Figure 2.5: Strain waveforms examples [5].

\subsection{2}

\section{Shear-Tensile sensitivity}

In multiaxial fatigue cases, the influence of the shear stress should be taken into account, given the fact that some materials present distinct mechanical behavior under shear, tensile or combined constraints.

For pure torsional problems, the Coffin-Manson rule can be adapted into a shear version, known as $\gamma \mathrm{N}$ curve, as seen in Eq. (2-4).

$$
\gamma_{a}=\left(\frac{\tau_{c}}{G}\right)(2 N)^{b_{\gamma}}+\gamma_{c}(2 N)^{c_{\gamma}}
$$

where $\mathrm{G}$ is the shear modulus of elasticity, $\tau_{\mathrm{c}}$ and $\gamma_{\mathrm{c}}$ are the shear elastic and shear plastic coefficients, and $b_{\gamma}$ and $c_{\gamma}$ are their respective exponents. Although the $\gamma \mathrm{N}$ curve is a direct adaptation of the $\varepsilon \mathrm{N}$ equation, there is no universally accepted model to correlate their coefficients. Different correlations are proposed in the literature. Lagoda et al., for instance, provides a summary of the most common ones in his work [10]. Thus, experimental data is necessary to evaluate which one is most suitable for describing the tensile and shear sensitivity of a given material.

Together, the $\varepsilon \mathrm{N}$ and $\gamma \mathrm{N}$ experimental curves can be used to correlate the effects of each type of stress on fatigues life and identify for which load configuration the material is more sensitive. Shear-tensile correlation models enhance the understanding of the material behavior under shear, tensile and combined stresses, and are of great use in the life prediction of real components under multiaxial constraints, as well as material selection and design in new mechanical applications. 
For the curves comparison it is necessary to calculate an equivalent $\varepsilon \mathrm{N}$ curve using data from the $\gamma \mathrm{N}$ equation. In this work, it was done adapting two different failure criteria. This process is discussed in Section 2.3.3.

\subsection{3}

\section{Failure Criteria}

The Maximum Distortional Energy and Maximum Shear-Stress criteria are two classical idealizations of failure by yielding, and can also be used to predict failure by rupture or fatigue. Both methods were adapted to receive strain input and are used to convert data obtained from the torsional fatigue experiments into an equivalent uniaxial strain.

\subsubsection{1}

\section{Maximum Distortional Energy Criterion}

The Maximum Distortional Energy Criterion, also known as von Mises criteria, models the material's yielding using energy concepts. For that, the total elastic energy of a material is separated in two parts: one causing volumetric changes on the material, and the other associated with its shear distortions [11]. Yielding is assumed to occur when the part related to shear distortion ( $\left.\mathrm{U}_{\text {distortion }}\right)$ is equal to the maximum elastic distortion energy in simple tension $\left(\mathrm{U}_{\text {tension }}\right)$, as seen in Eqs. (2-5), (2-6), (2-7) in terms of the principal stresses. This value is named the yield critical stress $\left(\sigma_{\mathrm{yp}}\right)$ or von Mises stress $\left(\sigma_{\text {Mises }}\right)$.

$$
\begin{gathered}
U_{\text {distortion }}=\frac{1}{12 \mathrm{G}}\left[\left(\sigma_{1}-\sigma_{2}\right)^{2}+\left(\sigma_{2}-\sigma_{3}\right)^{2}+\left(\sigma_{3}-\sigma_{1}\right)^{2}\right] \\
U_{\text {tension }}=\frac{2 \sigma_{y p}^{2}}{12 \mathrm{G}} \\
\sigma_{y c}^{2}=\frac{1}{2}\left[\left(\sigma_{1}-\sigma_{2}\right)^{2}+\left(\sigma_{2}-\sigma_{3}\right)^{2}+\left(\sigma_{3}-\sigma_{1}\right)^{2}\right]
\end{gathered}
$$

The equations and procedures used on the conversion of this criterion's input from shear $(\tau)$ and tensile $(\sigma)$ stresses respectively into shear $(\gamma)$ and tensile $(\varepsilon)$ strains are exposed next. For more details on these postulates and correlations, see references $[12,13]$.

Written in terms of the tri-axial stresses, the Distortional Energy Criterion defines its critical stress value as stated in Eq. (2-8): 


$$
\sigma_{\text {Mises }}=\sqrt{\frac{1}{2}\left[\left(\sigma_{x}-\sigma_{y}\right)^{2}+\left(\sigma_{x}-\sigma_{z}\right)^{2}+\left(\sigma_{y}-\sigma_{z}\right)^{2}+6\left(\tau_{x y}^{2}+\tau_{x z}^{2}+\tau_{y z}^{2}\right)\right]}
$$

On a tridimensional state, the elastic stress-strain relations are stated as seen in Eqs. (2-9) to (2-14).

$$
\begin{gathered}
\sigma_{x}=\frac{E}{(1+v)(1-2 v)}\left[(1-v) \varepsilon_{x}+v\left(\varepsilon_{y}+\varepsilon_{z}\right)\right] \\
\sigma_{y}=\frac{E}{(1+v)(1-2 v)}\left[(1-v) \varepsilon_{y}+v\left(\varepsilon_{x}+\varepsilon_{z}\right)\right] \\
\sigma_{z}=\frac{E}{(1+v)(1-2 v)}\left[(1-v) \varepsilon_{z}+v\left(\varepsilon_{x}+\varepsilon_{y}\right)\right] \\
\tau_{x y}=G \gamma_{x y}=\frac{E}{2(1+v)} \gamma_{x y} \\
\tau_{x z}=G \gamma_{x z}=\frac{E}{2(1+v)} \gamma_{x z} \\
\tau_{y z}=G \gamma_{y z}=\frac{E}{2(1+v)} \gamma_{y z}
\end{gathered}
$$

Substitution Eqs. (2-9) to (2-14) into Eq. (2-8), we have:

$$
\sigma_{\text {Mises }}=\frac{E}{\sqrt{2}(1+v)} \sqrt{\left[\left(\varepsilon_{x}-\varepsilon_{y}\right)^{2}+\left(\varepsilon_{x}-\varepsilon_{z}\right)^{2}+\left(\varepsilon_{y}-\varepsilon_{z}\right)^{2}+\frac{3}{2}\left(\gamma_{x y}^{2}+\gamma_{x z}^{2}+\gamma_{y z}^{2}\right)\right]}
$$

Since $\sigma_{\text {Mises }}$ is a uniaxial stress, 1-D Hooke's Law stated in Eq. (2-16) can be applied into Eq. (2-15). The von Mises Criterion is then defined in terms of strain as stated in Eq. (2-17).

$$
\begin{gathered}
\sigma_{\text {Mises }}=E \varepsilon_{\text {Mises }} \\
\varepsilon_{\text {Mises }}=\frac{1}{\sqrt{2}(1+v)} \sqrt{\left[\left(\varepsilon_{x}-\varepsilon_{y}\right)^{2}+\left(\varepsilon_{x}-\varepsilon_{z}\right)^{2}+\left(\varepsilon_{y}-\varepsilon_{z}\right)^{2}+\frac{3}{2}\left(\gamma_{x y}^{2}+\gamma_{x z}^{2}+\gamma_{y z}^{2}\right)\right]}
\end{gathered}
$$

\subsubsection{2}

\section{Maximum Shear-Stress Criterion}

The Maximum Shear-Stress Criterion, also known as the Tresca Criterion, results from observations that, during yielding, the slip of ductile materials occurs along critically oriented planes, suggesting that the maximum shear stress is the driving force of the yielding [11]. Defining the principal stresses as $\sigma_{1}<\sigma_{2}<\sigma_{3}$, the critical stress is calculated as stated in Eq. (2-18). The maximum shear stress of 
a tridimensional loading configuration can be graphically represented as the diameter of the biggest Mohr Circle (Fig. 2.6).

$$
\sigma_{\text {Tresca }}=\max \left(\left|\sigma_{1}-\sigma_{2}\right| ;\left|\sigma_{1}-\sigma_{3}\right| ;\left|\sigma_{2}-\sigma_{3}\right|\right)=\left|\sigma_{1}-\sigma_{3}\right|
$$

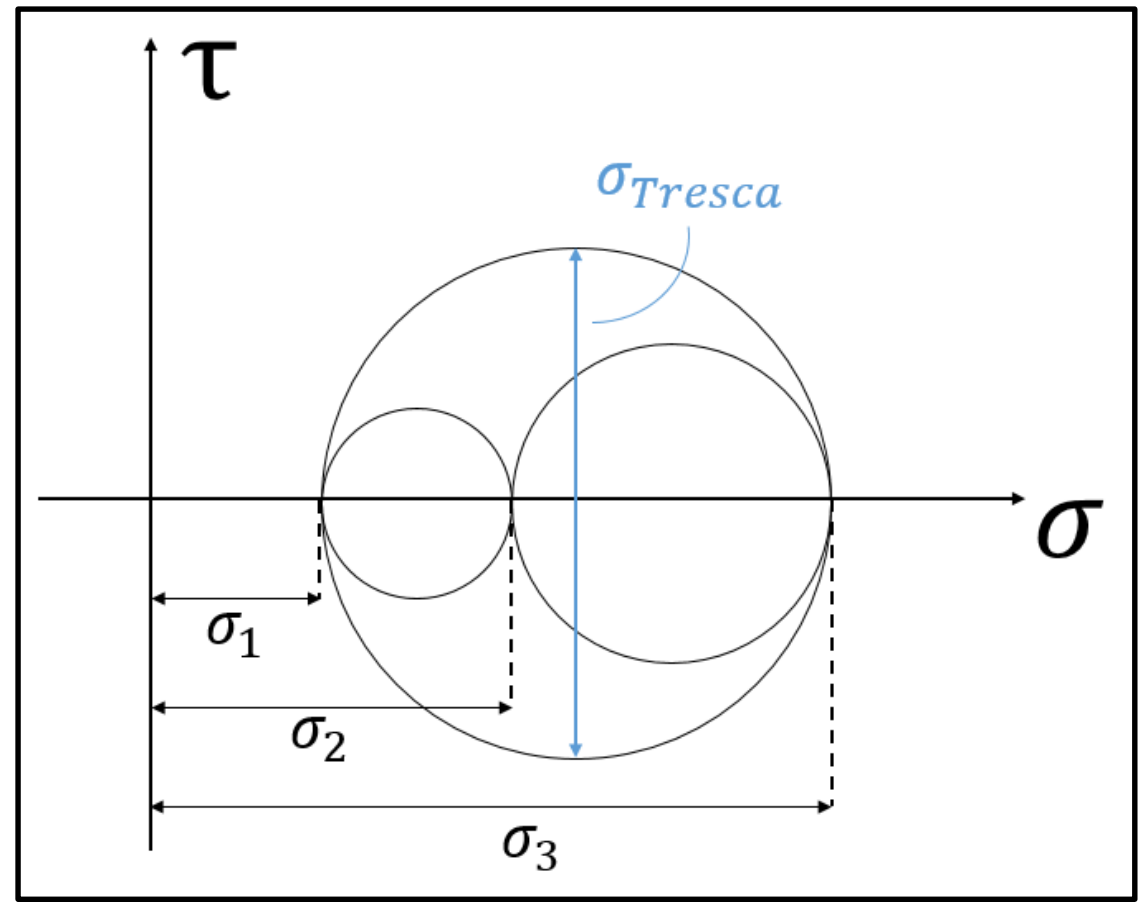

Figure 2.6: Mohr Circle of a tridimensional stress configuration.

Eq (2-18) can be used to relate the principal stresses and strain. By definition, no shear stresses and strains are presented in this configuration and, therefore, the elastic stress-strain relations are:

$$
\begin{aligned}
& \sigma_{1}=\frac{E}{(1+v)(1-2 v)}\left[(1-v) \varepsilon_{1}+v\left(\varepsilon_{2}+\varepsilon_{3}\right)\right] \\
& \sigma_{2}=\frac{E}{(1+v)(1-2 v)}\left[(1-v) \varepsilon_{2}+v\left(\varepsilon_{1}+\varepsilon_{3}\right)\right] \\
& \sigma_{3}=\frac{E}{(1+v)(1-2 v)}\left[(1-v) \varepsilon_{3}+v\left(\varepsilon_{1}+\varepsilon_{2}\right)\right]
\end{aligned}
$$

Substituting Eqs. (2-19) to (2-21) on Eq. (2-18) we have:

$$
\begin{gathered}
\sigma_{\text {Tresca }}=E \varepsilon_{\text {Tresca }}=\frac{E}{(1+v)(1-2 v)}\left|(1-2 v)\left(\varepsilon_{1}-\varepsilon_{3}\right)\right| \\
\varepsilon_{\text {Tresca }}=\frac{1}{(1+v)}\left|\varepsilon_{1}-\varepsilon_{3}\right|
\end{gathered}
$$




\subsection{4 \\ Critical Plane Approach}

Subsections 2.3.4 and 2.3.5 are intended for a brief explanation about the Critical Plane approach, its modeling and some of the most commons damage models. For more details about these topics, see references [1,13]. Also, in the present work the critical plane is always assumed on a free surface, which is true in all of the experiments conducted.

Extensive experimental evidence shows that, in most metallic alloys and other directional-damage materials, fatigue cracks tend to initiate on specific planes at the critical point, where the damage induced by the loading history is maximized. For this reason, these planes are defined as critical.

To properly represent this behavior, the discussed models assume that stresses on other planes would initiate different fatigue cracks that do not interact, because only the dominant one propagates on the critical plane.

All planes at the critical point are described by their latitudinal $(\theta)$ and longitudinal $(\varphi)$ angles from the surface, as shown in Fig. 2.7. The shear and normal stresses, which corroborate to the crack fatigue initiation, are $\tau_{\mathrm{A}}, \tau_{\mathrm{B}}$, and $\sigma_{\perp}$, and the critical plane only needs to be searched for in the angular ranges $0^{\circ}<\varphi<90^{\circ}$ and $0^{\circ}<\theta<180^{\circ}$, due to plane symmetries.

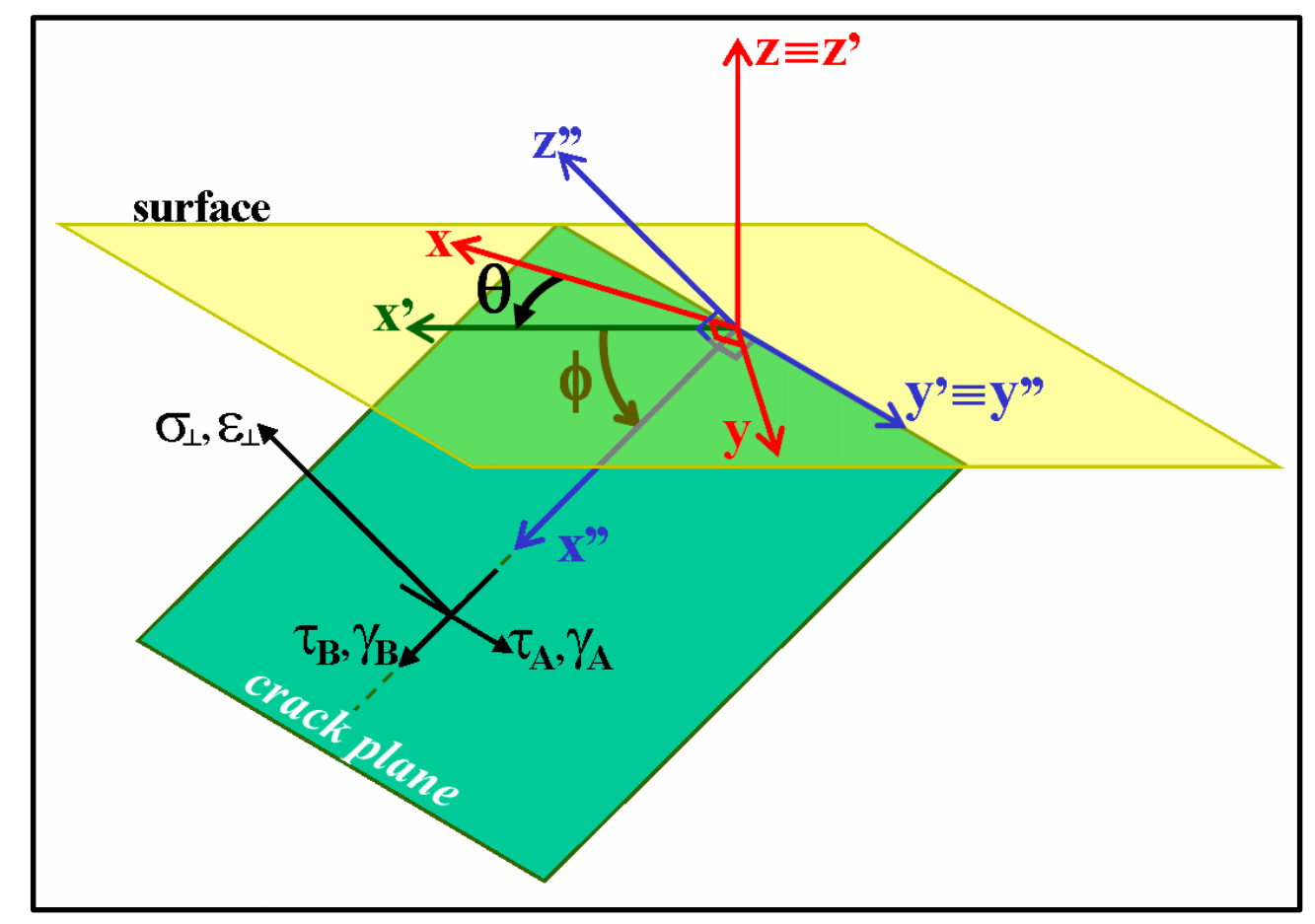

Figure 2.7: Coordinate transformations, where $\mathrm{z}$ is defined perpendicular to the free surface [1]. 
Bannantine and Socie proposed a simplified procedure to search for the critical plane assuming that, for directional-damage materials, the most common micro cracks always appear at $\varphi=90^{\circ}$ (Case A) or at $\varphi=45^{\circ}$ (Case B), shown in Fig. 2.8. They are formed in three different ways and are named:

- A90(T) cracks at $\varphi=90^{\circ}$, caused mainly by the tensile stress $\left(\sigma_{\perp}\right)$ or strain $(\varepsilon \perp)$ perpendicular to the plane;

- A90(S) cracks at $\varphi=90^{\circ}$, caused mainly by the in-plane shear stress $\left(\tau_{\mathrm{A}}\right)$ or strain $\left(\gamma_{\mathrm{A}}\right)$;

- B45(S) cracks at $\varphi=45^{\circ}$, caused mainly by the out-of-plane shear stress $\left(\tau_{\mathrm{B}}\right)$ or strain $\left(\gamma_{B}\right)$.

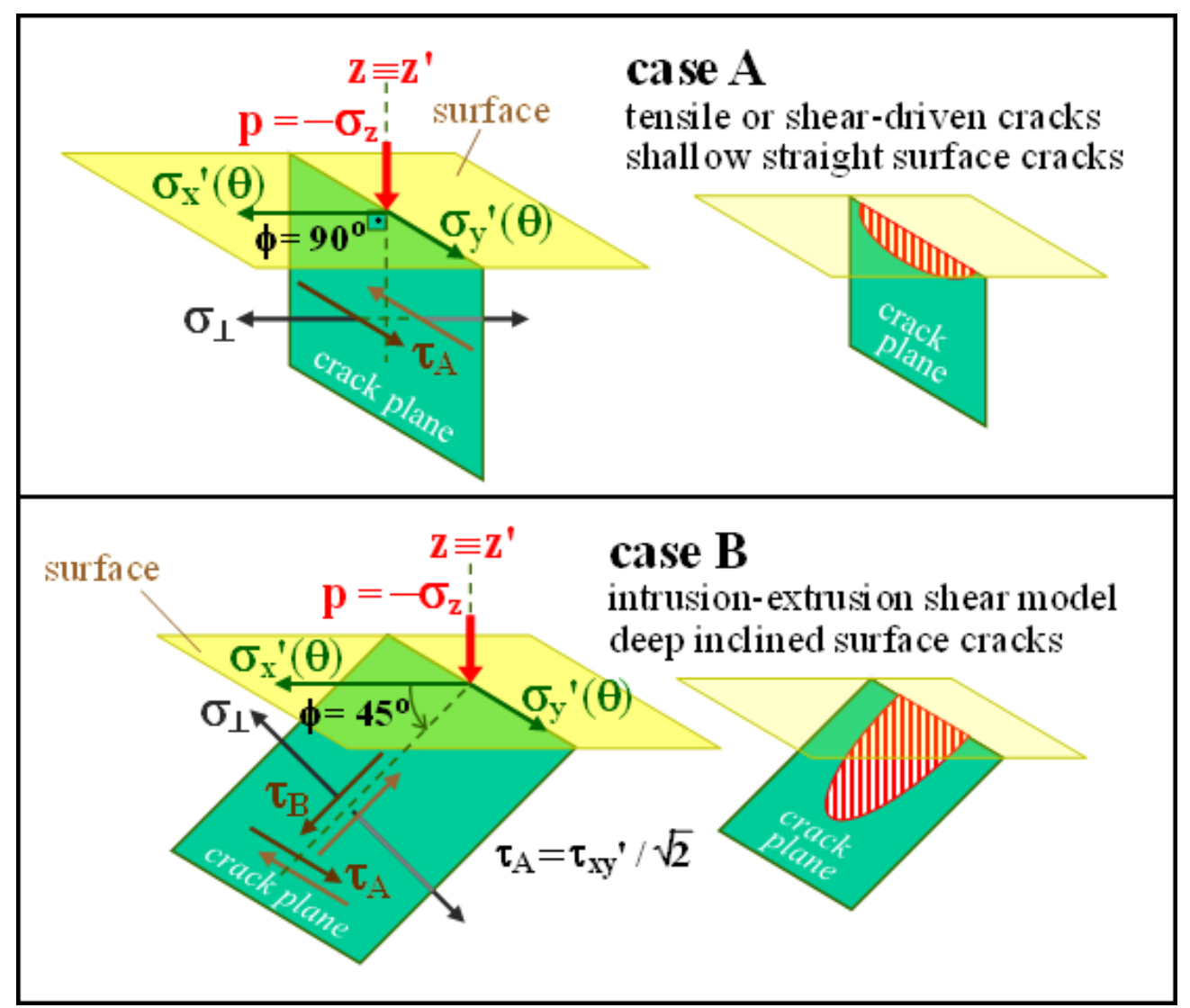

Figure 2.8: Stress states for the initiation of A90 and B45 cracks (modified from [1]).

This modeling highlights the importance of characterizing the tensile or shear sensitivity of materials to precisely predict their lives under cyclic multiaxial loads. For that reason, critical plane multiaxial fatigue damage models assume a different selection of those parameters to be the driven forces on the crack formation, being classified as shear or tensile models. 


\subsection{5}

\section{Critical Plane Multiaxial Fatigue Damage Models}

This subsection approaches four critical plane multiaxial fatigue damage models and debates about their applicability with respect to high or low-cycle fatigue cases for shear or tensile sensitive materials. The discussed models are Findley, Generalized Goodman, Fatemi-Socie and Smith-Watson-Topper.

Findley and Generalized Goodman are examples of damage models recommended for high-cycle fatigue. Findley's shear model, Eq. (2-23), assumes fatigue damage being mainly caused by the combination of the peak normal stress ( $\sigma \perp \max )$ perpendicular to the critical plane with the amplitude of the shear stress $(\Delta \tau / 2)$. The significance of the peak normal stress, which is directly related to the material's tensile sensitivity, can be calibrated by adjusting the parameter $\alpha_{\mathrm{F}}$ in the model.

For tensile sensitive materials, Goodman's alternate-mean equation commonly used in uniaxial fatigue can be adapted to a Generalized Goodman tensile model, Eq. (2-24), considering the alternate and mean of the plane's perpendicular stress $\left(\sigma_{\perp}\right)$.

$$
\begin{gathered}
\max _{\theta, \varphi}\left[\frac{\Delta \tau(\theta, \varphi)}{2}+\alpha_{F} \sigma_{\perp \max }(\theta, \varphi)\right]=\beta_{F} \\
\frac{\frac{1}{2} \Delta \sigma_{\perp}\left(\theta, 90^{\circ}\right)}{S_{F}(N)}+\frac{\sigma_{\perp \max }\left(\theta, 90^{\circ}\right)-\frac{1}{2} \Delta \sigma_{\perp}\left(\theta, 90^{\circ}\right)}{S_{U}}=1
\end{gathered}
$$

For low cycle fatigue, Fatemi-Socie and Smith-Watson-Topper models are recommended. Fatemi-Socie, Eq. (2-25), is a shear model which assumes that, instead of stress, the shear strain amplitude $(\Delta \gamma / 2)$ is the fatigue driving force along with the peak perpendicular stress. Also, a multiplicative parameter is used instead of the additive one to correct a wrong fatigue damage prediction that would happen under small non-damaging shear stresses and/or strain ranges.

$$
\max _{\theta, \varphi}\left[\frac{\Delta \gamma(\theta, \varphi)}{2}\left(1+\alpha_{F S} \frac{\sigma_{\perp \max }(\theta, \varphi)}{S_{Y c}}\right)\right]=\left(\frac{\tau_{c}}{G}\right)(2 N)^{b_{\gamma}}+\gamma_{c}(2 N)^{c_{\gamma}}
$$

Note that for pure torsional conditions, the maximum damage occurs when $\theta=90^{\circ}$ and $\sigma_{\perp \max }\left(90^{\circ}, \varphi\right)=0$. This reduced Eq. (2-25) to the $\gamma \mathrm{N}$ equation, Eq. (2-4). To calibrate its parameter $\alpha_{\mathrm{FS}}$, tension-compression experiments with mean stress $\left(\sigma_{\mathrm{m}}\right)$ equal to zero are recommended (this is discussed in section 4.8). 
Smith-Watson-Topper's (SWT) critical-plane tensile model, Eq. (2-26), is an adaptation from a uniaxial low-cycle fatigue model with the same name, considering in this version the peak normal stress and normal strain amplitude, both perpendicular to the critical plane, as the main cause of damage.

$$
\max _{\theta, \varphi}\left[\sigma_{\perp \max }(\theta, \varphi) \frac{\Delta \varepsilon_{\perp}(\theta, \varphi)}{2}\right]=\left(\frac{\sigma_{c}{ }^{2}}{E}\right)(2 N)^{2 b}+\sigma_{c} \varepsilon_{c}(2 N)^{b+c}
$$

This equation can be written for a given $\theta$ and $\varphi$ as stated in Eq. (2-27).

$$
\sigma_{\perp \max }(\theta, \varphi) \frac{\Delta \varepsilon_{\perp}(\theta, \varphi)}{2}=\sigma_{c}(2 N)^{b}\left[\left(\frac{\sigma_{c}}{E}\right)(2 N)^{b}+\varepsilon_{c}(2 N)^{c}\right]
$$

Note that under cyclic tension-compression with $\sigma_{\mathrm{m}}=0$, the maximum damage occurs at $\theta=0^{\circ}$. Since in this case $\sigma_{\perp \max }=\sigma=\sigma_{c}(2 N)^{b}$, Eq. (2-27) is reduced to the Coffin-Manson equation, Eq. (2-3). 


\section{3 \\ Components Design and Machine Adaptations}

This work proposes a design adaptation for a pair of hydraulic grips originally designed for an Instron 8501 Servohydraulic Fatigue Testing System (which is uniaxial) to be mounted on the 8874 Biaxial system. The adjustments were made by designing and manufacturing new pieces that could be assembled on the biaxial machine in order to emulate the mounting conditions from the 8501 system.

The chosen pair of grips were designed for a $250 \mathrm{kN}$ capacity machine [14], but with these adaptations they were used on a $25 \mathrm{kN}$ one [7]. Such disparity exacerbates problems that might be caused by misalignment of the grips. Those issues, as well as recommended precautions, are discussed in this chapter.

\section{1 \\ Components Design and Manufacturing}

\subsection{1 Pair of adapters}

Instron has a recommended hydraulic wedge action grip for the 8874 Biaxial Testing machine. This equipment has an integrated base, which is fixed onto the machine using six concentrically positioned screws within the center (Fig. 3.1), preventing rotational slide that could happen during torsional tests.

On the uniaxial machine, the hydraulic grip assembly is conducted using only one central double ended screw. Instead of an integrated base, the grip has one central threaded hole and the machine has a left-handed one, in which both ends of the piece are screwed in for the fixation of all equipment.

To enable the assembly of the grip in the new servo-hydraulic testing system, a pair of adapters were designed and manufactured to emulate the base and top of the machine in which the grips were originally utilized. Both adapters have a M30x2.0 left-handed threaded bore in its center, which mates with the double ended screw required for both grips assembly. Around this bore, 6 concentric holes are 
positioned for the screws to fix the lower adapter to the table and the upper one on the hydraulic actuator (Fig. 3.2).

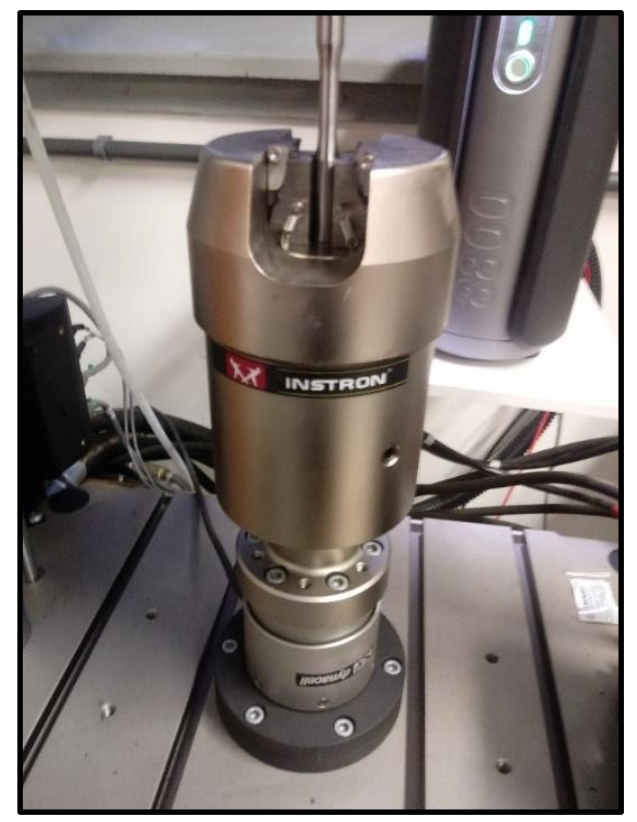

Figure 3.1: INSTRON 25kN/100Nm axial/torsional hydraulic grip.

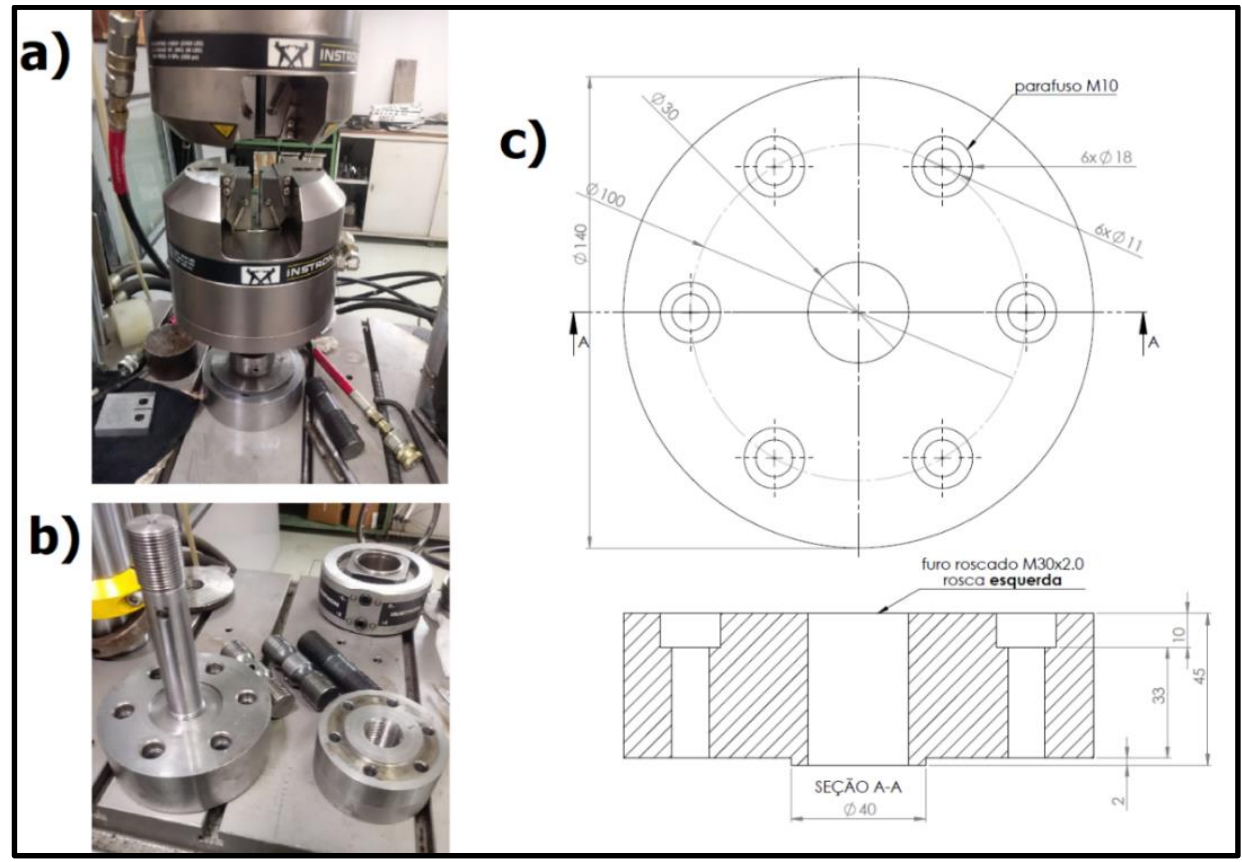

Figure 3.2: a) The assembly used. b) individual pieces used. c) schematics of the lower adapter.

Assuming the piece will be machined mostly on a manual lathe, a reliable way to guarantee proper alignment between the adapters is to machine both from the same work piece. After finishing the first piece, the central hole for the second piece can be made without changing the position of the work piece, guaranteeing that 
both adapters will be concentric. Also, the initial mark of the 6 concentric holes should be done on the lathe before the piece is moved to a drilling machine.

Such procedures assure that the corresponding threaded holes will be concentrically aligned within the tolerance applied during the machining, which normally is enough for later fine adjustments.

\subsection{2}

\section{Double-screwed thread}

To correct the misalignment found during the experiments with the adapted system, an external alignment fixture model was used (the usage procedures are discussed in subsection 3.3.2.3). A new thread was designed to increase the space necessary for this equipment to fit onto the assembly.

The work piece was taken from a left-over threaded rod from a batch of a rupture strength test order (Fig. 3.3). The test report indicated that this thread could withstand 650MPa without plastic deformation, which is significantly higher than the service loads required for our new thread.

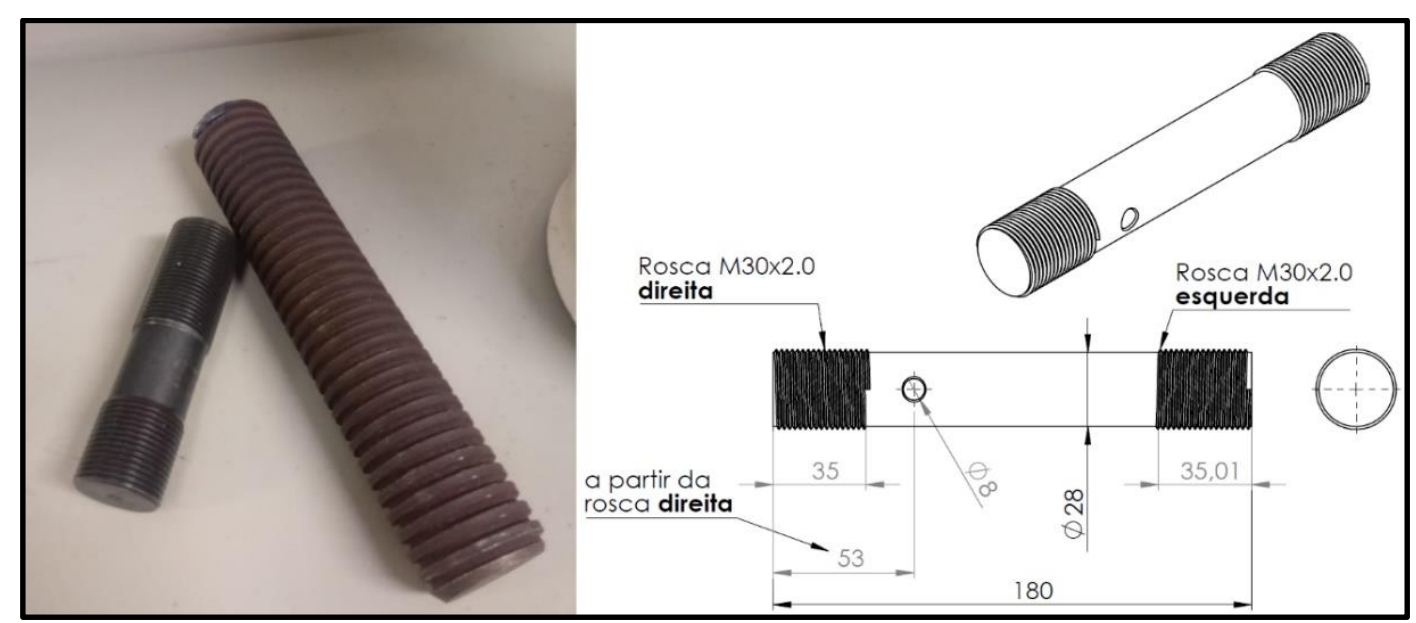

Figure 3.3: Picture of the left-over threaded rod together with the old threaded screw. Schematic of the new threaded screw.

The only modification on the new design was its length, which was increased within the height of the aligner. Buckling was not taken into consideration on the project because this piece will always be under tension, since pre-load washers are fixed onto the structure before experiments are conducted. This will be discussed on section 3.2 . 


\section{2}

\section{Assembly Protocol}

Each experimental testing has its own methodology and assembly requirements. The most common experimental and industrial procedures are regulated by government and private agencies which elaborate standards with requirements to be followed. Even when a new experiment is executed, some of those procedures should still be followed and used as a basis for the new ones to be implemented. In this present work, all standards used were elaborated by the American Society for Testing and Materials (ASTM), and the new assembly and experimental procedures were developed using their recommendation as a basis.

All testing executed in this present work have the same assembly standardized requirements, and follow the set-up illustrated in Fig. 3.4.

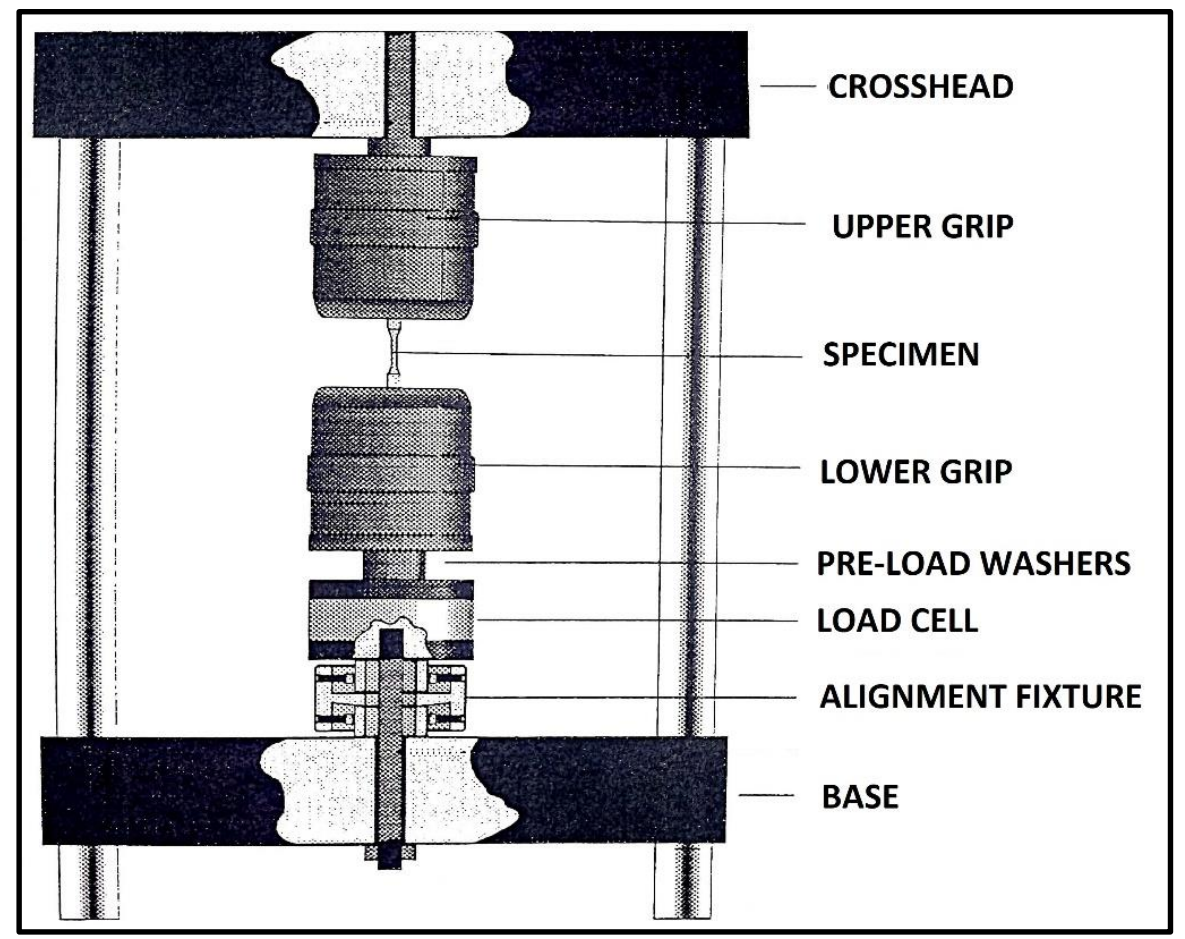

Figure 3.4: Schematics of the experimental set-up used (modified from [15]).

An important component in this assembly is a pair of split pre-load washers that is fixed between the hydraulic grips and the structure of the machine. It consists of two washers which have their external faces parallel between each other, and its internal faces slightly inclined or in a helical shape (Fig 3.5). When the pair is mounted with its internal faces in contact, it turns into one adjustable washer with 
a height that can vary by sliding the upper inclined washer or rotating the upper helical one.

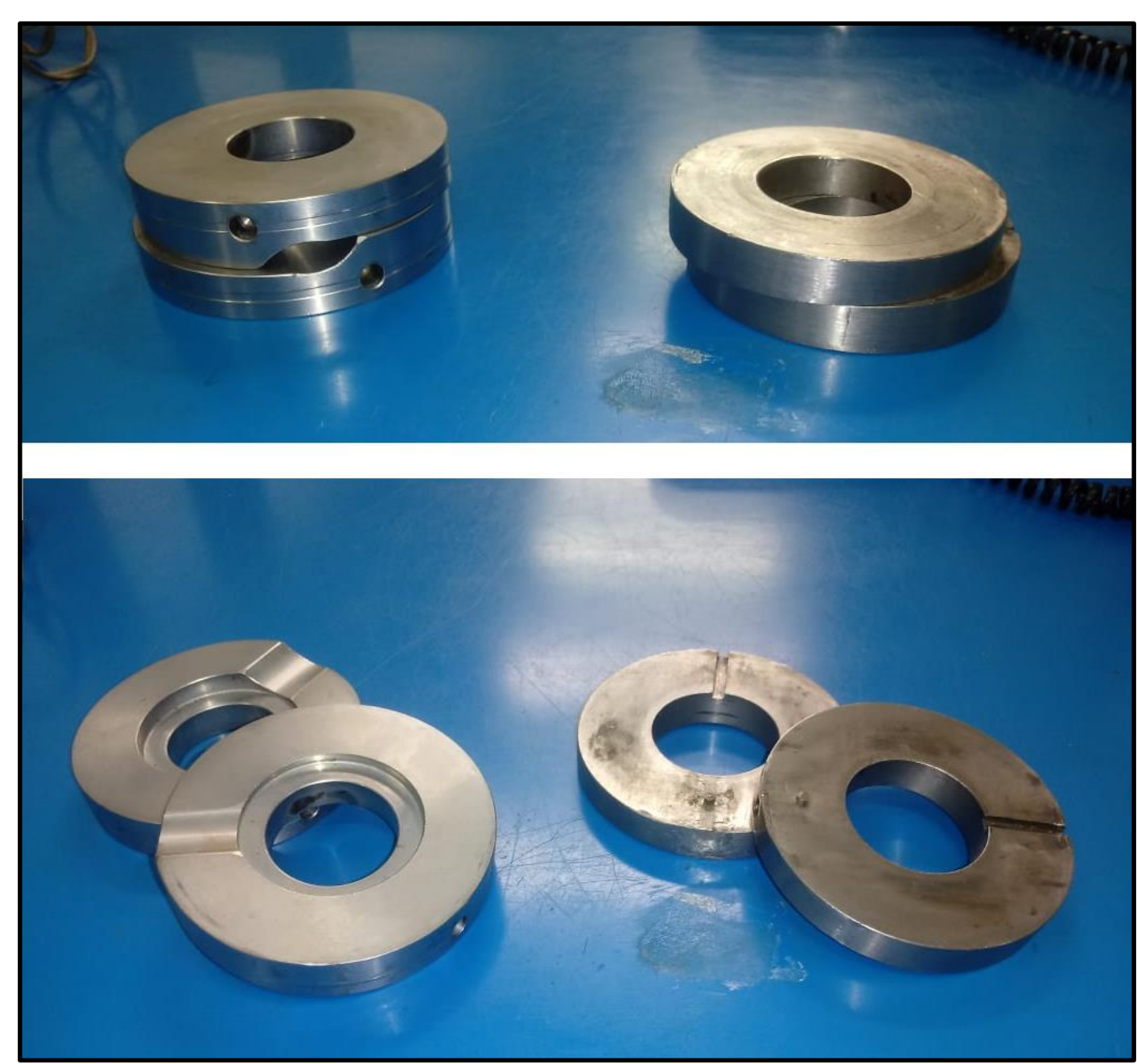

Figure 3.5: Two examples of pre-load washers. Helical pair on the left, inclined pair on the right.

The assembly goes on the following steps. First the hydraulic grip is mounted into the table or cross-head top with the washers in between on the minimum height configuration. All clearance between the grip and the washers is removed. A load bigger than the maximum expected during the experiment to be conducted is applied and the washers are adjusted to remove all new clearance that appears. Finally, the machine is unloaded, putting the washers under compression. With this procedure, it is guaranteed that the washers will be at compression during all the experiment, avoiding the appearance of a gap on the mounted system which can cause vibration and fatigue problems.

During trial multiaxial experiments, it was observed that the hydraulic grip was slipping when the helical washers were the chosen ones. Since the grips are fixed 
using a double threaded screw, with one end being left-handed, both clockwise (cw) and counter clockwise (ccw) rotations were dislocating the grip up (Fig 3.8). In fact, those washers are recommended for tensile-compression experiments and most of the grips designed for torsion experiments are fixed via 6 concentric bolts instead of the one in the middle, (the same way used on the adapters designed in this present work). With that mounting configuration, this slipping caused by rotation no longer happens.

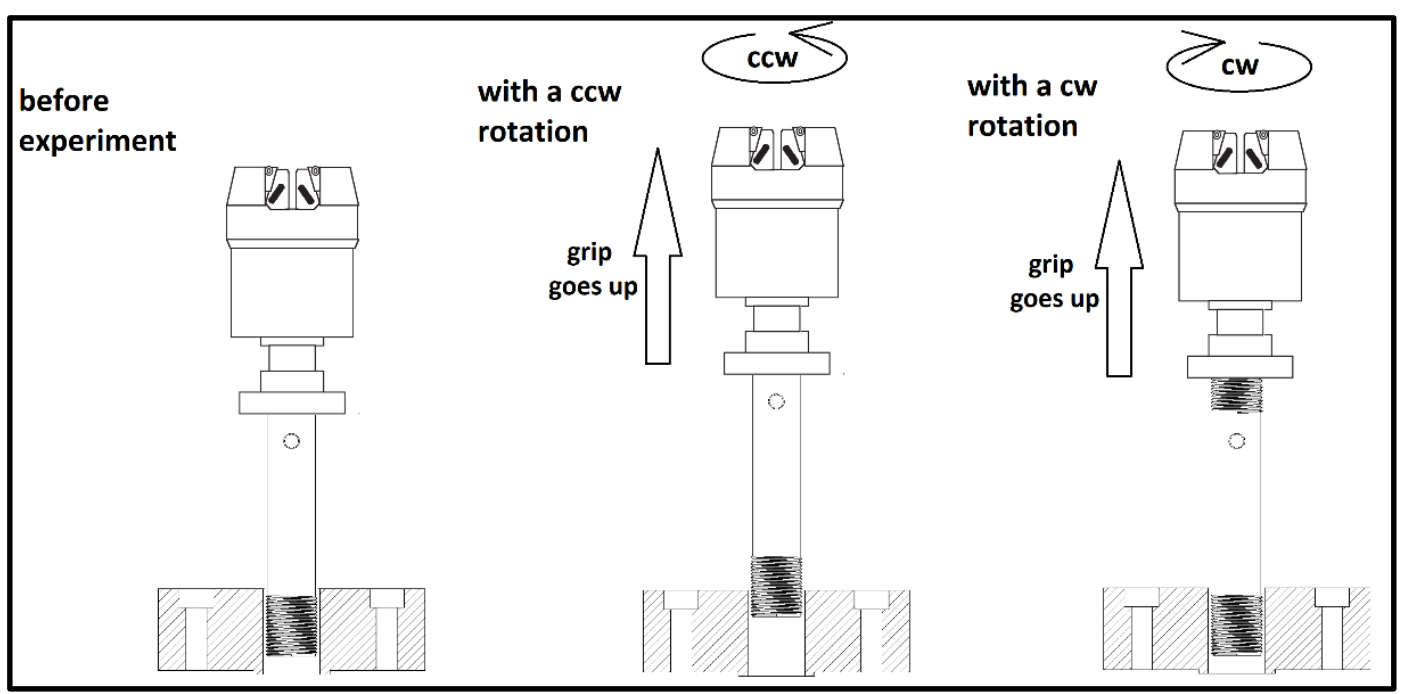

Figure 3.6: Schematics of the problem.

Nevertheless, the use of the inclined washers mitigated this problem, and experiments could be conducted under low torsional capacities of the machine.

\section{3}

\section{Alignment}

One of the highest concerns on axial-torsional experimental testing is to maintain proper alignment between the upper and lower grips. As stated on ASTM E606 Standard, a change in axial concentricity of less than or equal to $0.05 \mathrm{~mm}$, measured between the bottom and top specimen fixture under cyclic force, is a measure of success with respect to minimizing lateral deflection of the loading train. Also, for a proper strain-controlled testing, no maximum bending strains (corroborated be misalignments) shall exceed 5\% of the minimum axial range imposed during any test [9].

Neglecting proper maintenance to always keep the testing system in proper alignment constitutes a hazard to the system itself, besides the obvious 
consequences of incorrect readings for any experiment done on a system in such conditions.

\subsection{1}

\section{Misalignment Consequences}

A possible permanent consequence is damage to the hydraulic grips, since the misalignment can submit them to transverse forces they were not design to withstand. This can deform or even fracture the backstop plates of the jaw faces, which leads to tearing of the screws and springs used in the assembly, and in turn can cause damage to the threaded hole where the screws are connected (Fig. 3.7). Proper maintenance of the grips is necessary to identify those problems before the replacement of the screws and plates flattening (with a manual or hydraulic press, for example) is no longer possible.

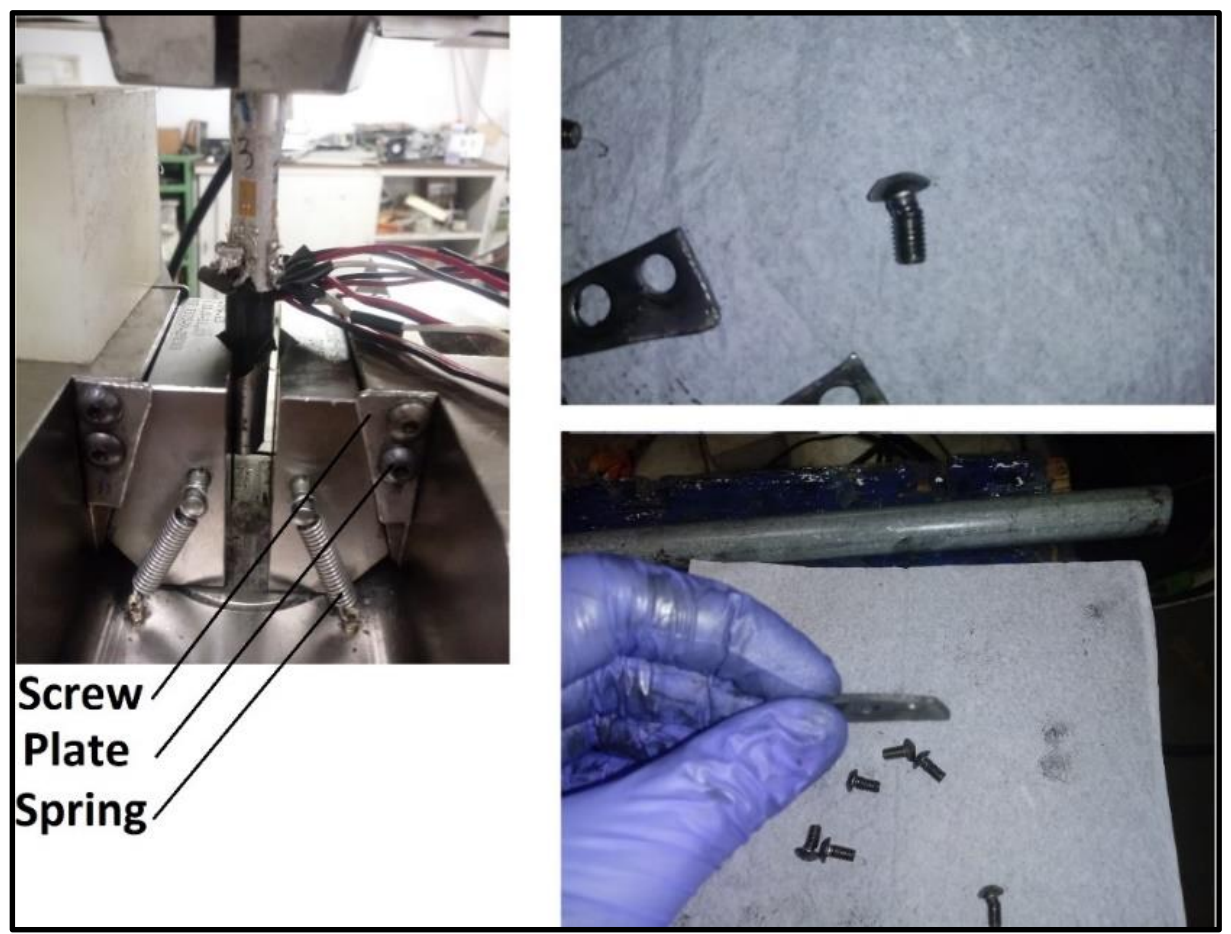

Figure 3.7: Bending of the backstop plates and shearing of the screws, caused by usage of a misaligned system.

On the occurrence of the specimen's buckling, the misalignment increases the chance of a grip to laterally rotate, consequentially bending the hydraulic piston column. If subjected to enough bending moment, the column deformation can be irreversible, causing machine malfunction (Fig 3.8). 


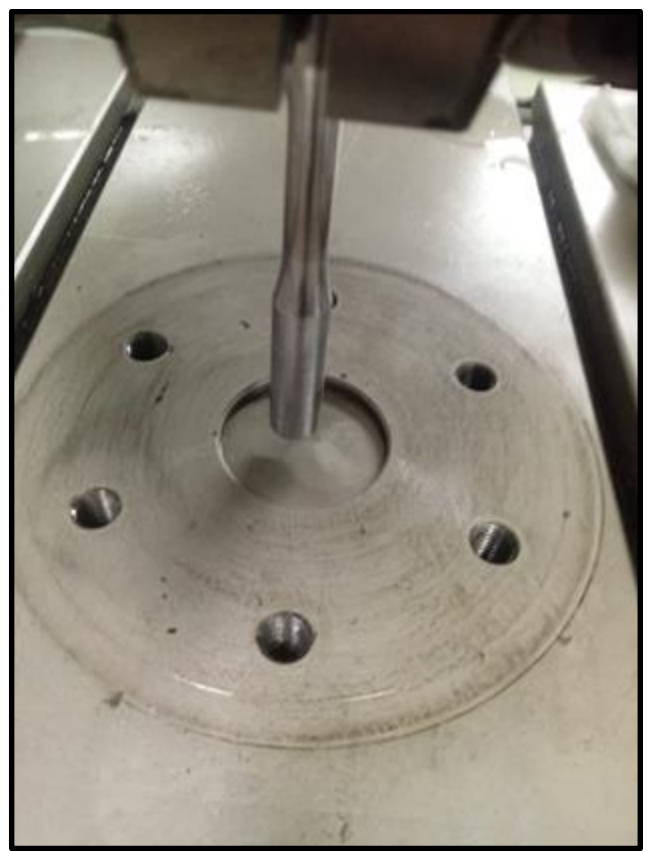

Figure 3.8: Misalignment caused be a bent hydraulic piston column. The specimen should be pointing towards the center of the undercut circle.

It is strongly advisable to configure and activate the maximum and minimum limits of both force and position before activating the hydraulic piston. With a properly defined minimum position limit, the machine will stop before buckling is enough to damage the grips and/or the testing machine.

\subsection{2}

Alignment Methodology

All hydraulic testing systems evaluated during this work were designed with its hydraulic actuators either under the base table or above the crosshead top. All methods presented next assume the grip to be perfectly aligned with respect to the actuator where it is fixed. Therefore, the alignment procedures discussed should be conducted on the other grip. Instron 8874 has two actuators above its crosshead top, and for that reason all protocol listed in this work was conducted on the grip assembled onto the base.

\subsubsection{1}

\section{Visual Identification of Misalignment}

First, it is necessary to qualitatively assess the misalignment. An easy method for this primary evaluation is to simply clip a new specimen (or any piece that is 
guaranteed to be straight) on the upper grip and observe its eccentricity within the lower grip. Any considerable misalignment will be identified without the use of measuring tools (Fig. 3.9).

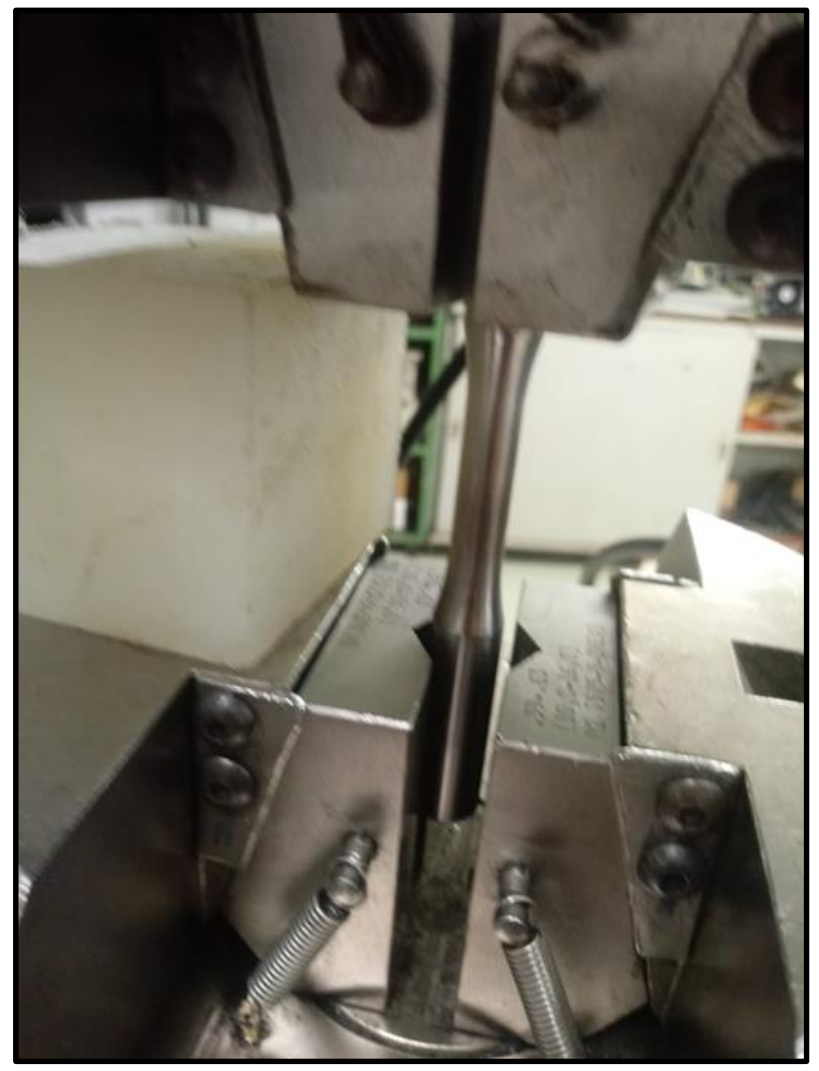

Figure 3.9: Example of a considerably misaligned assembly. The specimen should be within the same distance from each jaw face.

To correct the misalignment, it is necessary to proceed in two steps, starting by loosening the screws that hold the assembly onto the base. Once the lower grip (or adapter, in this work's case) is in place but not tight, one can fix the specimen onto both grips. The very transverse force of the jaw faces will push the structure towards a better alignment position, and the way the specimen deforms visually indicates the location of this position.

Following the initial placement, the use of a rubber hammer is recommended to gently push the lower adapter in the directions necessary for alignment. This procedure generates an acceptable primary result, which should be followed by quantitative procedure to assure that the alignment is within the required tolerance of the experiment. Some of those methodologies are discussed in subsections 3.3.2.2 to 3.3.3.4. 


\subsubsection{2 Dial Indicator Method}

A standard method to quantify misalignments is using a dial indicator. For the setting of this procedure, one needs to attach the magnetic base of the dial onto the grip assembled on the actuator (top in our case) and the contact tip to the surface of the other grip (Fig. 3.10). It is important that the tip is substantially pressed against the surface, in such a way that no vibration is enough to cause the loss of contact between the tip and the surface.

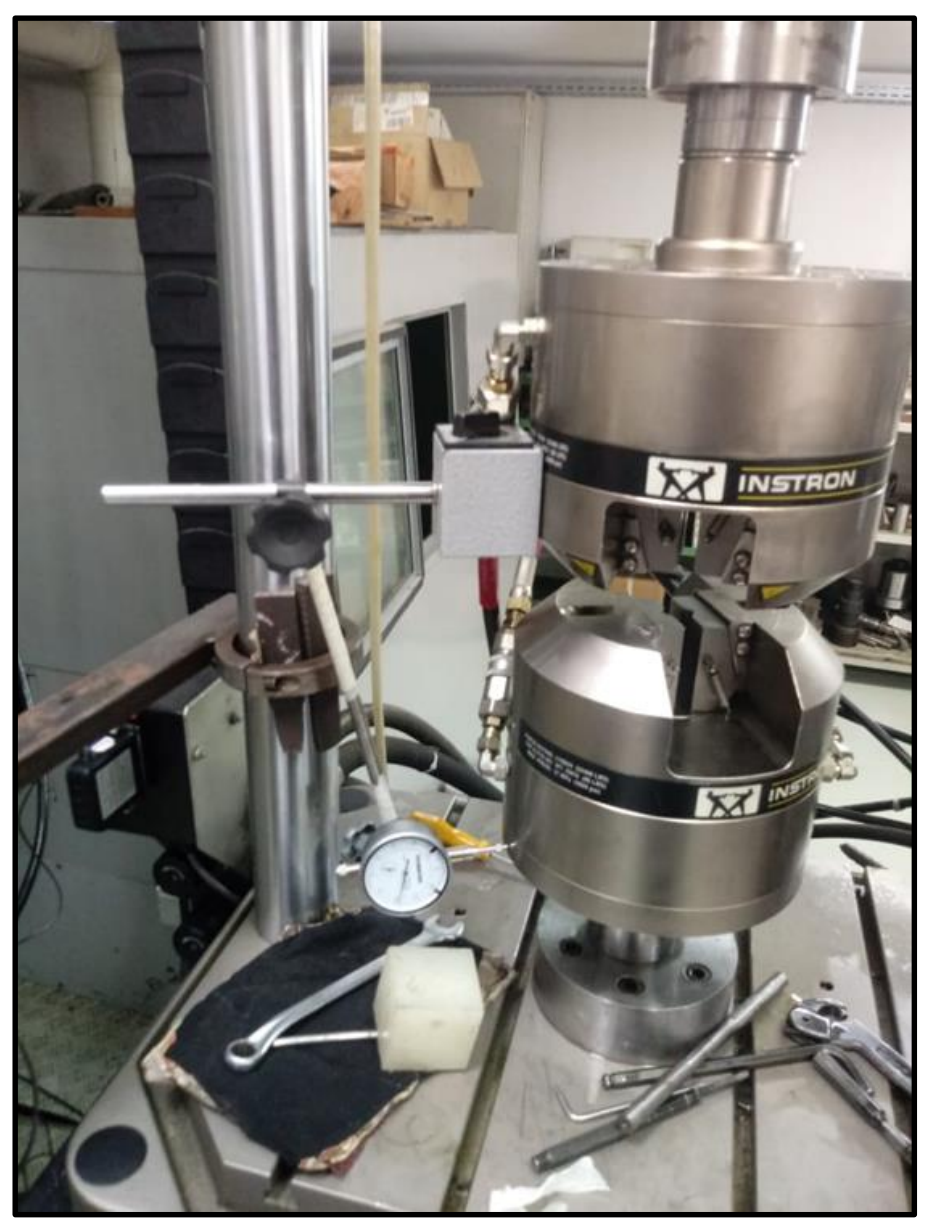

Figure 3.10: Example of an assembly for the Dial Indicator Method.

To execute the measurement, the top grip is rotated around its central axle (the screwed thread in our case), and the points of maximum positive and negative deviations are marker to be later corrected by gently hammering the assembly towards the negative and against the positive deviations. When the dial readings are within the tolerance needed, one can proceed to tighten both grips and the alignment is done. 
One important point to remember, in order to prevent an unfortunate loss of expensive delicate equipment, is to always remove the dial indicator before, not after, hammering the structure and then reinserting the dial afterwards for further readings.

\subsubsection{3}

\section{Strain Reading Method}

If necessary, a more precisely misalignment quantification can be done using strain gauges. The specimen instrumentation is conducted fixing four strain gauges parallel to its neutral axis and spaced 90 degrees between each other (Fig. 3.11).

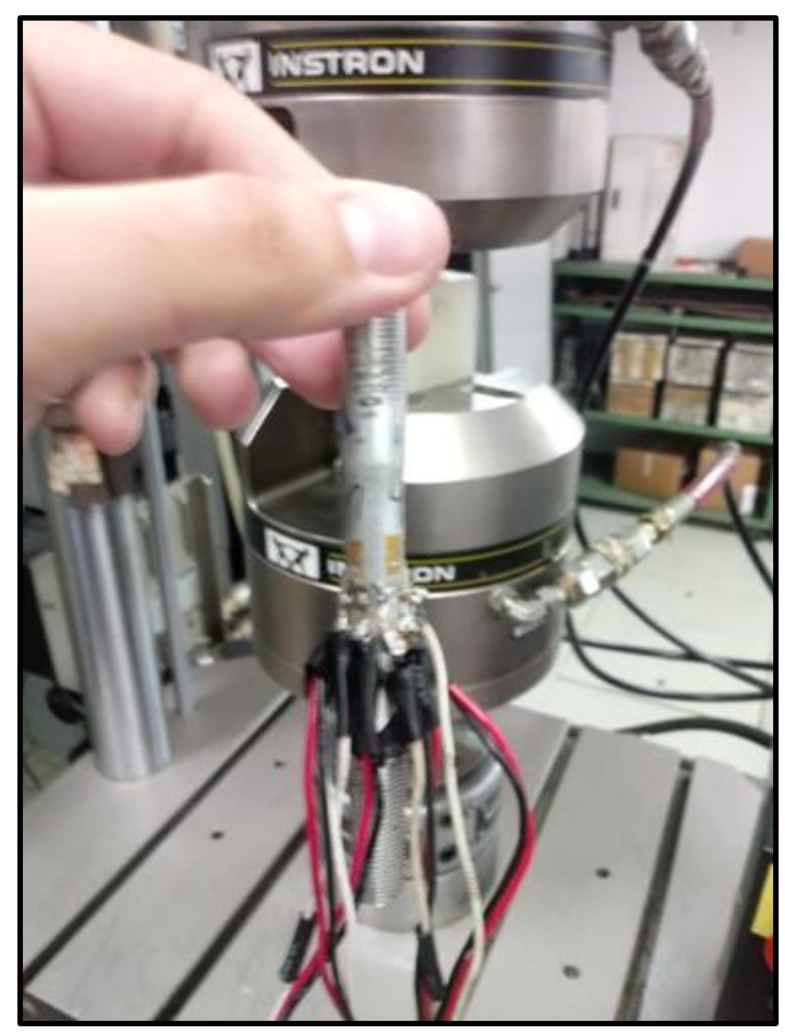

Figure 3.11: Specimen instrumentation.

The reference reading, where strains are considered zero, is when the specimen is clipped onto only one grip.

Through the readings of the strain gauges after the second grip clips the specimen, it is possible to determine the strain variation of 4 points on the horizontal cross-section of the specimen. Pure axial force yields the specimen equally, and any deviant reading on the strain gauges is an indication that the specimen is suffering intrusive stresses caused by misalignment. 
The advantage of this method is that a data acquisition system (Daq) gives real time readings of those strains while adjustments are conducted, which helps to better visualize the directions the assemble needs to be pushed to (Fig. 3.12).

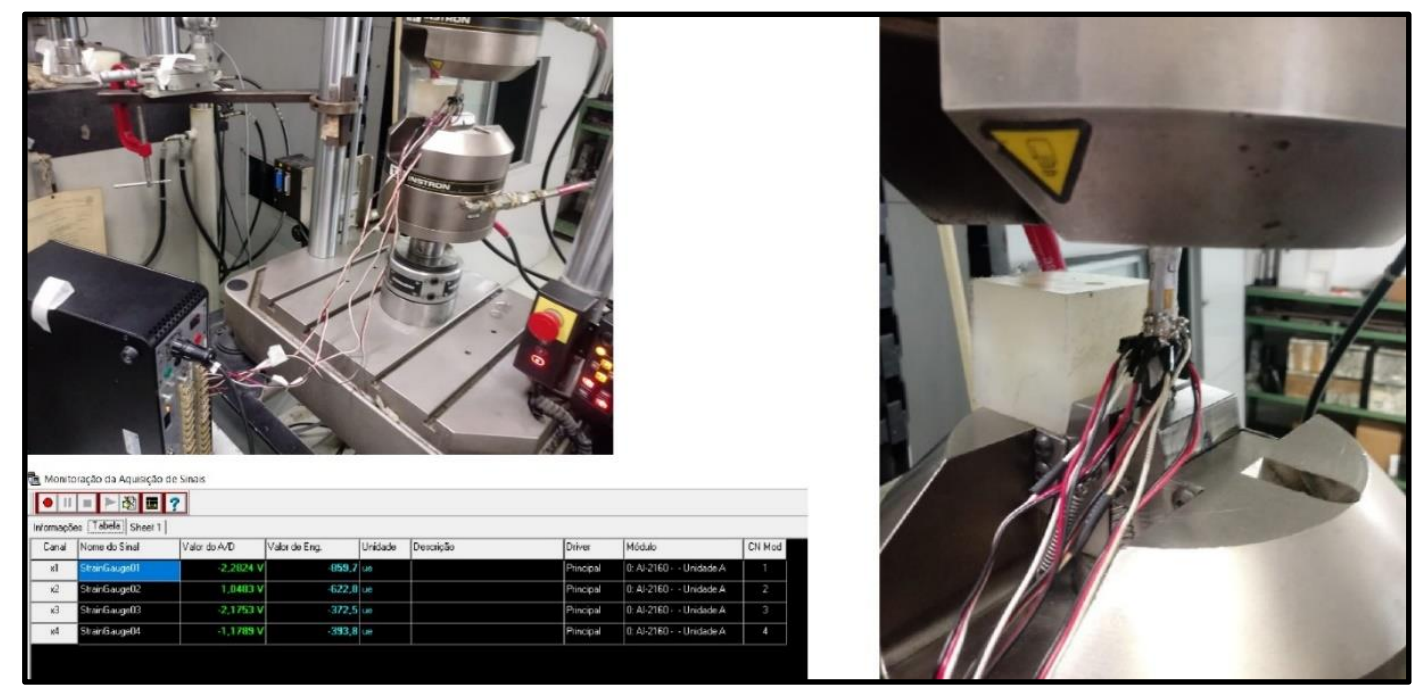

Figure 3.12: Experimental setup, as well as the Daq reading on the computer screen.

\subsubsection{4 \\ External Alignment Fixture Method}

All the previously discussed methods correct concentric misalignment, which normally is enough since it is expected that a testing machine from a trustworthy company will have its table and crosshead precisely parallel, and the hydraulic grips are assembled perpendicular to then. The inclusion of a pair of adapters on the assembly can be a source of angular misalignment, since their faces might not have been machined with the required parallelism. For those and similar cases, an advisable solution is the use of an external alignment tool. In this work the Instron Alignment Fixture Model 8000-073 is discussed and information used on this section are referenced to the manual of this equipment[15]. Similar systems can be used, or even built, to deal with this type of misalignment.

This alignment fixture consists of a central housing with upper and lower rings inside, which slides on each other. The upper ring has a spherical surface that mates with the spherical upper surface of the central housing, and a variation on its position changes the angle of the Fixture's top. On the other hand, the lower ring has a flat surface, so a change on its position only varies the Fixture's horizontal location (Fig. 3.13). 


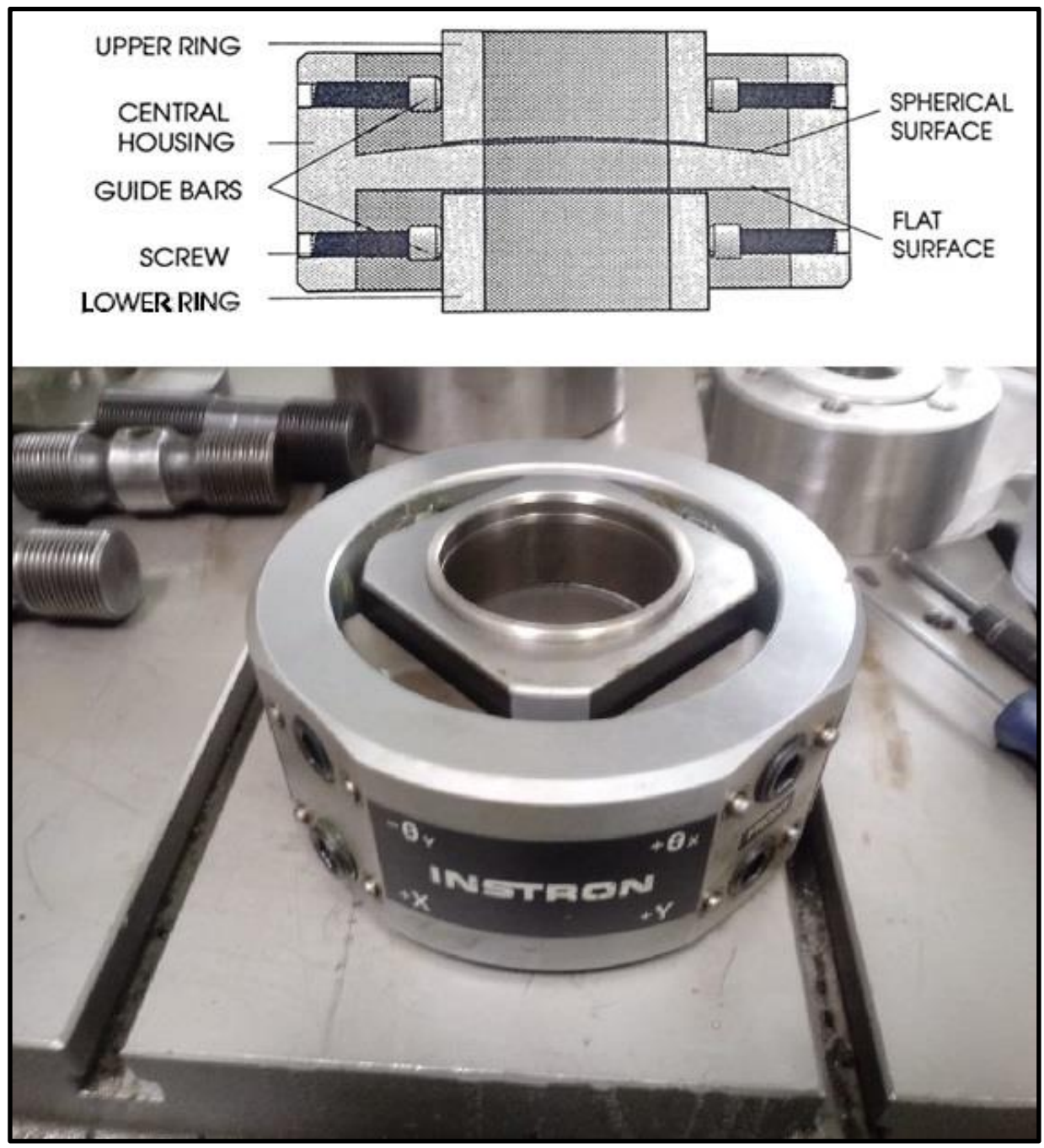

Figure 3.13: Instron Alignment Fixture Model 8000-073 (photo and schematic [15]).

The rings are dislocated by four pairs of screws arranged at 90 degree intervals around the circumference of the central housing, and guide bars on their tips are supported against the rings to hold then on the desired position.

Deciding the position of both rings requires a better understanding of how both types of misalignments affects the specimen. Concentric and angular misalignments cause different patterns of deformation on the specimen. For example, assuming that both grips are parallel and concentric, when the upper grip is rotated through some angle, the resulting strain is positive all along the outer curvature of the specimen and negative on the inner curvature (Fig. 3.14 - left). On the other hand, when the upper grip is offset through some distance, the resulting strain is zero in the center of a section, with symmetric values between the top and bottom strains, but with opposite sign (Fig. 3.14 - right). 


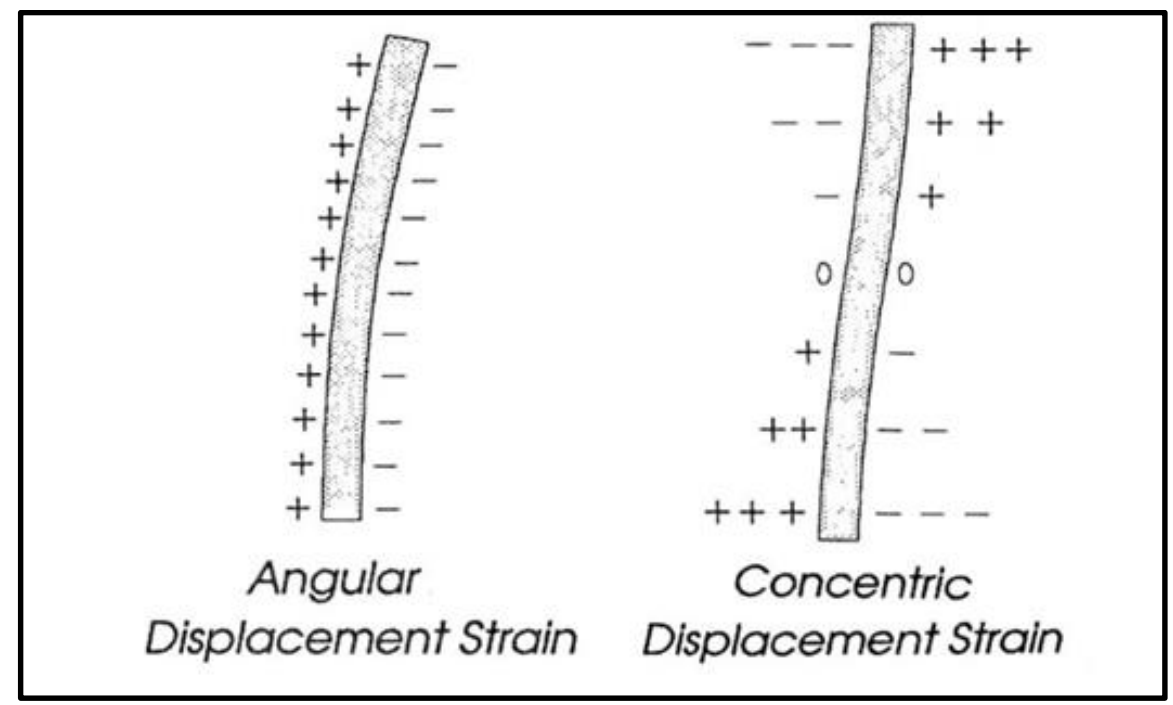

Figure 3.14: Types of strain displacement on the specimen [15].

All misalignment will be quantified by a combined displacement strain. Assuming only elastic deformations on the specimen (which is easily achieved using a ductile metal specimen only constrained by the clipping forces of the grips), the superposition principle is valid and the strain can be decomposed into a sum of an angular and a concentric one.

To align the assembly with this fixation model, four reading are necessary, one coinciding with the position of each pair of screws from this equipment. The information of those readings shows how much each ring has to me moved.

Instron Alignment Fixture manual [15] recommends the strain gauge method to quantify the misalignment, which is adapted in order to also detect angular misalignment. For that, it is necessary to use 8 strain gauges to read the strains on the top and bottom of the 4 positions (Fig 3.15). With this data, it is possible to decompose those displacements into the concentric and angular counterparts and adjust the screws accordingly, while observing the strain variation readings on the Daq.

A more time-consuming reading can be done using the dial indicator. With the magnetic base stuck on the upper grip, one puts the pointer on one of the four upper positions of the specimen (same position of the upper strain gauges on the strain gauge method) and move the actuator down until the pointer reaches the lower position (same position of the lower strain gauges). The dial variation of the four readings shows how the specimen deformed, and the screws can be adjusted accordingly. 


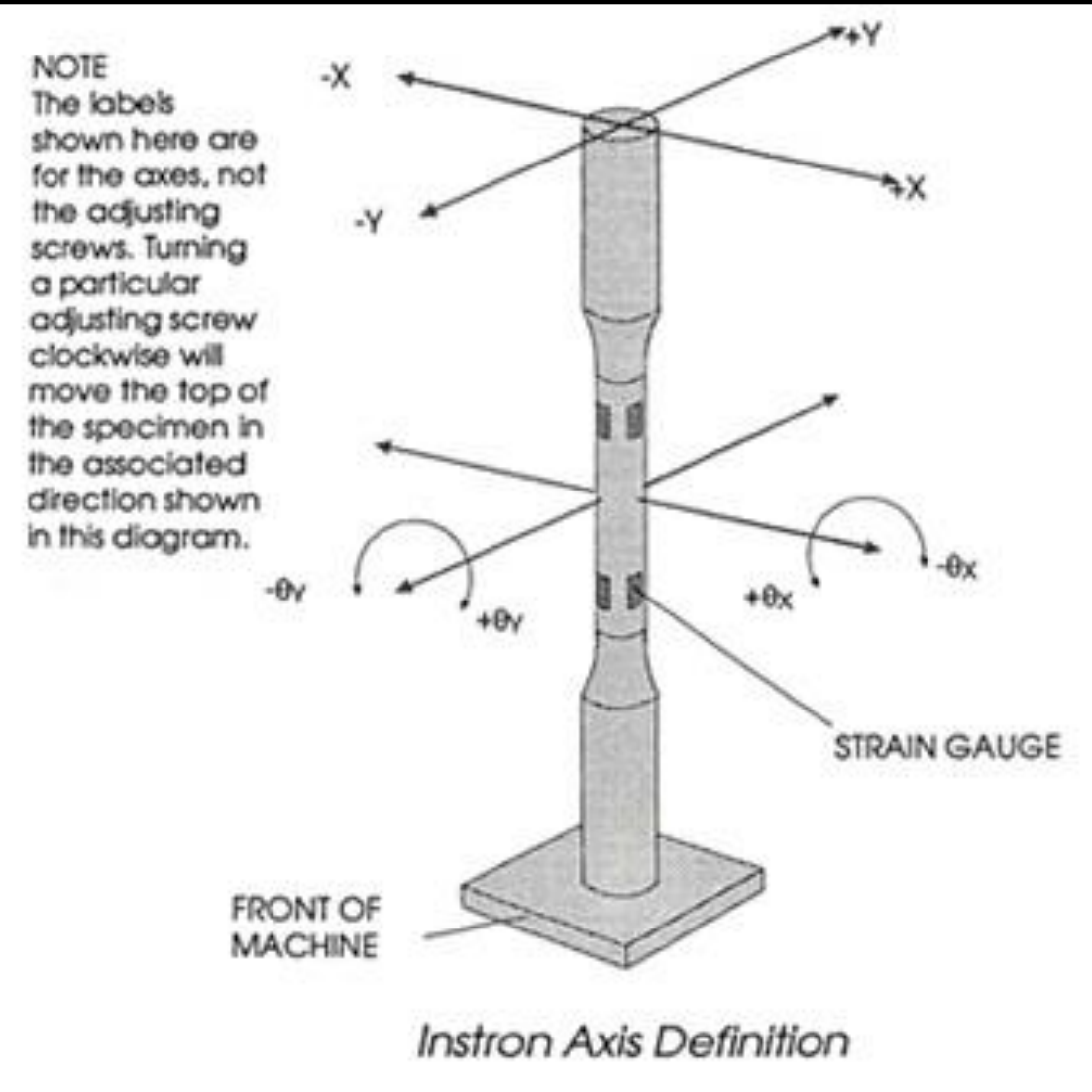

Figure 3.15: Schematic of the strain gauge configuration for this reading [15]. 
4

\section{Experimental Methodology}

\section{1}

Specimen Design

All specimens were designed following the procedures listed on the E606 Standard [9]. A schematic of the specimen is shown in Fig. 4.1 and the measurements used for each material are shown in Table 4.1.

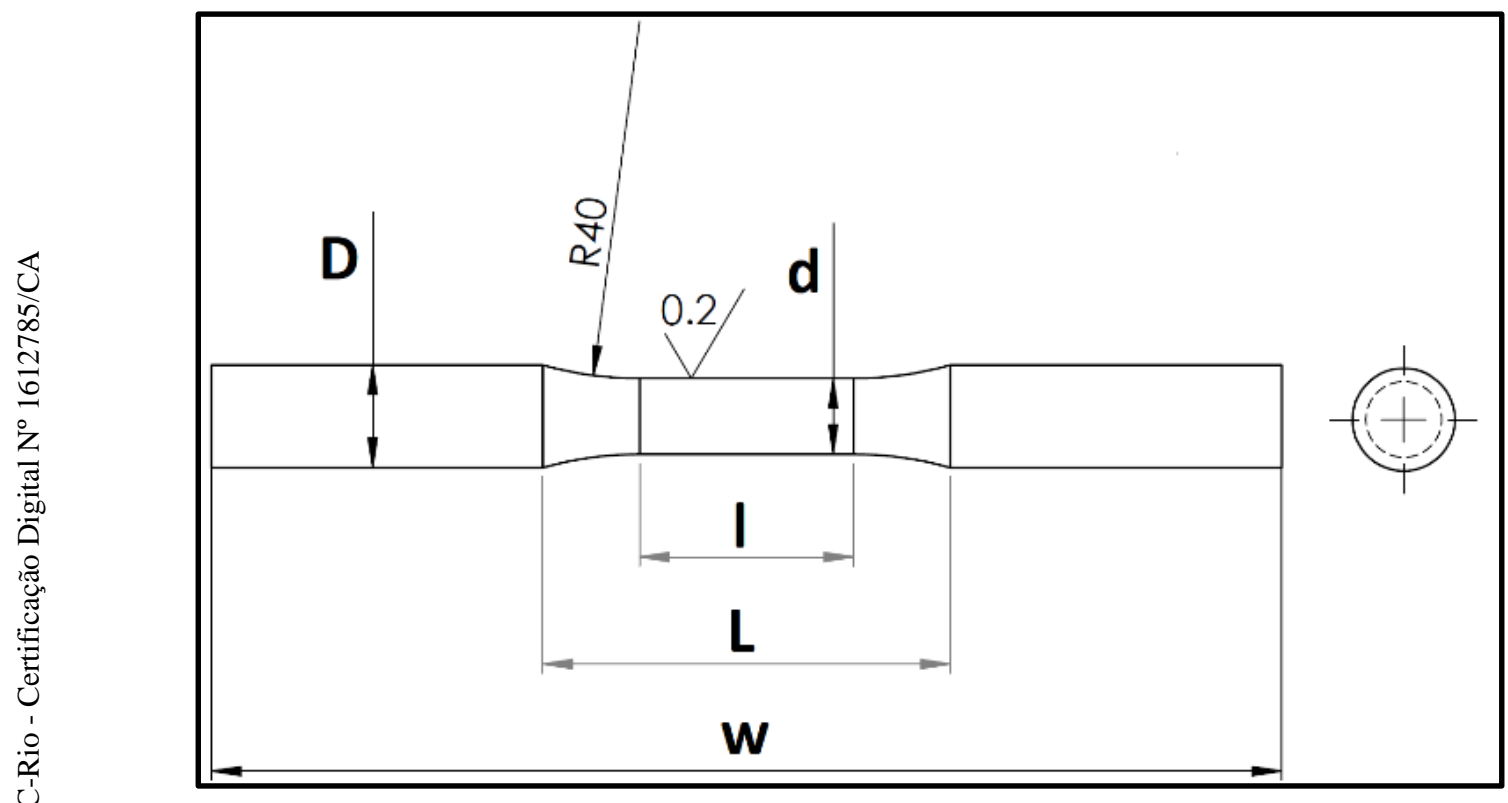

Figure 4.1: Schematic of the specimen.

Table 4.1: Specimen measurements (in $\mathrm{mm}$ )

\begin{tabular}{|c|c|c|}
\hline Dimensions & SAE 1020 Steel & 6351-T6 Aluminum \\
\hline D & 11.8 & 11.8 \\
\hline d & 8.5 & 10 \\
\hline I & 24 & 18 \\
\hline L & 45.7 & 34.9 \\
\hline w & 120 & 120.8 \\
\hline
\end{tabular}




\section{2 Mechanical Properties}

For the SAE 1020 steel alloy, all procedures were conducted following the recommendations in the ASTM E8 Standard Methods for Tension Testing of Metallic Materials [17] and in the ASTM E111 Standard Test Method for Young's Modulus, Tangent Modulus, and Chord Modulus [18]. A total of 2 rupture tests were executes and their data was used to determine the yield strength $\left(\mathrm{S}_{\mathrm{Y}}\right)$, ultimate strength $\left(\mathrm{S}_{\mathrm{U}}\right)$, reduction of the cross-section area of the specimen (AR) and Young's Modulus (E). Each property was calculated as the arithmetic mean from each experiment results.

Yield strength was graphically measured using the Offset Method, in which a line parallel to the elastic curve of the material in drawn within a specified offset, as shown in Fig. 4.2. The point of cross between the line and the stress-strain curve is defined as the Yield point, with its stress value equal to $S_{Y}$ [17].

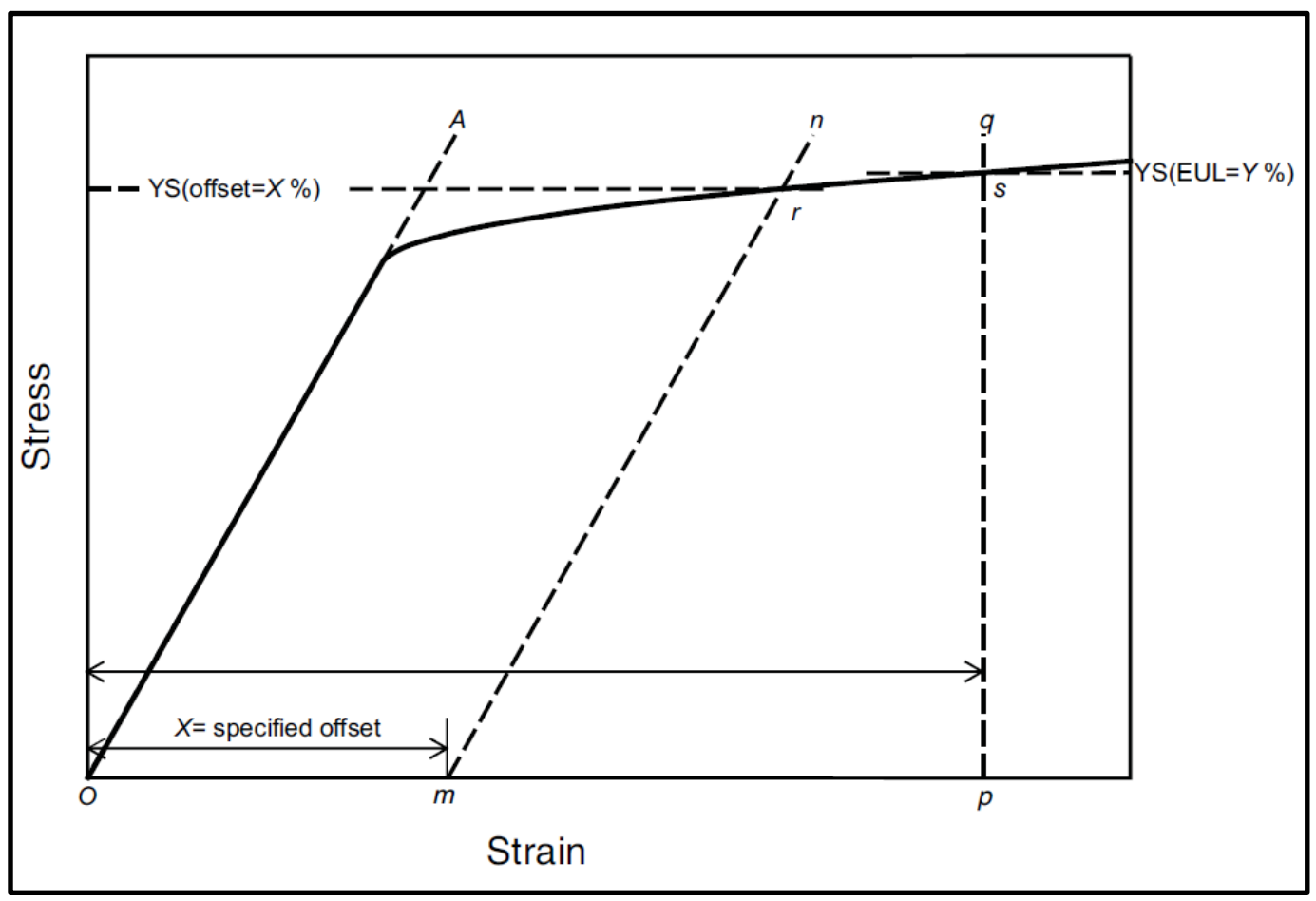

Figure 4.2: Stress-strain diagram with the lines needed for the determining $\mathrm{S}_{\mathrm{Y}}$ via Offset Method (Modified from [17]).

The Young's Modulus was also graphically measured calculating the slope of the stress-strain graphic at its elastic part. Both ends of the fractured specimens were fitted together and their diameter was measured for the area reduction calculation. The ultimate strength $\left(\mathrm{S}_{\mathrm{U}}\right)$ is calculated by dividing the maximum force $(\mathrm{F})$ carried 
by the specimen during the rupture test by its original cross-sectional area $\left(\mathrm{A}_{0}\right)$, as stated in Eq. (4-1).

$$
\mathrm{S}_{\mathrm{U}}=\frac{1}{A_{0}} \max (F)
$$

Incongruences were found between data from Lima et al. tension testing [16] and the observed 6351-T6 Aluminum elastoplastic behavior, leading to the conclusion that only the stated value for reduction of the cross-section area was suitable for use.

Tension testing for aluminum were not conducted in this work, and for that reason $\mathrm{S}_{\mathrm{U}}$ was not calculated. On the other hand, $\mathrm{S}_{\mathrm{Y}}$ and $\mathrm{E}$ were determined using the stress and strain data from 2 strain-controlled low-cycle fatigue experiments conducted by Lima et al. The first hysteresis loop on the stress-strain graphic starts as a monotonic curve, the same seen during a tension testing, and for that reason both the Offset Method and the slope calculation are applicable.

Poisson's ratio $(v)$ was estimated as $v=0.29$ for steel and $v=0.32$ for aluminum. The shear modulus, yield strain $\left(\varepsilon_{\mathrm{Y}}\right)$ and ultimate strain $\left(\varepsilon_{\mathrm{U}}\right)$ were calculated using Eqs. (4-2) to (4-4).

$$
\begin{gathered}
G=\frac{E}{2(1+v)} \\
\varepsilon_{U}=\ln \left(\frac{1}{1-A R}\right) \\
\varepsilon_{Y}=\frac{S_{Y}}{E}
\end{gathered}
$$

\section{3 \\ Measuring $\varepsilon N$ Properties}

All tension-compression experimental data was obtained in accordance to the E606 Standard [9], using the Instron 8501 Servo Hydraulic Fatigue Testing System, shown in Fig. 4.3a. The chosen criteria for determining failure was the Force Drop in $50 \%$, which stated that when the tensile constraint reaches half of the maximum reached value a crack can be assumed to be present there, reducing the cross-section area of the specimen. An Instron 2630-100 Series Clip-on Extensometer, shown in Fig. 4.3b, was chosen to measure the strain amplitudes and to control the servo hydraulic machine during the tests. 


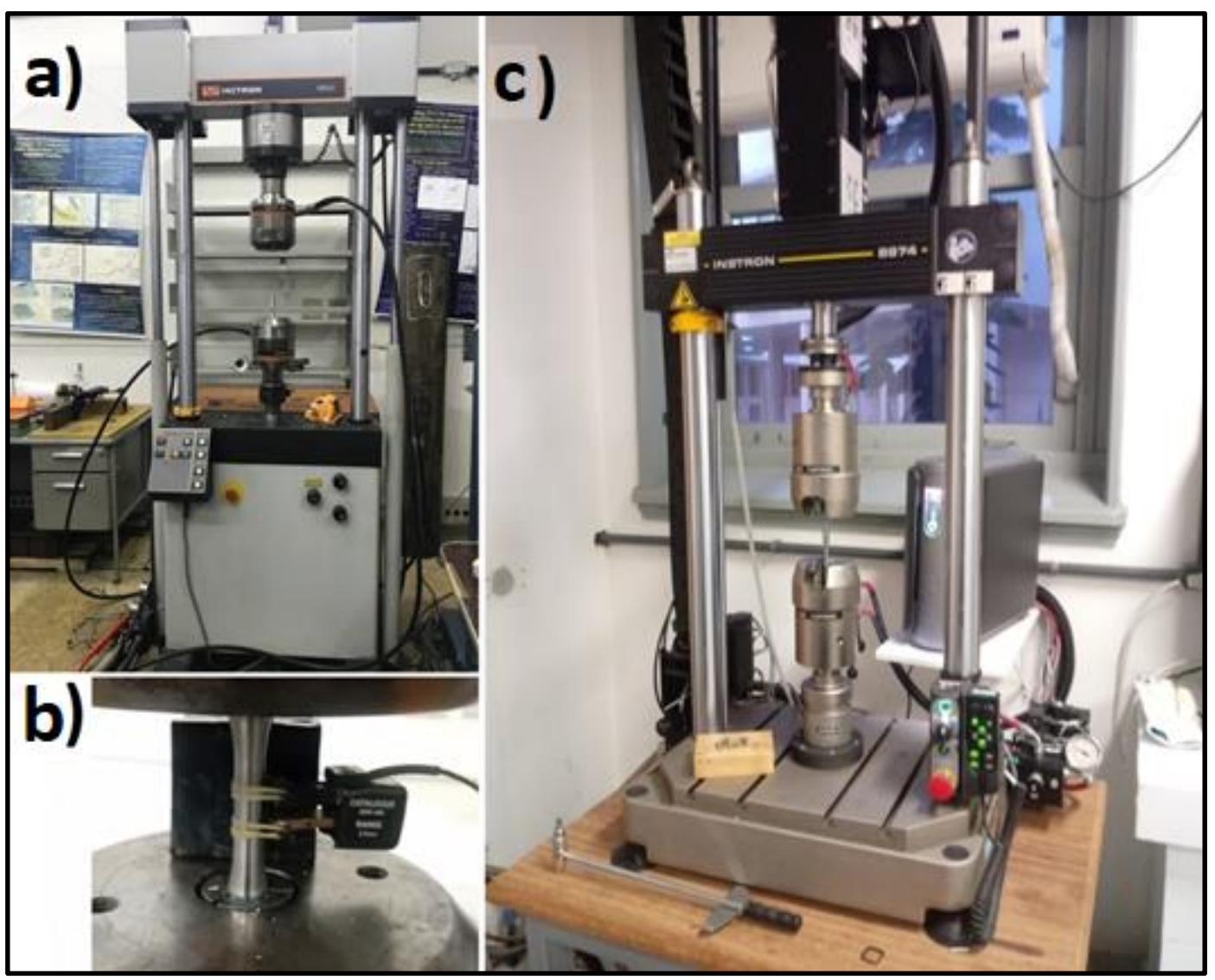

Figure 4.3: a) Instron 8501 Servo Hydraulic Fatigue Testing System; b) Instron 2630-100 Series Clip-on Extensometer; c) Instron 8874 Biaxial Servo Hydraulic Fatigue Testing System.

\section{4 \\ Elastoplastic Behavior}

Data from the strain-controlled experiments was also used to identify the elastoplastic behavior of each material and to plot their cyclic Ramberg-Osgood curves. All curves were plotted using ten stress-strain points.

Each stress value was determined using the stress-sample plot, which is analogous to the stress-time graphic since the used data acquisition has a constant frequency. In each graphic, the stress values stabilized around the mark of 100,000 samples. Therefore, the maximum stress value it this region was the selected one.

The experiments were conducted on a constant strain amplitude, so the strain value at the maximum stress is known to be equal to the strain amplitude. Fig. 4.4 shows the stress-sample graphics for both steel and aluminum at the strain amplitude of 0.06 . 


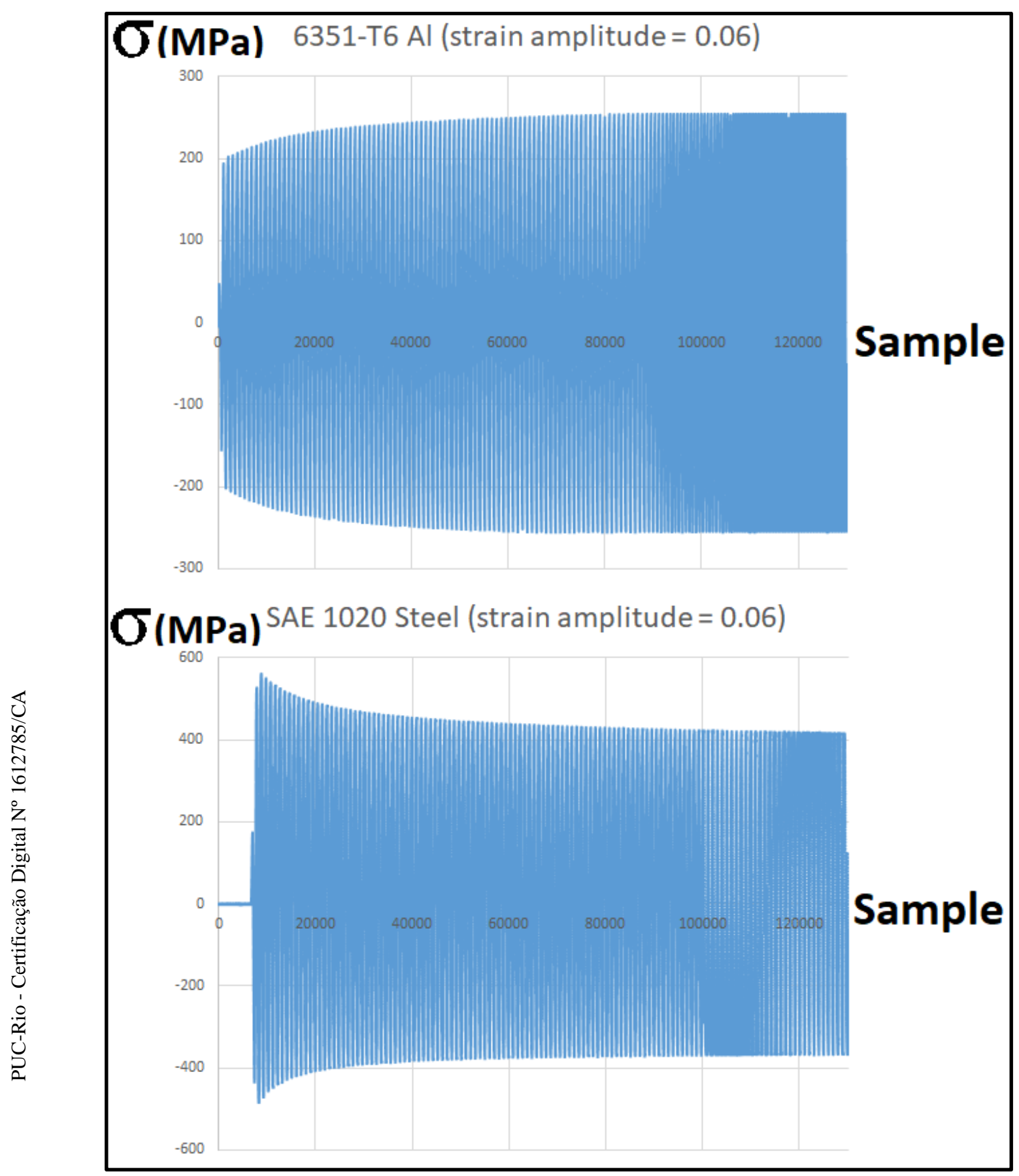

Figure 4.4: Stress-sample graphic with the first 130,000 data acquired from two strain controlled cyclic tensile-compression tests. Note that the stress amplitude necessary to maintain the strain amplitude constant decreases on steel, while on aluminum it increases.

\section{5}

\section{Measuring YN Properties}

All torsional experimental data was obtained using the Instron 8874 Biaxial Servo Hydraulic Fatigue Testing System, shown in Fig. 4.3c. As stated in the E2207 Standard for Strain-Controlled Axial-Torsional Fatigue Testing with Thin-Walled Tubular Specimens, the shear stress profile tends to be non-linear for a specimen 
under elastoplastic deformations [5]. Tubular specimens are recommended because, depending on their wall thickness, the shear stress gradient can be ignored and the hypothesis of a uniformly distributed shear stress is valid.

Also, strain control demands the use of torsional or biaxial extensometers, an expensive piece of equipment that was not available for the present work. To overcome this problem, a simplified semi-empirical method is proposed here to calculate the shear strain using the angular displacement readings provided by the LVDT of the testing machine.

The proposed methodology is based on the hypothesis that, for uniform geometries (without the presence of notches), the strain profile is still linear even for plastic deformations. This hypothesis is reasonable as long as the cross sections can still be assumed to remain planar. Using the linear strain profile, it is possible to neglect in the analysis the complicated shear stress profile, as shown in Fig. 4.5. Then, using Eq. (4-5) [19], it is possible to relate the measured angular displacement with the shear strain in both elastic and plastic regimes.

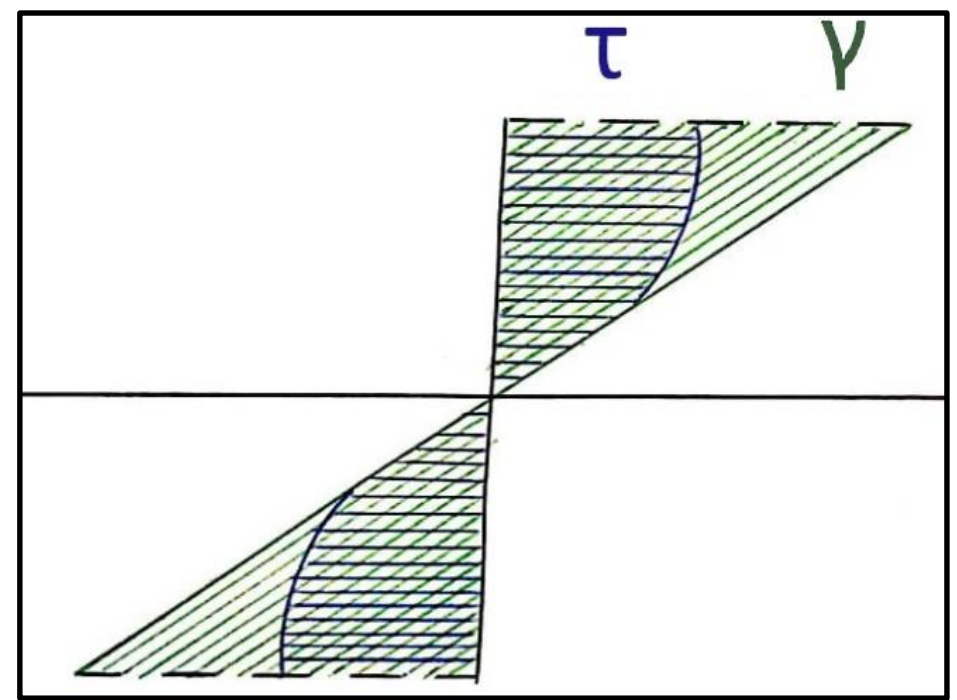

Figure 4.5: Elastoplastic shear stress and strain profiles on a specimen's cross-section area under pure torsion.

$$
\gamma_{a}=\frac{d}{2 L}\left(\varphi_{a} \frac{\pi}{180}\right)
$$

Eq. (4-5) was adapted to receive as input the angle amplitude $\left(\varphi_{\mathrm{a}}\right)$ in degrees, which was the controlling parameter on each torsional experiment, and to calculate the amplitude of the deformation $\left(\gamma_{\mathrm{a}}\right)$ to be used in the $\gamma \mathrm{N}$ equation. With the exclusion of the shear stress from the equations, a tubular specimen was not a 
requirement anymore, and the same specimen design used on the tensilecompression experiments could be used for the torsional experiments. Note however that the shear strain gradient from the solid (instead of hollow) shaft can have a significant effect on the fatigue life, even though it is not modeled in the present work.

As recommended in the E606 standard, the specimen has two soft notches. This diameter variation was not considered in Eq. (4-5), simplifying the model geometry to a uniform solid shaft with the same diameter as the smaller one from the specimen. The criteria of failure and minimum number of experiments were the same used in the tensile-compression experiments, giving the desired $\gamma \mathrm{N}$ curve.

\section{6}

\section{Curve Fitting}

For both tensile-compression and torsional life prediction curves, the experimental data was fitted by Coffin-Manson's $\varepsilon \mathrm{N}$ curve and its shear version $\gamma \mathrm{N}$ using a MATLAB programming code. Its computing environment offers the nonlinear least-squares solver lsqnonlin(), which was used to fit all experimental data. In the $\varepsilon \mathrm{N}$ curve-fitting, the inputted data was the Young's Modulus (E), vector of applied strain amplitudes $\left(\varepsilon_{\mathrm{a}}\right)$ and corresponding vector of resulting number of cycles to failure $(\mathrm{N})$. The working variables were: $\sigma_{\mathrm{c}}, \varepsilon_{\mathrm{c}}, \mathrm{b}$ and c. Similarly, in the $\gamma \mathrm{N}$ curve-fitting, the inputted data was the Shear Modulus, the vectors $\gamma_{\mathrm{a}}$ and $\mathrm{N}$, with the working variables as $\tau_{c}, \gamma_{c}, b_{\gamma}$ and $c_{\gamma}$.

To fit a curve that is physically admissible, a proper choice of boundary values for the working variables is necessary. In the present work, they were chosen to encompass the possible values from a variety of experimental data and estimative propositions listed on Castro et al [1]. The mentioned data indicates that most metallic structural alloys have their elastic and plastic exponents respectively in the range of $-0.2<b<-0.05$ and $-0.9<c<-0.3$. For that reason, the shown intervals were chosen as the exponent boundaries. Lagoda et al. [10] states that it is of common practice among authors to assume parallelism between $\varepsilon N$ and $\gamma \mathrm{N}$ equations, considering $\mathrm{b}=\mathrm{b}_{\gamma}$ and $\mathrm{c}=\mathrm{c}_{\gamma}$.

Through the proposed estimates and experimental data presented in Castro et al, a reasonable boundary for the elastic and plastic coefficients is $S_{u}<\sigma_{c}<2 S_{u}$ and 
$\varepsilon_{\mathrm{y}}<\varepsilon_{\mathrm{c}}<\varepsilon_{\mathrm{U}}$, where $\mathrm{Su}$ is the ultimate strength and $\varepsilon_{\mathrm{y}}$ and $\varepsilon_{\mathrm{U}}$ are the deformation in the yield and ultimate strengths, respectively. For the shear coefficients, the upper boundaries were repeated and the lower boundaries were divided by 2 .

The same procedure was used for the cyclic Ramberg-Osgood curve fitting, with $H_{c}$ and $h_{c}$ as the working variables and $E / 1000<H_{c}<E / 100$ and $0<h_{c}<0.5$ as their ranges. And the solver was also used for the calibration of the Fatemi-Socie equation, using $\alpha_{F S}$ as the only variable and restricting it to only positive values (more details on section 4.8).

\section{7}

\section{Comparison Procedures}

As stated in subsection 2.3.3, von Mises and Tresca criteria were adapted in order to calculate the equivalent uniaxial strain from the torsional experiments. For a better visualization, Fig. 4.6 shows the stress and strain Mohr circles in pure torsion.

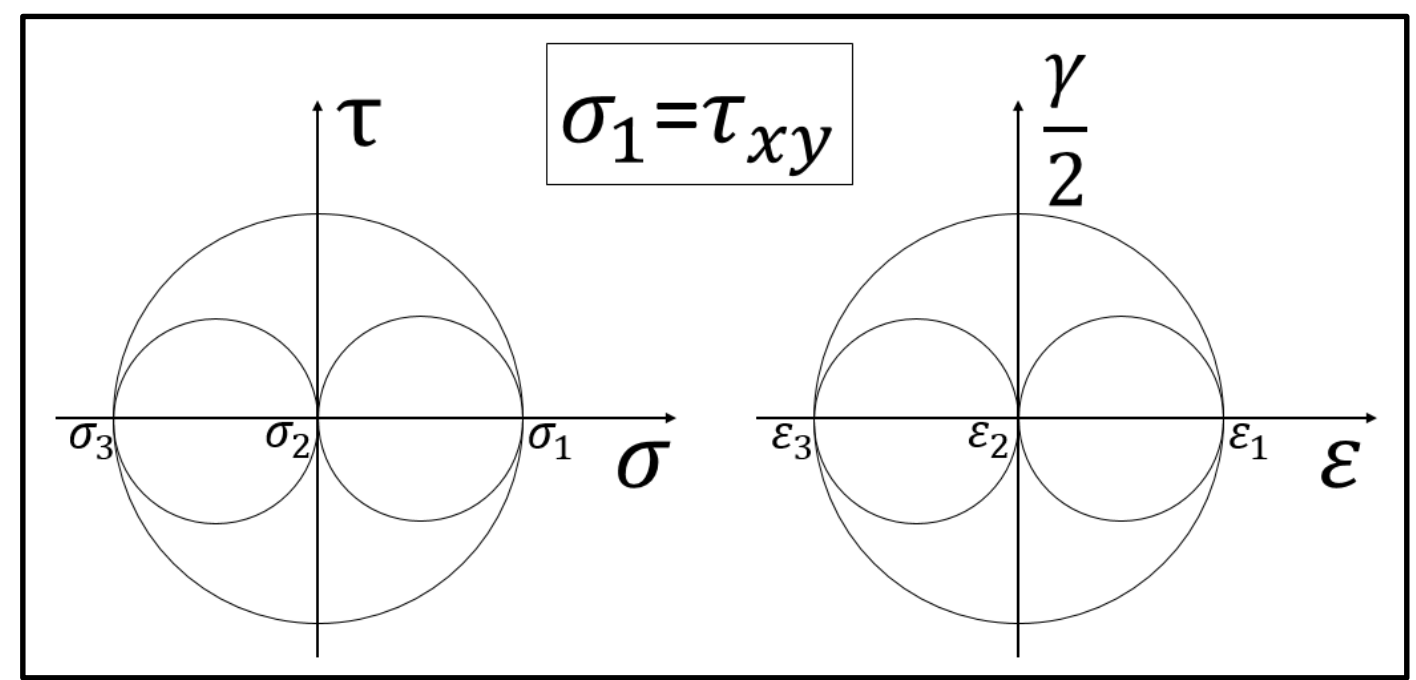

Figure 4.6: Stress and strain Mohr circles for pure torsion.

Since all experiments were conducted on the plastic regimen, it was necessary to use the effective Poisson ratio $(\bar{v})$ on the formulation, a value in-between the elastic and plastic Poisson ratios $(v \leq \bar{v} \leq 0.5)$.

In pure torsion with $\gamma_{x y}=\gamma_{x z}=0$ and $\gamma_{y z}=\gamma$, Eqs. (2-17) and (2-22) are reduced to Eqs. (4-6) and (4-7), respectively. 


$$
\begin{gathered}
\varepsilon_{\text {Mises }}=\frac{\sqrt{3}}{2(1+\bar{v})} \gamma \\
\varepsilon_{\text {Tresca }}=\frac{1}{1+\bar{v}} \gamma
\end{gathered}
$$

These are the formulas applied for all point on the $\gamma \mathrm{N}$ curve to generate the two equivalent $\varepsilon N$ curves. Since the experiments in the present work where conducted with high strain values, $(\bar{v})$ is assumed to be equal to the plastic Poisson ratio, reducing Eqs. (4-6) and (4-7) to Eqs. (4-8) and (4-9), respectively.

$$
\begin{aligned}
& (\varepsilon N)_{\text {Mises }}=\frac{1}{\sqrt{3}}(\gamma N) \\
& (\varepsilon N)_{\text {Tresca }}=\frac{2}{3}(\gamma N)
\end{aligned}
$$

\section{8 \\ Fatemi-Socie Damage Model Calibration}

The particular cases where Fatemi-Socie and SWT equations reduce to shear and tensile Coffin-Manson, respectively (this is discussed in subsection 2.3.5), are useful for the calibration of those models.

Findley and Generalized Goodman calibrations require high-cycle fatigue experiments, which is beyond the scope of this present work. SWT equation's calibration requires shear stress data from pure-torsion experiments, which was not acquired for the reasons discussed in section 4.5. Calibration of these damage models was, therefore, not conducted.

Fatemi-Socie's calibration, on the other hand, requires the stress data only from the tension-compression experiments. Since in pure torsion the equation is reduced to the shear Coffin-Manson curve, this data is used to calculate the $\gamma \mathrm{N}$ constants and exponents. For tension-compression with $\sigma_{\mathrm{m}}=0$, the maximum values of the strain amplitude $(\Delta \gamma / 2)$ and the peak normal stress perpendicular to the critical plane $\left(\sigma_{\perp \max }\right)$ are found on the plane with $\varphi=45^{\circ}$, and their values can be calculated using the Mohr Circle (Fig. 4.7). 


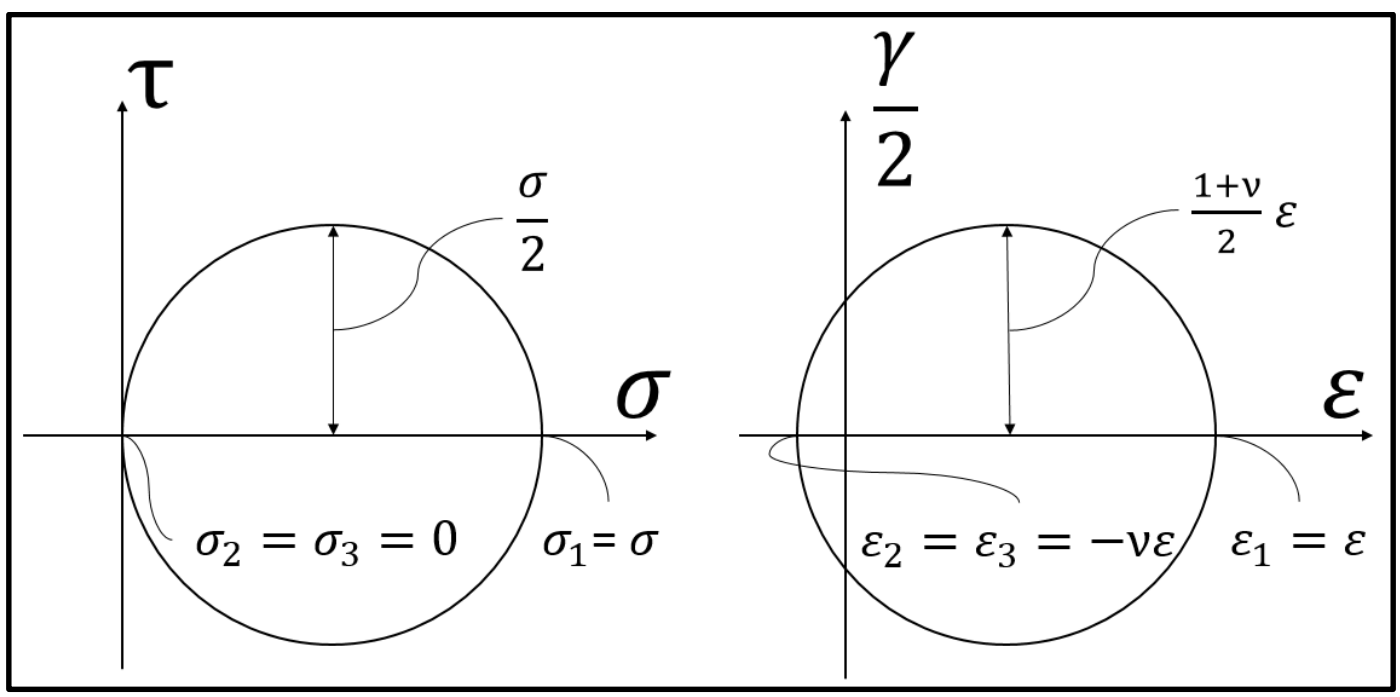

Figure 4.7: Stress and strain Mohr Circles for a pure axial tension stress state.

With the given values from the tension-compression stress-strain state, Fatemi-Socie equation is reduced to Eq. (4-10).

$$
\frac{\Delta \varepsilon}{2}(1+\bar{v})\left(1+\alpha_{F S} \frac{\sigma_{\max }}{2 S_{Y c}}\right)=\left(\frac{\tau_{c}}{G}\right)(2 N)^{b_{\gamma}}+\gamma_{c}(2 N)^{c_{\gamma}}
$$

For each material, all ten stress-strain points used on the cyclic RambergOsgood curve fitting, along with the measured life of their respective experiments, was inputted for the $\sigma_{\max }, \Delta \varepsilon$ and $\mathrm{N}$ values. Along with the $\gamma \mathrm{N}$ constants and exponents calculated for the shear Coffin-Manson curve, $\alpha_{\mathrm{FS}}$ was calculated using the nonlinear least-squares solver lsqnonlin(). 


\section{5 \\ Results and Discussion}

\section{1 \\ Components Performance}

During the alignment procedure, it was discovered that the upper part of the machine was misaligned in respect with the lower part beyond the maximum reach offered by the external aligner. Further investigation suggested that the central column, where the upper grip and the load cell are installed, was inclined and causing severe angular and concentric misalignment. For that reason, all torsional experiments were conducted on the Mechanical Testing Laboratory of the Military Institute of Engineering (IME), which already had an Instron 8874 with the recommended gripping system installed. Nevertheless, all performance evaluation of the designed pieces was conducted on a misaligned system.

With the replacement of the helical pre-load washers for the inclined ones, torsional testing could be performed using torques up to $35 \mathrm{Nm}$ and frequencies up to $1.5 \mathrm{~Hz}$. As expected, the double threaded bolt has not presented any defected or performance problems during all experimental works conducted on the machine after its installation.

\section{2 \\ Experimental Results}

The tensile-test mechanical properties for each material are listed in Tab. 5.1. Their cyclic Ramberg-Osgood plots and equations are shown in Figs. 5.1 and 5.2 and Eqs. (5-1) and (5-2). For the $\varepsilon N$ curve fitting, data from Lima et al.'s work [16] was used in conjunction with new data acquired in the present work. Both $\varepsilon \mathrm{N}$ curves are shown in Fig. 5.3 and Eqs. (5-3) and (5-4). For the $\gamma \mathrm{N}$ curve fitting, ten $\left(\varphi_{\mathrm{a}}, \mathrm{N}\right)$ points were measured for each material and converted to $\left(\gamma_{\mathrm{a}}, \mathrm{N}\right)$ points, as shown in Fig. 5.4, resulting in Eqs. (5-5) and (5-6). All angular displacements and their corresponding number of cycles are listed in Tab. 5.2. Figs. 5.5 and 5.6 shows, for 6351-T6 Al and SAE 1020 respectively, the comparison between the fitted $\varepsilon N$ curve 
and the equivalent $\varepsilon \mathrm{N}$ curves obtained from the shear data using von Mises and Tresca criteria.

Table 5.1: Mechanical properties for SAE 1020 and 6351-T6 Al

\begin{tabular}{|c|c|c|}
\hline Property & SAE 1020 Steel & 6351-T6 Aluminum \\
\hline $\mathrm{S}_{\mathrm{u}}$ & $599 \mathrm{MPa}$ & - \\
\hline $\mathrm{S}_{\mathrm{y}}$ & $558 \mathrm{MPa}$ & $223 \mathrm{MPa}$ \\
\hline $\mathrm{S}_{\mathrm{yc}}$ & $418 \mathrm{MPa}$ & $277 \mathrm{MPa}$ \\
\hline$v$ & 0.29 & 0.32 \\
\hline $\mathrm{E}$ & $194.4 \mathrm{GPa}$ & $69.4 \mathrm{GPa}$ \\
\hline $\mathrm{G}$ & $75.35 \mathrm{GPa}$ & $26.29 \mathrm{GPa}$ \\
\hline $\mathrm{AR}$ & $40 \%$ & $57 \%[16]$ \\
\hline$\varepsilon_{\mathrm{y}}$ & 0.00287 & 0.00321 \\
\hline$\varepsilon_{\mathrm{u}}$ & 0.616 & 0.844 \\
\hline
\end{tabular}

Table 5.2: Angular displacements and their corresponding number of cycles up to failure for SAE 1020 and 6351-T6 Al

\begin{tabular}{|c|c|c|c|}
\hline \multicolumn{2}{|c|}{ SAE 1020 Steel } & \multicolumn{2}{c|}{ 6351-T6 Aluminum } \\
\hline $\begin{array}{c}\text { Angular } \\
\text { displacement }\left(\phi_{\mathrm{a}}\right)\end{array}$ & $\begin{array}{c}\text { Number of cycles } \\
\text { up to failure }(\mathrm{N})\end{array}$ & $\begin{array}{c}\text { Angular } \\
\text { displacement }\left(\phi_{\mathrm{a}}\right)\end{array}$ & $\begin{array}{c}\text { Number of cycles } \\
\text { up to failure (N) }\end{array}$ \\
\hline 8 & 1038 & 7 & 763 \\
\hline 7 & 2230 & 6 & 874 \\
\hline 6 & 2889 & 5 & 1780 \\
\hline 5 & 5190 & 5 & 2030 \\
\hline 4 & 10260 & 4.5 & 2525 \\
\hline 3.8 & 11837 & 4.2 & 6851 \\
\hline 3.8 & 10839 & 4 & 6440 \\
\hline 3.5 & 17507 & 4 & 8819 \\
\hline 3.5 & 18747 & 3.7 & 18337 \\
\hline 3 & 28664 & 3.5 & \\
\hline
\end{tabular}




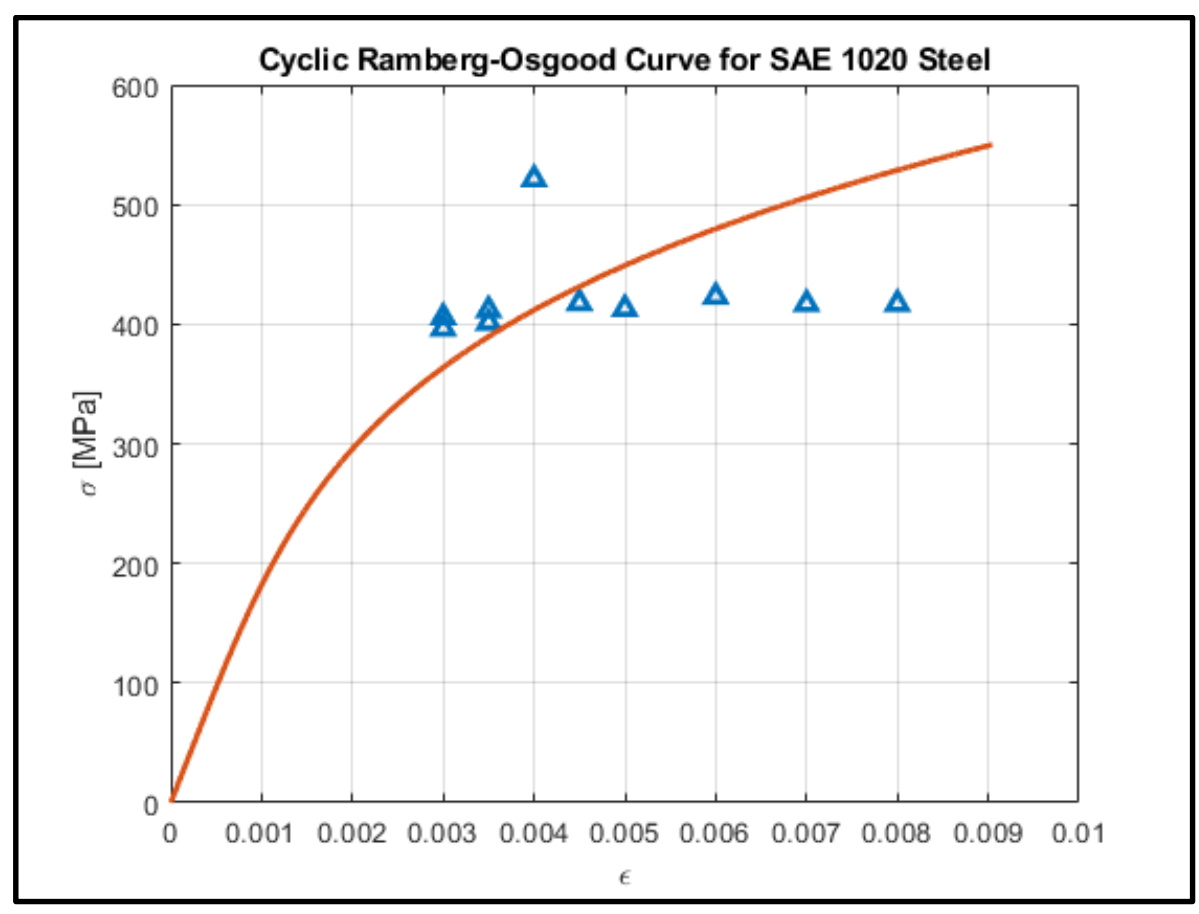

Figure 5.1: SAE 1020 cyclic Ramberg-Osgood curve.

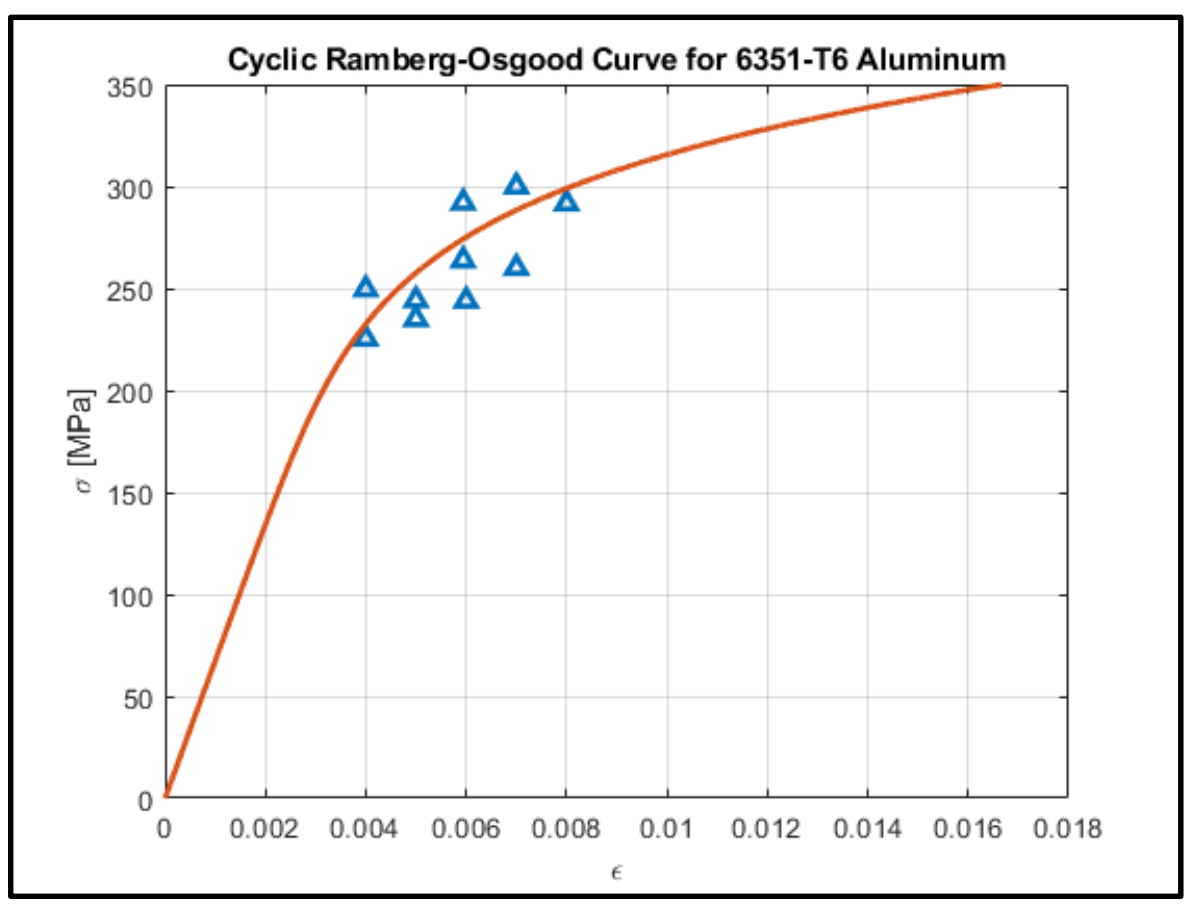

Figure 5.2: 6351-T6 Al cyclic Ramberg-Osgood curve.

$$
\begin{gathered}
\text { SAE } 1020 \text { Steel: } \varepsilon=\left(\frac{\sigma}{E}\right)+\left(\frac{\sigma}{1882.7}\right)^{\frac{1}{0.242}} \\
6351-\text { T6 Aluminum: } \varepsilon=\left(\frac{\sigma}{E}\right)+\left(\frac{\sigma}{638.6}\right)^{\frac{1}{0.135}}
\end{gathered}
$$




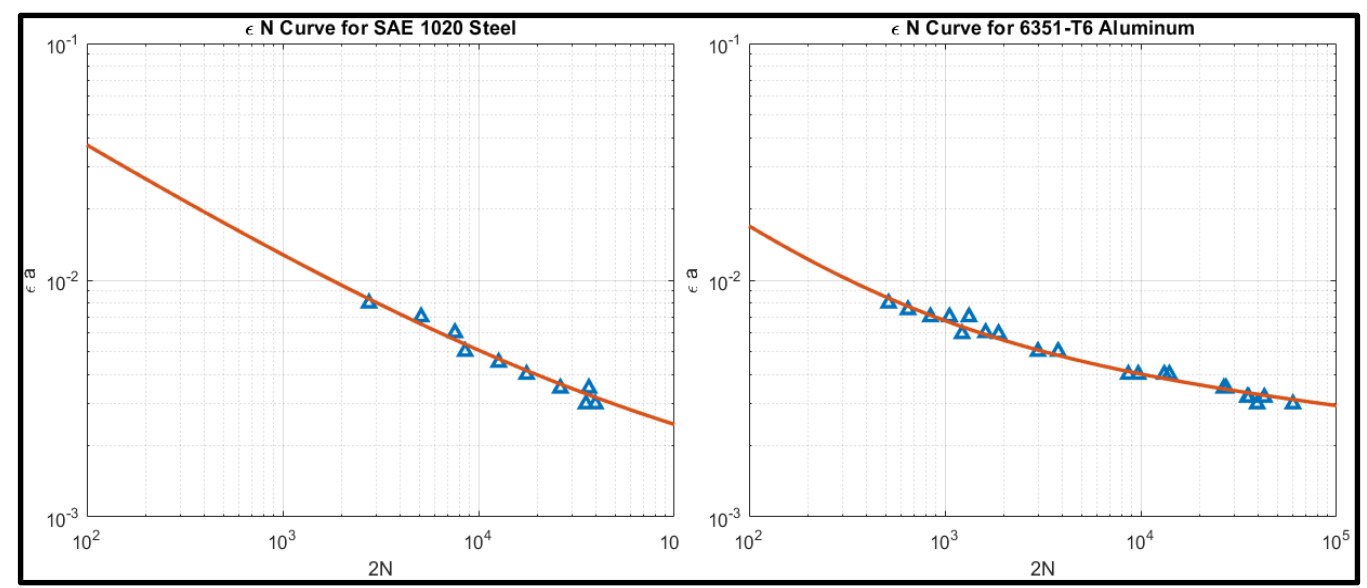

Figure 5.3: SAE 1020 and 6351-T6 Al $\varepsilon \mathrm{N}$ curves.

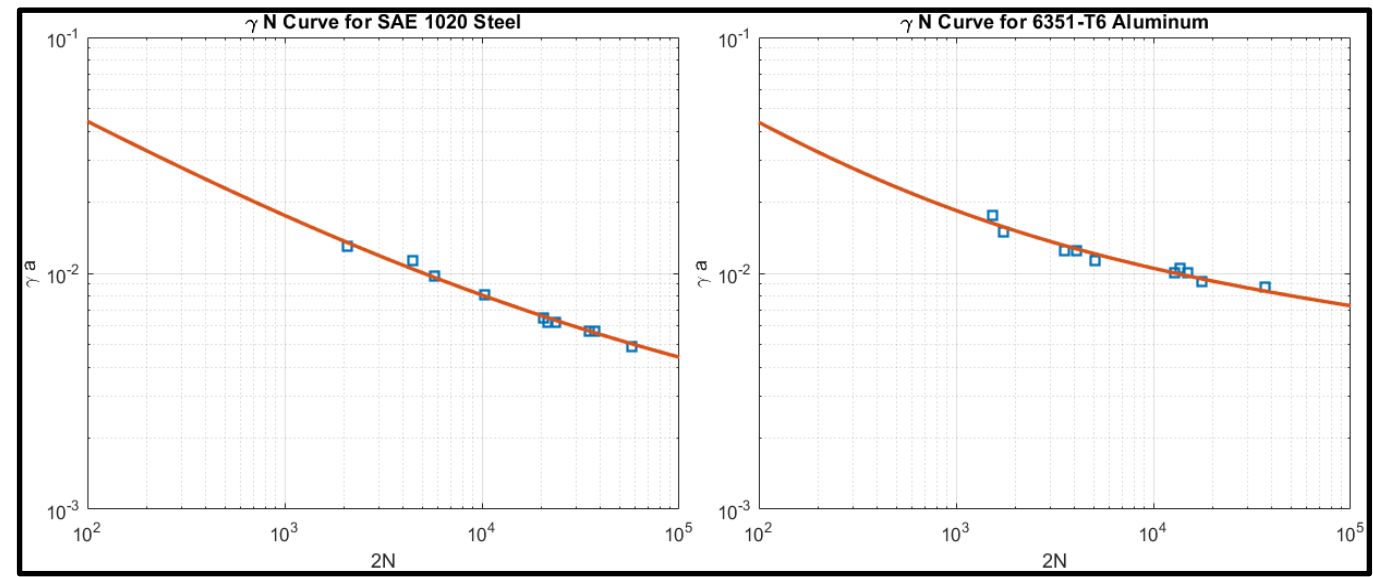

Figure 5.4: SAE 1020 and 6351-T6 Al $\gamma \mathrm{N}$ curves.

SAE 1020 Steel: $\varepsilon_{a}=\left(\frac{893.9}{E}\right)(2 N)^{-0.099}+0.368(2 N)^{-0.515}$

6351 - T6 Aluminum: $\varepsilon_{a}=\left(\frac{555.7}{E}\right)(2 N)^{-0.092}+0.268(2 N)^{-0.682}$

SAE 1020 Steel: $\gamma_{a}=\left(\frac{824.2}{G}\right)(2 N)^{-0.112}+0.336(2 N)^{-0.476}$

$6351-$ T6 Aluminum: $\gamma_{a}=\left(\frac{548.1}{G}\right)(2 N)^{-0.099}+0.458(2 N)^{-0.590}$ 


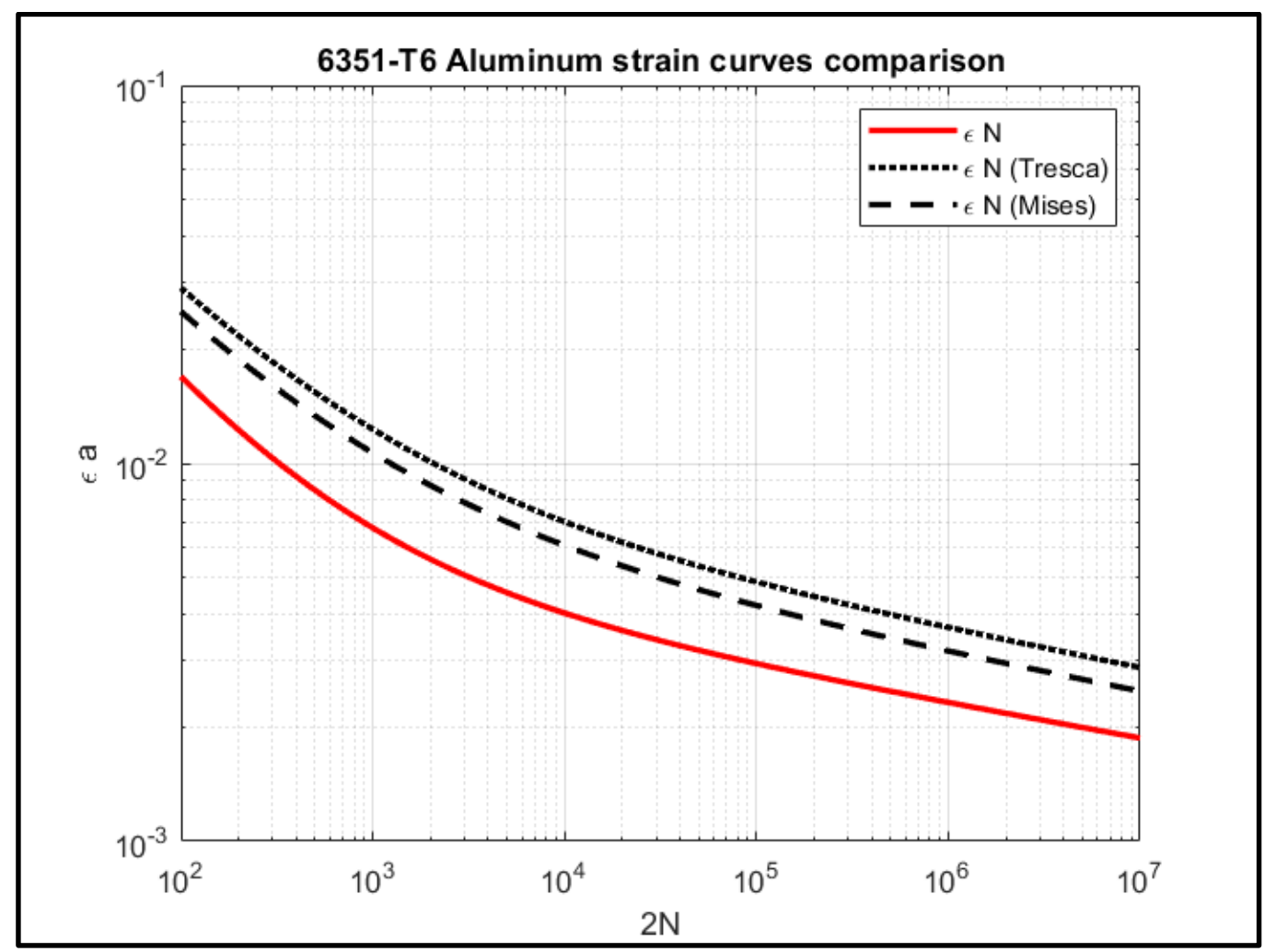

Figure 5.5: Comparison between $\varepsilon \mathrm{N}$ curves with $(\varepsilon \mathrm{N})_{\text {Mises }}$ and $(\varepsilon \mathrm{N})_{\text {Tresca }}$ equivalent curves for 6351-T6 Aluminum.

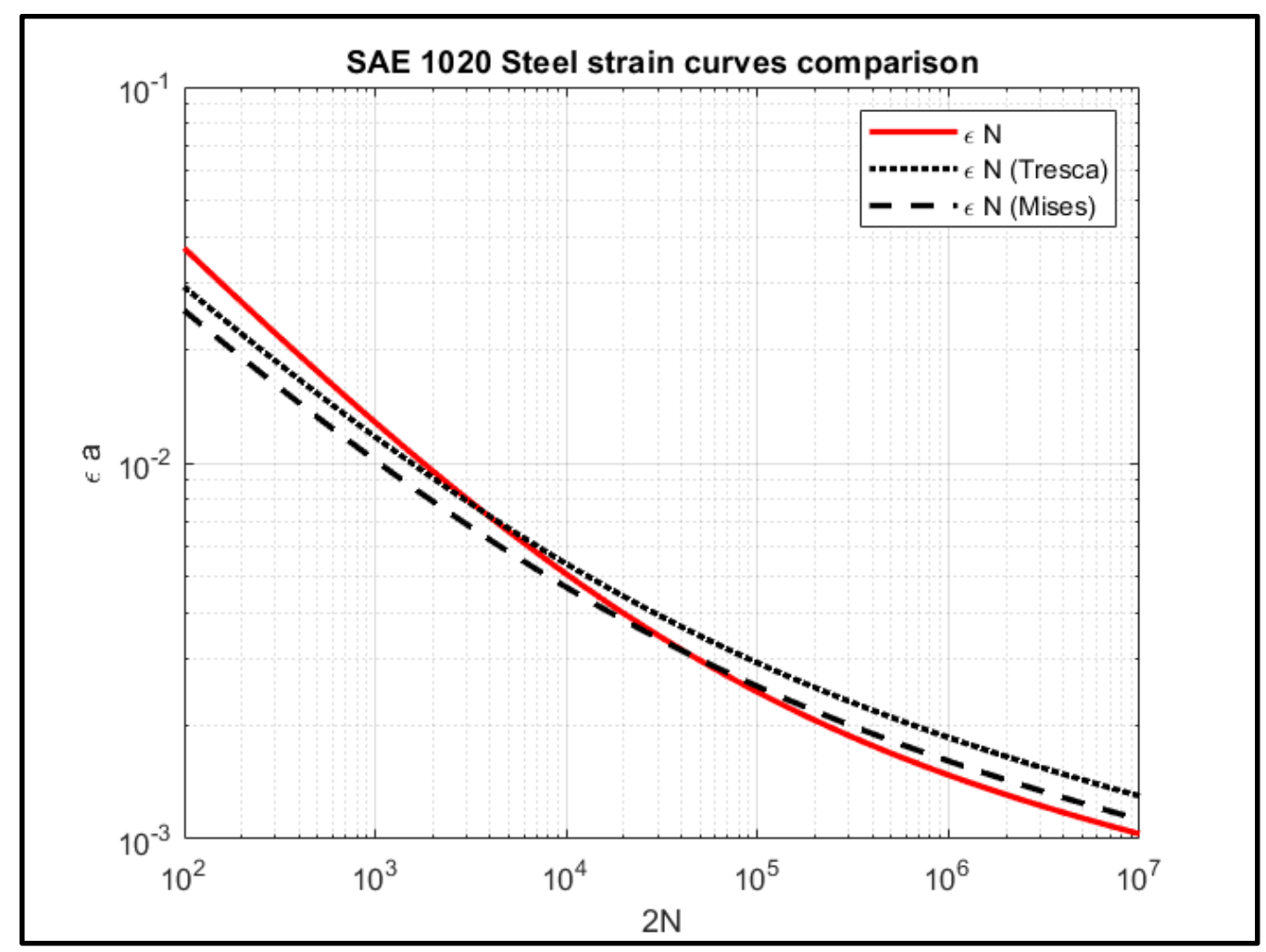

Figure 5.6: Comparison between $\varepsilon N$ curves with $(\varepsilon N)_{\text {Mises }}$ and $(\varepsilon N)_{\text {Tresca }}$ equivalent curves for SAE 1020 Steel. 


\section{3 Discussion}

All stress-sample graphics used for the cyclic Ramberg-Osgood plot have shown that SAE 1020 Steel cyclic softens and 6351-T6 Aluminum cyclic hardens. This can also be seen by comparing their cyclic and monotonic yield strengths. SAE 1020 Steel has $S_{y c}<S_{y}$, showing the softening after some elastoplastic cycles. On the other hand, 6351-T6 Aluminum has $\mathrm{S}_{\mathrm{y}}<\mathrm{S}_{\mathrm{yc}}$.

For 6351-T6 $\mathrm{Al}$ (Fig. 5.5), since the fitted $\varepsilon \mathrm{N}$ curve was lower than the von Mises and Tresca equivalent ones obtained from shear data, it can be concluded that it is more sensitive to tensile deformations instead of shear and, therefore, models such as SWT and Generalized Goodman are recommended for its fatigue damage calculation. In other words, at least under the zero mean loads applied in the tests, it is expected that a tensile microcrack is initiated in this material, instead of a classic Forsyth shear one.

SAE 1020, on the other hand, had mixed results. As seen in Fig. 5.6, under low cycle fatigue its $\varepsilon \mathrm{N}$ curve was higher than the von Mises and Tresca equivalent ones obtained from shear data. Therefore, a shear-sensitive low-cycle model such as Fatemi-Socie is recommended for its low cycle fatigue calculations. Note however that, under high cycle fatigue, this trend tends to reverse, with tensile damage becoming the major damage mechanism, as the tension-compression $\varepsilon \mathrm{N}$ curve drops below the shear-equivalent ones. As a result, for long lives it should be recommended for this steel to use a tensile-based damage model such as the Generalized Goodman, instead of a shear-based such as Findley. In summary, the studied data indicates that this steel is shear-sensitive under low-cycle fatigue and tensile-sensitive for longer lives.

Socie et al. [13] investigated in his work the crack initiation and propagation behavior in multiaxial fatigue for a few materials. For that, different materials were subjected to pure tension and pure torsion experiments, and the crack behavior was monitored up to failure during each test. With the gathered data, he created the socalled Damage Maps in which the crack behavior is separated in nucleation, shear propagation and tensile propagation. Figure 5.7 shows the damage map for SAE 1045 Steel under pure tension. Note that the y-axis is the damage fraction, which is the ratio between the number of cycles at each moment and the number of cycles 
when failure occurred. So, a vertical line drawn on the damage map would tell the entire behavior of the crack up to failure.

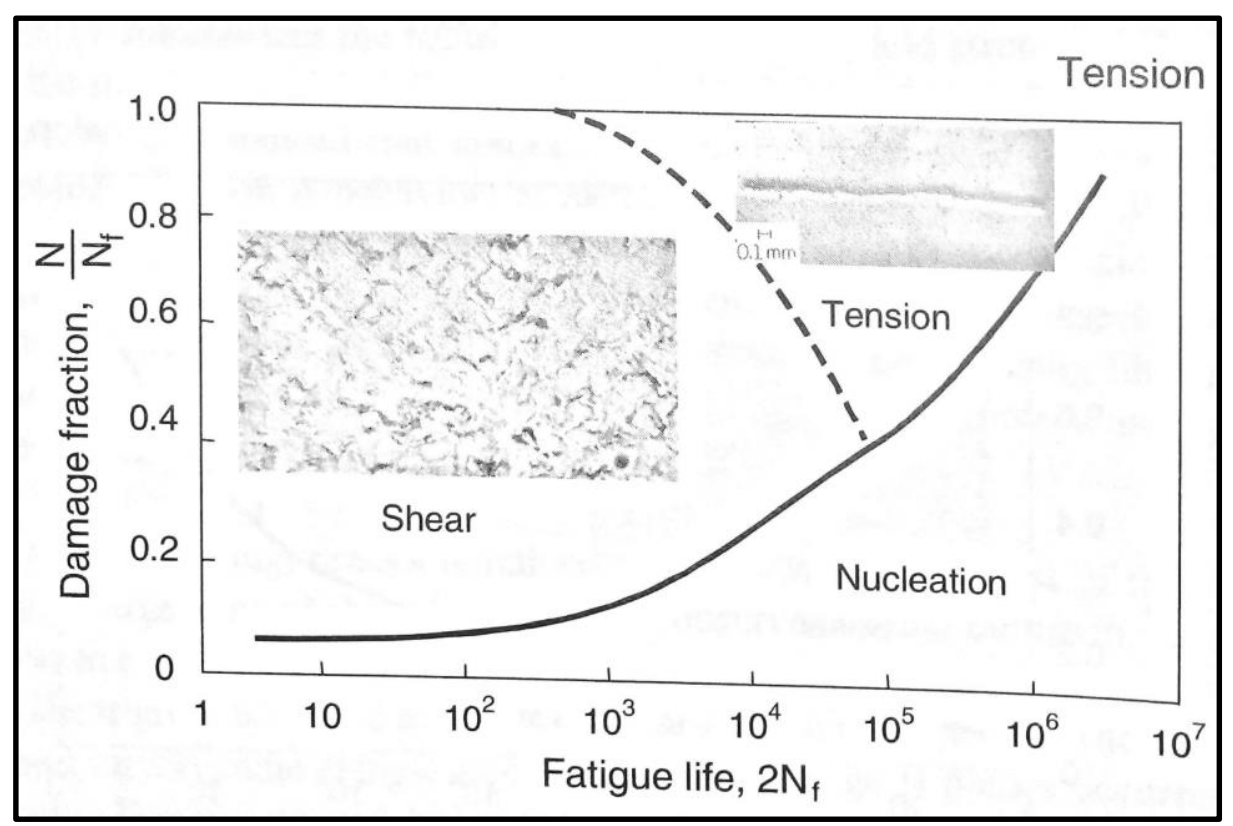

Figure 5.7: Damage Map for 1045 Steel [13].

Note that, like the $\varepsilon \mathrm{N}$ comparison graphics presented in this work, the damage maps can be used to characterize the shear-tensile sensitivity of the material, since the type of crack propagation dictated which type of stress is causing it.

A similar pattern can be observed when the 1020 steel $\varepsilon N$ comparison graphic and the 1045 steel damage map are compared. Both had a mixed behavior, with a pronounced shear sensitivity on low-cycle fatigue and tensile sensitivity when fatigue transitions to a high-cycle regime. The life cycle where their transition begins is also very similar. While 1045 steel has its transition behavior in the range of $10^{3}<2 \mathrm{~N}<10^{5}$, the studied SAE 1020 steel has its transition from sheardominated to tensile-dominated near $2 \mathrm{~N}=5 \cdot 10^{3}$ using Tresca and $2 \mathrm{~N}=5 \cdot 10^{4}$ using the von Mises criterion.

To further explore the above comparison between 1020 and 1045 transition behaviors, data from Socie et al. [20] and Leese et al. [21] from 1045 steel testing were input on the curve-fitting software to plot its $\varepsilon \mathrm{N}$ comparison graphics, which can be seen in Fig. 5.8. For the von Mises criterion, it can be seen in the figure that the SAE 1045 steel has its transition from shear-dominated to tensile-dominated near $2 \mathrm{~N}=10^{4}$, compatible with the $10^{3}<2 \mathrm{~N}<10^{5}$ range from the damage map from Fig. 5.5. 


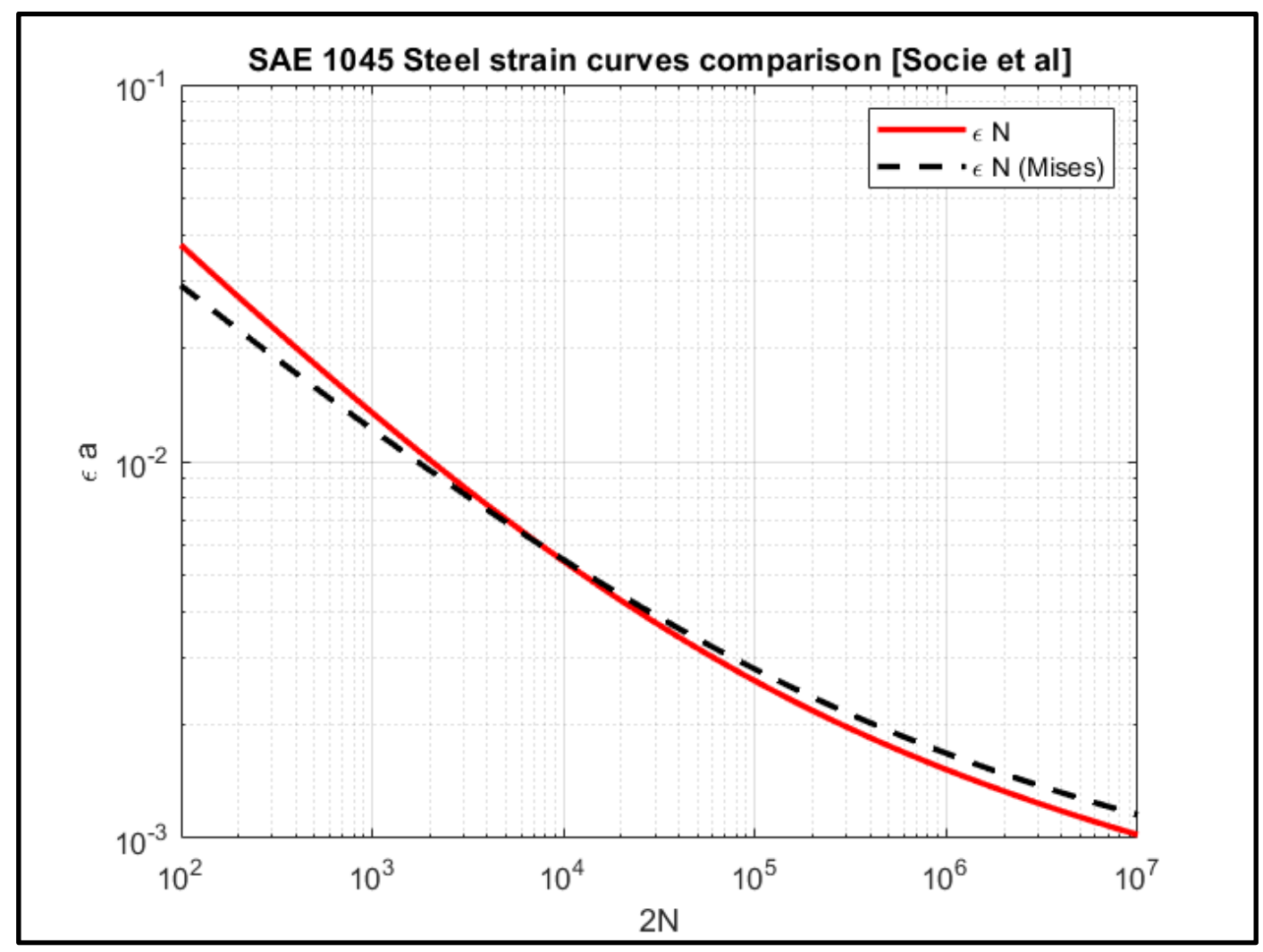

Figure 5.8: $\varepsilon N$ Comparison graphic of SAE 1045.

Socie states that the Tresca criterion is not a good correlation parameter for the SAE 1045 steel, giving life prediction results in the range of a conservative factor of 7 to a non-conservative factor of 3.5 depending on the load configuration [20]. This is the reason why Fig. 5.8 only shows the comparison between the tensile and shear-equivalent von Mises $\varepsilon N$ curves, instead of Tresca's. The $\varepsilon N$ Comparison graph for the SAE 1045 steel leads to the same conclusion towards the shear-tensile sensitivity behavior taken from its damage maps, which was also verified in the SAE 1020 steel studied in this work.

Finally, the calibrated value of Fatemi-Socie's $\alpha_{F S}$ parameter also corroborates towards the conclusions stated about the shear-tensile sensitivity behavior of each material. For SAE 1020 Steel, $\alpha_{F S}=0.127$ was the result from the solver, indicating a small influence of the tensile stress on the damage process of the material. Therefore, this steel is shear sensitive on the majority of its low-cycle life. However, $\alpha_{\mathrm{FS}}=1.677$ was the result for 6351-T6 Aluminum, which indicates that the tensile stress influence on the damaging process is almost the double of the shear strain. This aluminum is, then, tensile sensitive and Fatemi-Socie is not a proper model to be used for it. 


\section{6 Conclusion}

In this work, shear $(\gamma \mathrm{N})$ and tensile $(\varepsilon \mathrm{N})$ low-cycle fatigue properties were measured for SAE 1020 Steel and 6351-T6 Aluminum alloys. Both materials are not present on Lagoda et al.'s list of low-cycle fatigue properties, thus this data serves as an expansion to their research.

A simplified method was proposed to semi-empirically estimate the low-cycle fatigue properties under torsional constraints. This method was used to measure the shear low-cycle fatigue properties for each material. Using the measured tensile and shear sets of data, each material was characterized as either shear or tensile sensitive, and the most appropriate multiaxial critical-plane fatigue damage models were recommended accordingly. The characterization process of shear-tensile sensitivity was compared with the damage maps proposed by Socie et al., and similar results were obtained. Fatemi-Socie damage model was calibrated for each material, and the results of this process also led towards the same conclusions obtained from the comparison with the damage maps. Moreover, the elastoplastic behavior of each material was characterized.

A methodology to adapt the Instron 8874 Biaxial System was proposed in order to perform cyclic torsional and multiaxial fatigue experiments using the grips from the Instron 8501 Fatigue Testing System. A pair of adapters and other components were manufactured, allowing the grips designed for one machine to be assembled onto the other. In the aforementioned mounting conditions, different types of misalignments were identified and their correction procedures were explained in detail. Problems caused by usage of non-properly aligned systems were listed and techniques to mitigate the consequential issues are discussed. Also, the performance of the manufactured components was evaluated on the misaligned machine.

The methods discussed in this work, alongside with its recommendations and precautions, are valuable for many experimental measurements, and can be useful as a guide for the setup of future uniaxial and multiaxial testing. 


\section{1}

\section{Future Works}

A set of strain-controlled torsional low-cycle fatigue experiments with tubular specimens is proposed for each material as future work. A comparison between the $\gamma \mathrm{N}$ curve fitted using this data and the one proposed in the present work would lead to the evaluation of the stress gradient influence on the low-cycle fatigue behavior and life predictions of each material.

High-cycle pure tension and pure torsional experiments are also proposed for each material, to better characterize in future work the shear-tensile sensitivity of the given materials under such circumstances.

A deeper study of the Critical Plane Damage models is also suggested. The calculation of their $\alpha$ and $\beta$ coefficients and their usage for fatigue life predictions under multiaxial out-of-phase experiments are of great contribution.

Metallography and crack propagation measurements of the 6351-T6 Aluminum are also a suggestion for future work, in order to plot its entire damage map along with the $\varepsilon \mathrm{N}$ and $\gamma \mathrm{N}$ initiation data in the present work. 


\section{Bibliography}

[1] CASTRO, Jaime Tupiassu Pinho; MEgGIOLARO, Marco Antonio. Fatigue design techniques (in 3 volumes). CreateSpace, Scotts Valley, CA, USA, 2016.

[2] "Jet Crash Off Italy Kills 35". The New York Times. 11 January 1954

[3] Atkinson, R. J., Winkworth, W. J., Norris, G. M., Behavior of skin fatigue crack at the corners of windows in a Comet I fuselage, Ministry of Avia-tion, 1962

[4] Job, M., Air Disaster, Aerospace publications, 1996

[5] ASTM, E. 2207. Standard Practice for Strain-Controlled Axial-Torsional Fatigue Testing with Thin-Walled Tubular Specimens, 2002.

[6] MIRACLE, Daniel B. et al. ASM handbook. Materials Park, OH: ASM international, 2001.

[7]https://www.instron.us/-/media/literature-library/products/2012/10/8874servohydraulic-fatigue-testing-system.pdf?la=en

[8] TIMOSHENKO, Stephen. History of strength of materials: with a brief account of the history of theory of elasticity and theory of structures. Courier Corporation, 1983.

[9] ASTM, E. 606. Standard practice for strain controlled fatigue testing, 1998.

[10] LAGODA, T. et al. Correlation of Uniaxial Cyclic Torsion and TensionCompression for Low-Cycle Fatigue. Materials Science, v. 53, n. 4, p. 522-531, 2018.

[11] POPOV, Egor Paul et al. Introduction to mechanics of solids. 1968.

[12] SADD, Martin H. Elasticity: theory, applications, and numerics. Academic Press, 2009.

[13] SOCIE, Darrell F.; MARQUIS, Gary B. Multiaxial fatigue. Warrendale, PA: Society of Automotive Engineers, 2000.

[14]https://www.instron.us/en-us/products/testing-systems/dynamic-and-fatiguesystems/servohydraulic-fatigue/8802

[15] M11-08000-1 Issue A. Instron Alignment Fixture. Instron User's Guide. January 1994. 
[16] Lima, G.W., 2018. Determinação Experimental do Limite de Fadiga de uma Liga de Alumínio por Termografia (undergraduate thesis)

[17] STANDARD, A. S. T. M. E8. Standard test method for tension testing of metallic materials. West Conshohocken (USA): ASTM, 2004.

[18] AMERICAN SOCIETY FOR TESTING AND MATERIALS. COMMITTEE E-28 ON MECHANICAL TESTING. Standard test method for Young's modulus, tangent modulus, and chord modulus. ASTM International, 2004.

[19] Gere, James M., and S. P. Timoshenko. "Mechanics of Materials 2e." Brooks/Cole Engineering 198, no. 4 (1984).

[20] FATEMI, Ali; SOCIE, Darrell F. A critical plane approach to multiaxial fatigue damage including out-of-phase loading. Fatigue $\&$ Fracture of Engineering Materials \& Structures, v. 11, n. 3, p. 149-165, 1988.

[21] LEESE, Gail E.; MORROW, JoDean. Low cycle fatigue properties of a 1045 steel in torsion. In: Multiaxial Fatigue. ASTM International, 1985. 


\section{Appendix A}

Programming Codes using MATLAB

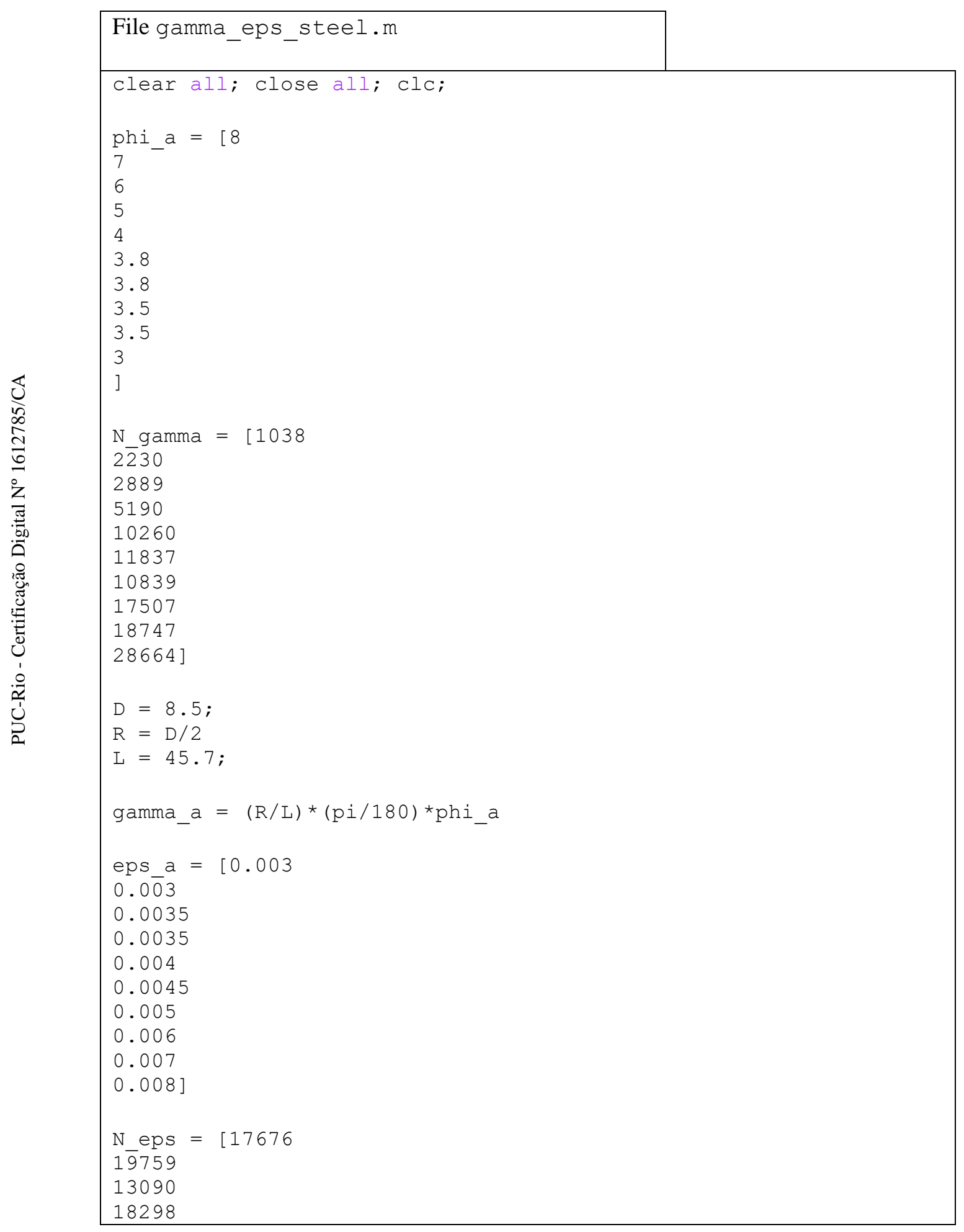




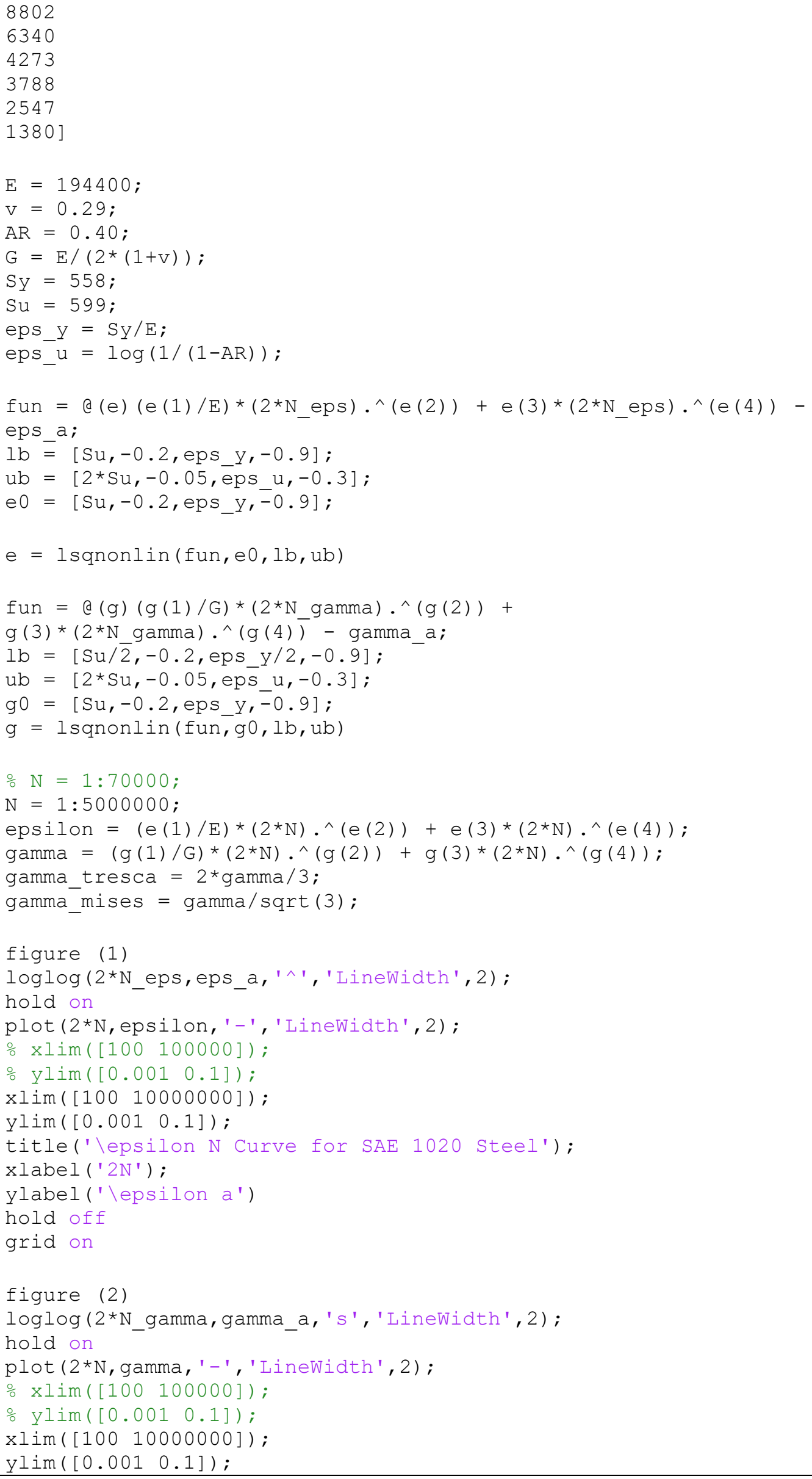




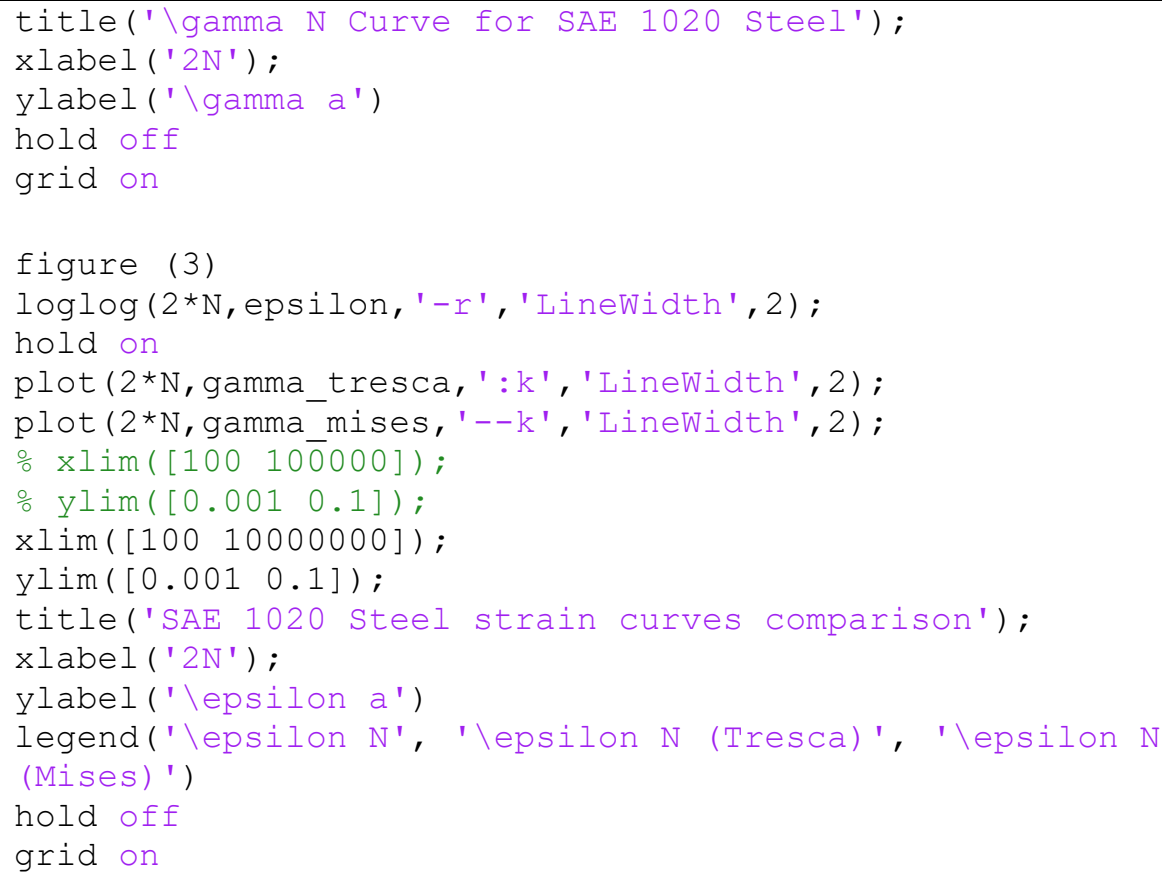




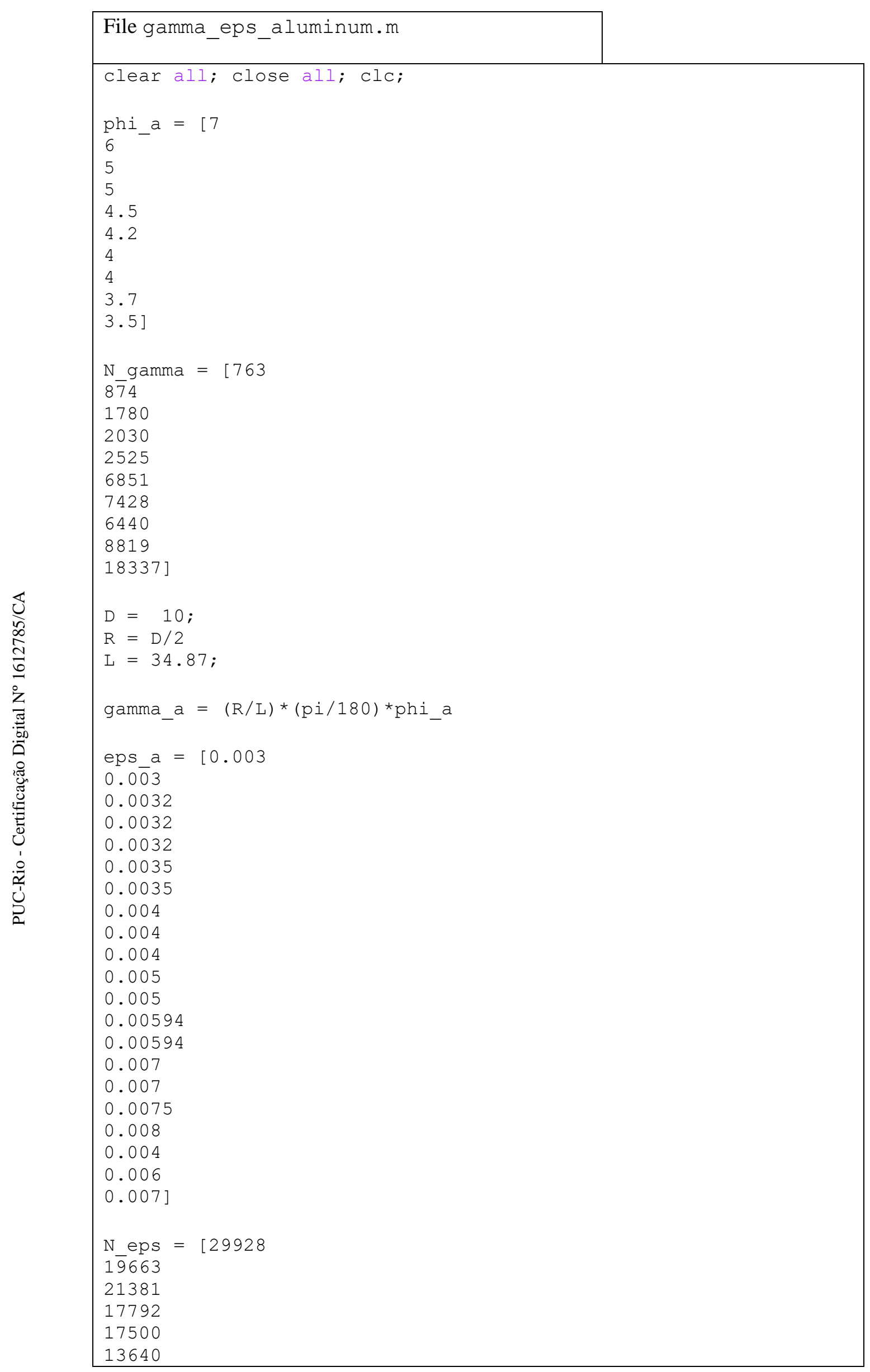




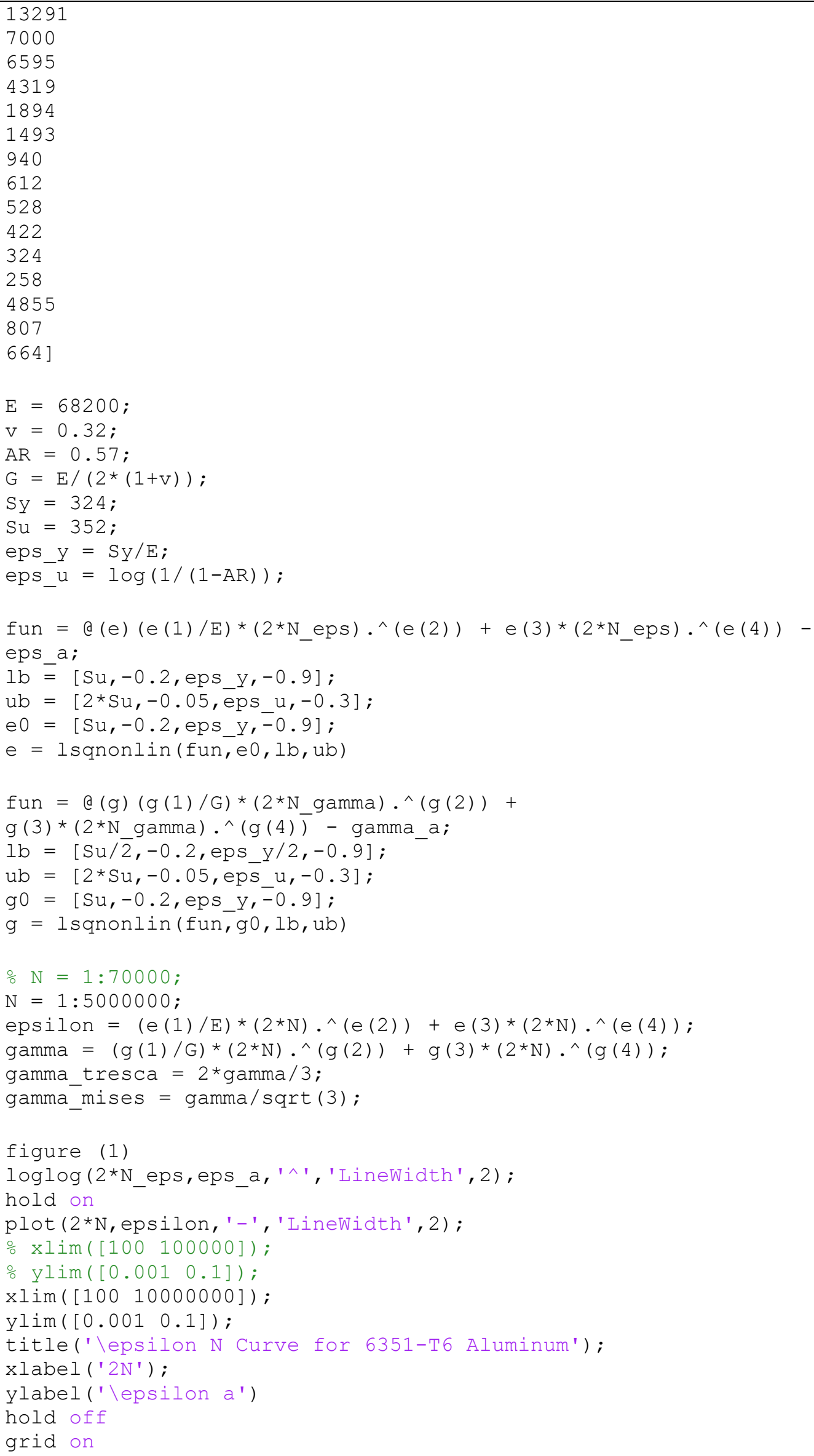




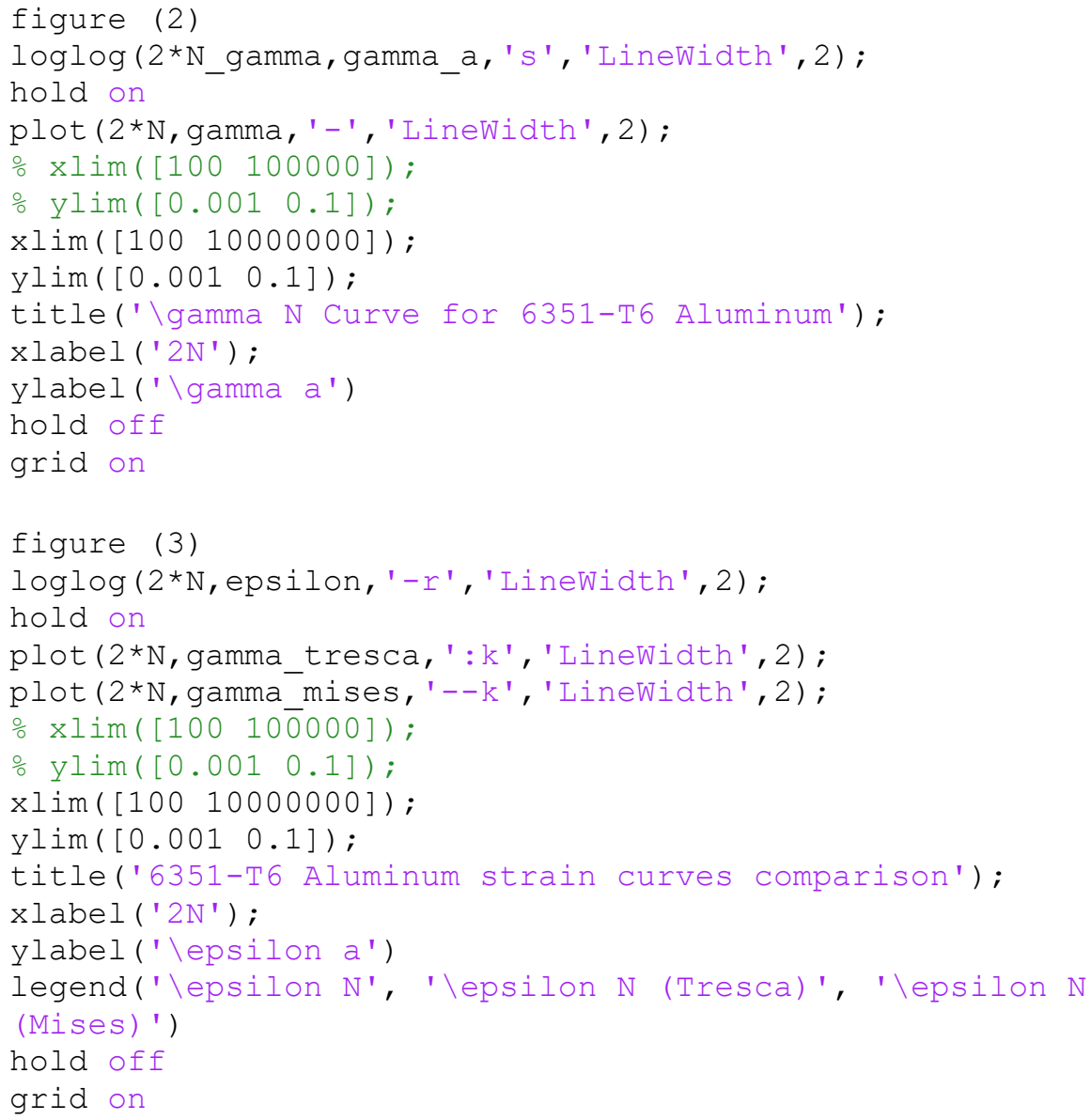




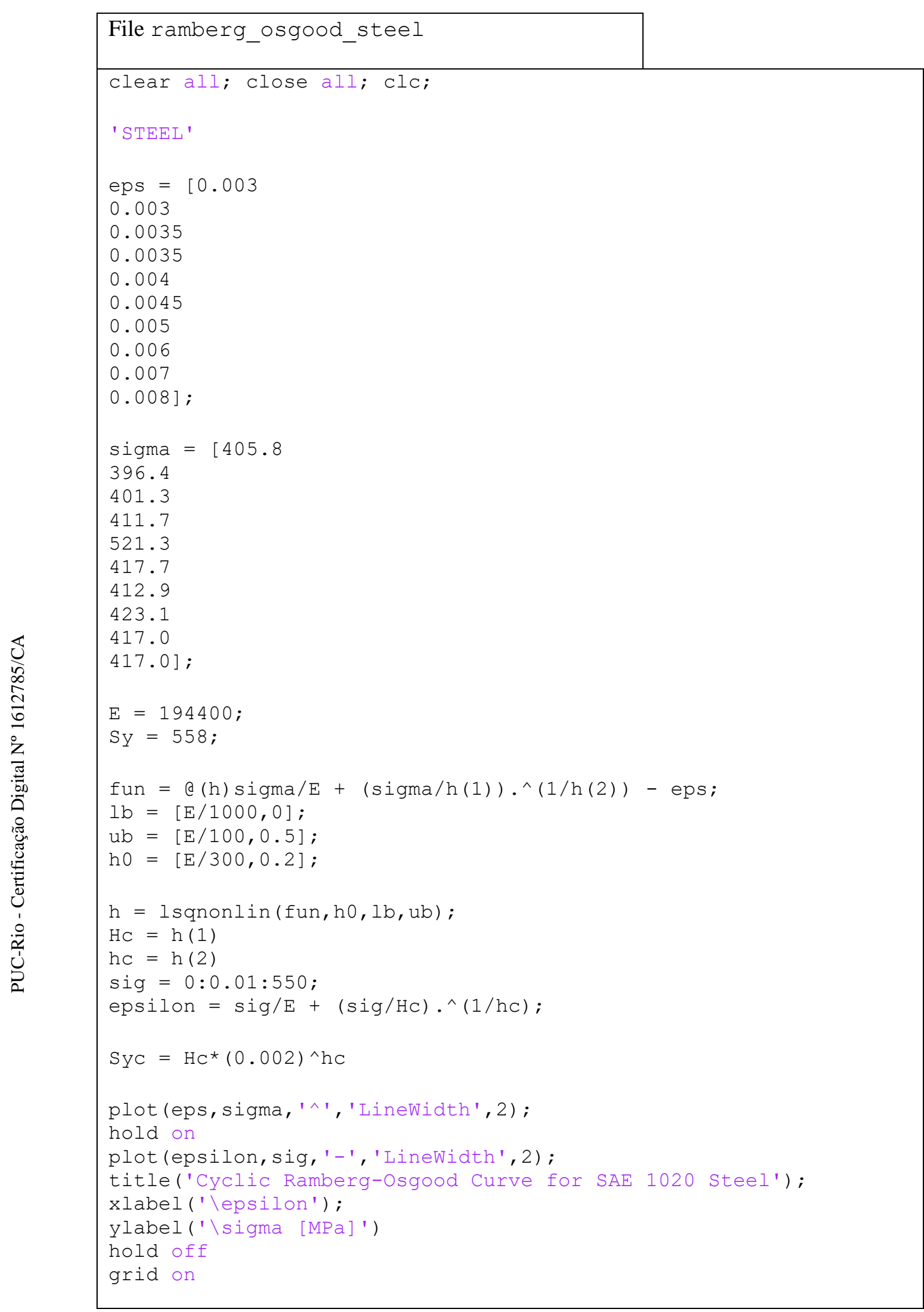




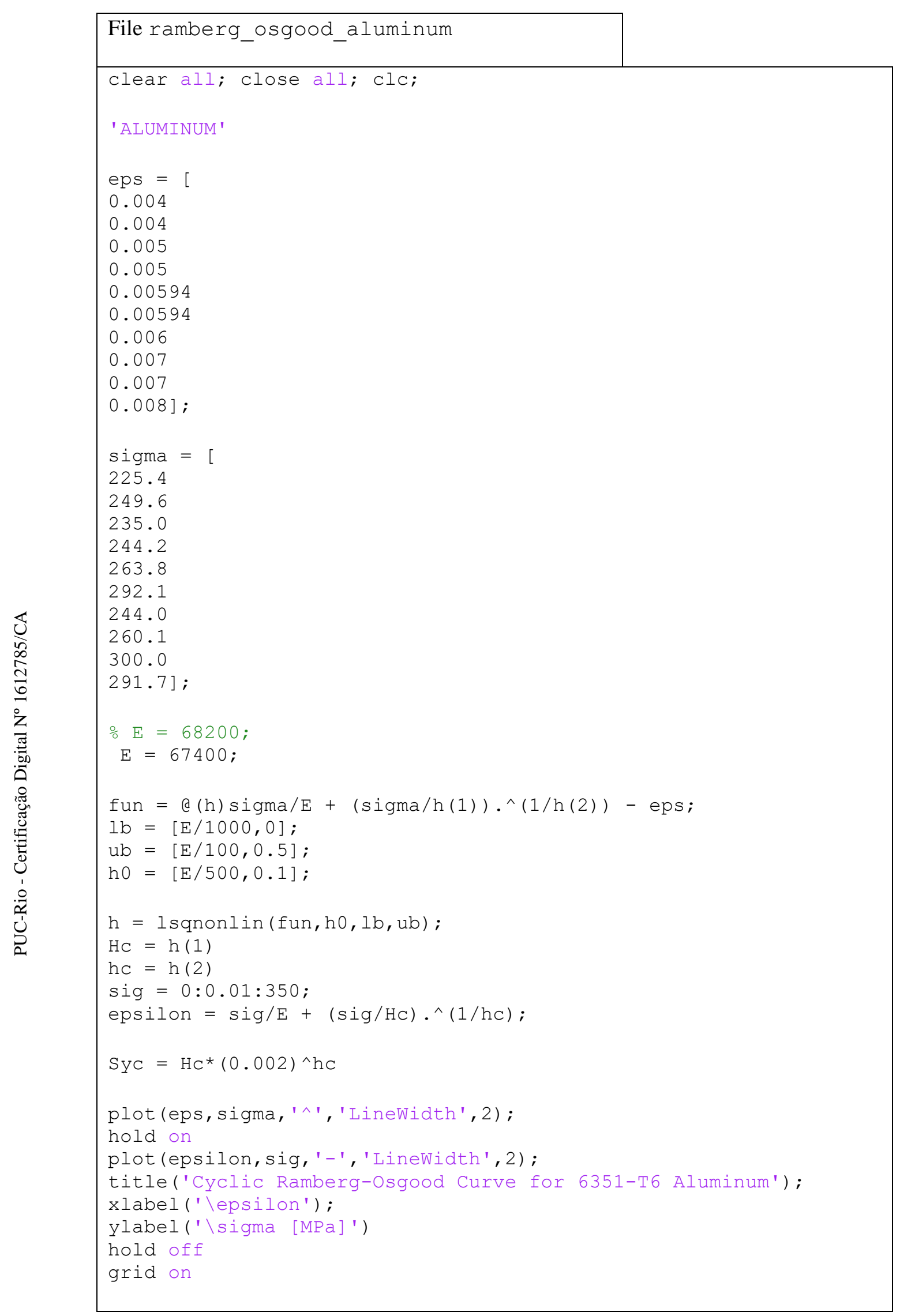




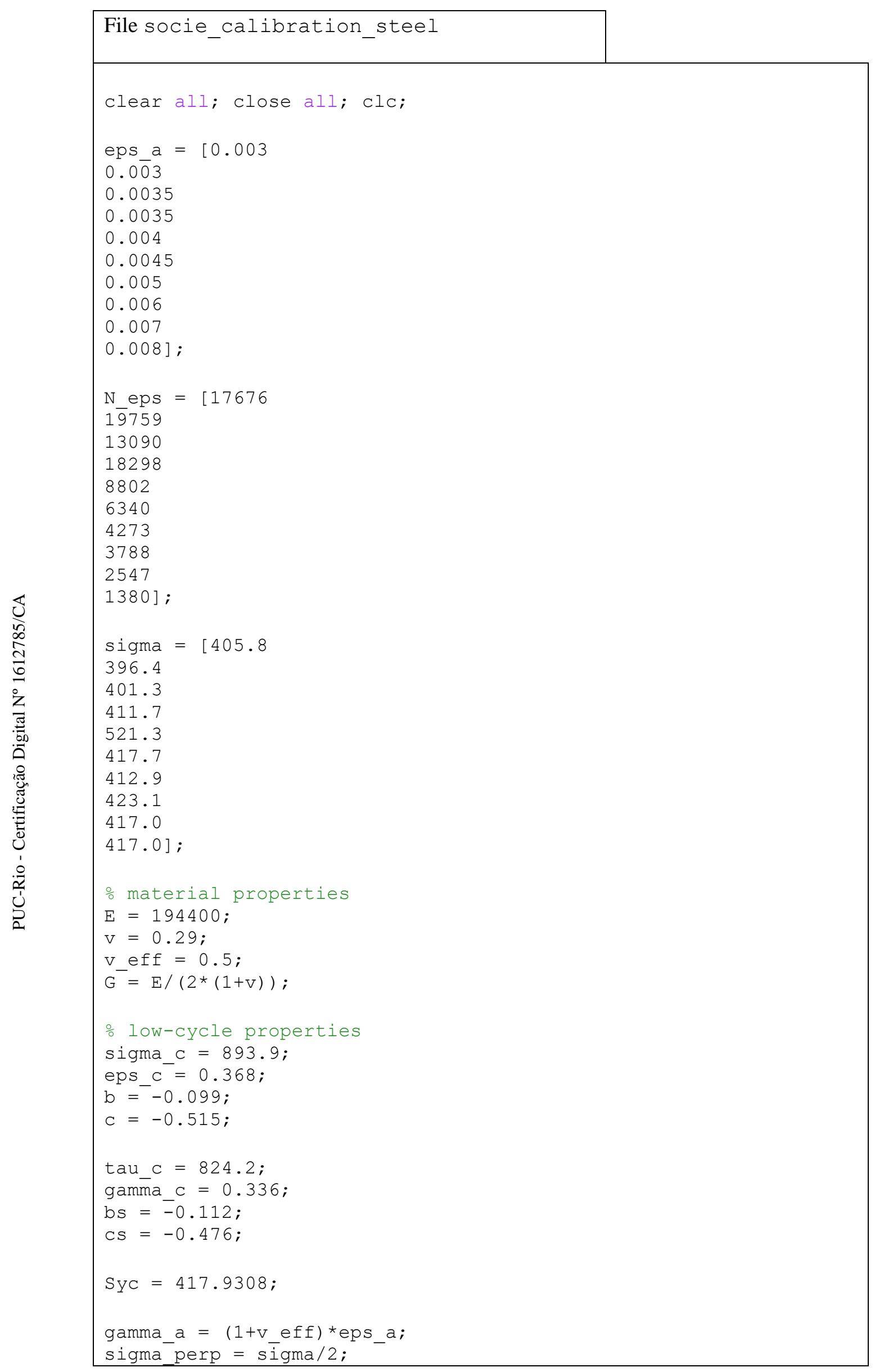




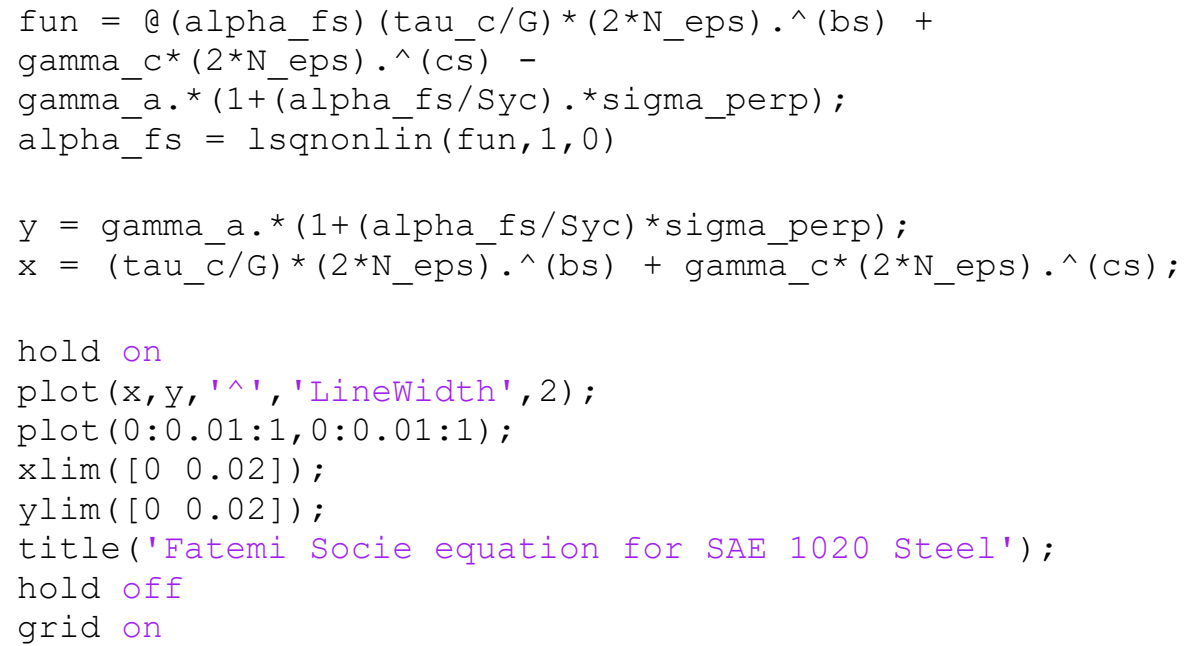




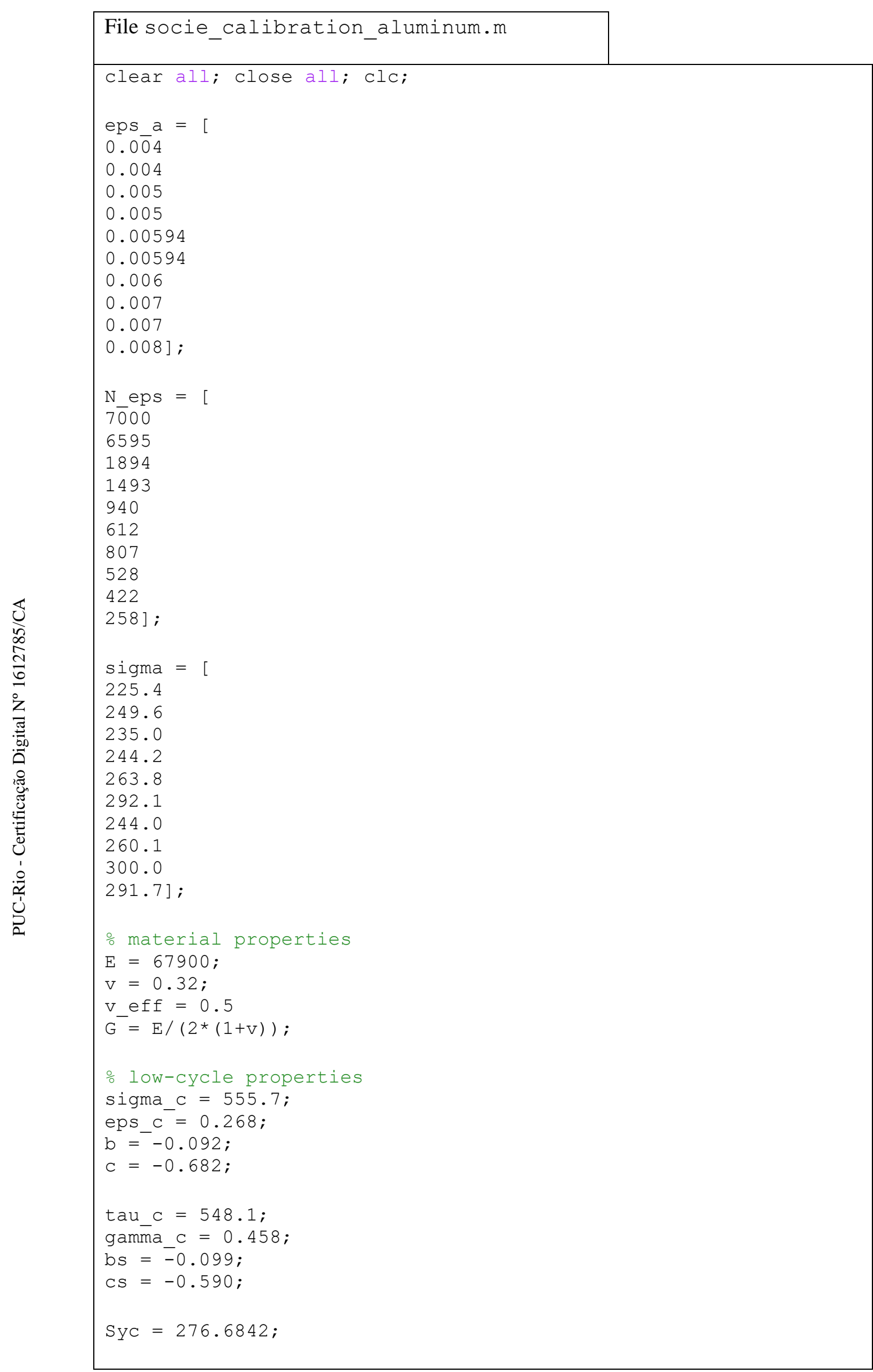




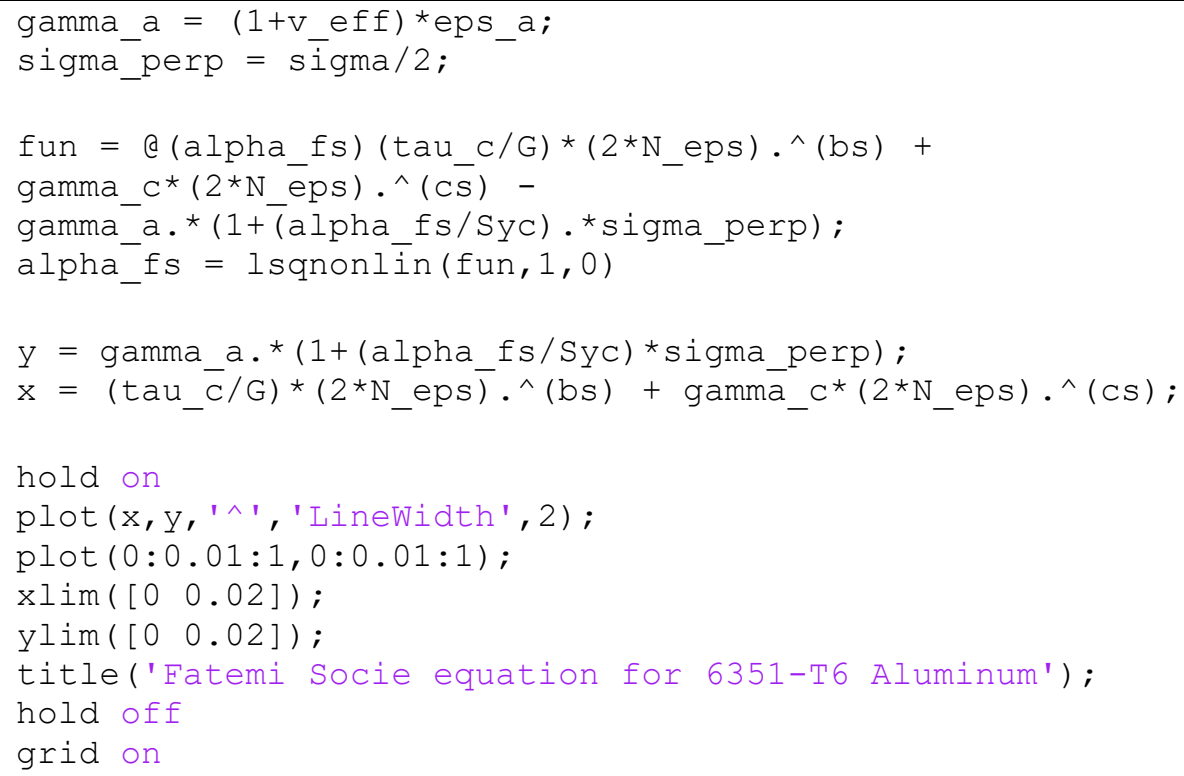

